\title{
msspep
}

\section{RESEARCH SUPPORT FOR PLASMA DIAGNOSTICS ON ELMO BUMPY TORUS:- \\ INVESTIGATION OF DIAMAGNETIC \\ DIAGNOSTICS FOR THE ELECTRON RINGS}

by

Kenneth H. Carpenter

Department of Electrical Engineering

University of Missouri - Rolla

Rolla, Missouri 65401

February 1981 


\section{DISCLAIMER}

This report was prepared as an account of work sponsored by an agency of the United States Government. Neither the United States Government nor any agency Thereof, nor any of their employees, makes any warranty, express or implied, or assumes any legal liability or responsibility for the accuracy, completeness, or usefulness of any information, apparatus, product, or process disclosed, or represents that its use would not infringe privately owned rights. Reference herein to any specific commercial product, process, or service by trade name, trademark, manufacturer, or otherwise does not necessarily constitute or imply its endorsement, recommendation, or favoring by the United States Government or any agency thereof. The views and opinions of authors expressed herein do not necessarily state or reflect those of the United States Government or any agency thereof. 


\section{DISCLAIMER}

Portions of this document may be illegible in electronic image products. Images are produced from the best available original document. 


\section{Printed in the United States of America Available from}

National Technical Information Service

U.S. Department of Commerce 5285 Port Royal Road

Springficld, Virqinia 22161

NTIS Price Codes: Printed Copy: A06; Microfiche: A01

This report was prepared as an account of work sponsored by the United States Government. Neither the United States nor the Department of Energy nor any of their employees, nor any of their contractors, subcontractors, or their employees, makes any warranty, express or implied, or assumes any legal liability or responsibility for the accuracy, completeness or usefulness of any information, apparatus, product or process disclosed, or represents that its use would not infringe privately owned rights. 


\section{RESEARCH SUPPORT FOR PLASMA DIAGNOSTICS \\ ON ELMO BUMPY TORUS:- \\ INVESTIGATIOÑ OF DI IAMAGNETIC \\ DIAGNOSTICS FOR THE ELECTRON RINGS}

\section{by}

Kenneth H. Carpenter

$$
95^{10^{381}}
$$

\section{$\checkmark$ Department of Electrical Engineering \\ University of Missouri - Rolla \\ Rolla, Missouri 65401}

\section{February 1981}

Report prepared by University of Missouri - Rolla under subcontract number 7676/X01

for

$$
\begin{gathered}
\text { OAK RIDGE NATIONAL LABORATORY } \\
\text { Oak Ridye, Tennessee } 37830 \\
\text { operated by } \\
\text { UNION CARBIDE CORFORATION } \\
\text { for the } \\
\text { DEPARTMENT OF ENERGY } \\
\text { Contract No. W-7405-eng-26 }
\end{gathered}
$$


Diamagnetic diagnostics for the EBT electron rings are fundamental to the experiment. The diamagnetic flux pickup loops on each cavity output signals proportional to ring perpendicular energy. A data analysis technique is described, which in its simplest form is subtracting $1 / 4$ the signal from each neighboring cavity pickup loop from the central one's, which provides a signal proportional to the energy in a single ring. The calibration factor relating absolute perpendicular energy to diamagnetic signal depends weakly on the geometrical model for the ring. Calculations with a bumpy cylinder MHD equilibrium code give calibration factors in reasonable agreement $(20 \%)$ to the values obtained using a simple, concentric cylindrical current sheet model. The cylindrical current sheet model is used to show that diamagnetic field components measured external to the plasma require high precision or correlation with other diagnostics in order to fix model parameters. A computer simulation shows an assumption of constant ring thickness and energy density with increasing length (and energy) is compatible to diamagnetic field observations on NBT. 
This report covers the work performed during the period May 15, 1980, to January 31, 1981, under Basic Agreement No. 7676, Project Authorization No. X01, a subcontract from Union Carbide Corporation to the University of Missouri. This is the final report for this Project Authorization. The work was performed by the Principal Investigator, Dr. Kenneth H. Carpenter, with assistance from Mr. Frank Zykan during Summer 1980. Dr. Carpenter is Associate Professor in the Department of Electrical Engineering of the University of Missouri - Rolla, and Mr. Zykan was a Graduate Research Assistant in that department. 


\section{ACKNOWLEDGEMENTS}

The cooperation, assistance, and hospitality provided by members of the Oak Ridge National Laboratory Fusion Energy Division Staff during this work is gratefully acknowledged. Special thanks are due to Dr. G. R. Haste and Dr. R. J. Colchin for their direction of the work and to Dr. C. L. Hedrick for providing helpful discussions along with a copy of his MHD equilibrium code. Thanks also are due Computer Sciences Division members D. N. Clark, T. C. Tucker, Dr. P. W. Gaffney, and Dr. R. C. Goldfinger for helpful discussions on computational techniques. 
TABLE OF CONTENTS

page

ABSTRACT ........................

FORWARD ...................... $i$.

ACKNOWLEDGEMENTS ...................... iv

LIST OF TABLES AND FIGURES ............ vii

I. INTRODUCTION ..................... 1

II. CORRECTION OF PERPENDICULAR ENERGY SIGNALS FOR 3 CROSS TALK BETWEEN SECTORS

Derivation of voltage-energy calibration in the 3 presence of cross talk

Correction matrix for diamagnetic flux signals . . 5

Hand calculation algorithm ........ . 6

III. EXAMINATION OF RELATIONSHIP OF EBT ELECTRON RING 8 GEOMETRY TO DIAMAGNETIC FIELD COMPONENTS WHICH CAN BE OBSERVED FROM OUTSIDE THE PLASMA

Previous ring field simulations and revised

Simulation of NBT radial diamagnetic field measurements

EBT ring geometry from external field measurements

IV. "BUMPY CYLINDER" MHD EQUILIBRIUM CODE MODEL FOR CALIBRATION OF ELECTRON RING ENERGY DIAGNOSTIC COMPARISON TO CURRENT SHEET MODEL

The bumpy cylinder MHD equilibrium code. . . . 16

Normalization of variables in EOUIL code specification of input values - interpretation of output values

General observations on EQUIL output ...... 19

Current sheet model for bumpy cylinder . . . . . 21

Comparison of MHD equilibrium model and current 22 sheet model flux loop energy calibration factors 
V. CONCLUDING COMMENTS AND RECOMMENDATIONS . . . . 25

VI. REFERENCES. . . . . . . . . . . . . . 27

APPENDIX - FORTRAN LISTINGS AND INPUTS AND OUTPUTS. • . 28

Cross talk compensation programs. . . . . . 28

EBTOFF program. ................ 49

FLDEQ program ................ 57

EQUIL program ............... 70

BUMCAL program............... . 98 
page

Table 1. Data from typical model ring calculations for perpendicular energy signal correction coefficients.

Figure 1. Simulated radial diamagnetic field component versus length of model ring for a detector $1 \mathrm{~cm}$ away from midplane and $5 \mathrm{~cm}$ away from edge of ring.

Figure 2. Simulated radial diamagnetic field versus length of model ring.

Figure 3. Simulated axial diamagnetic field components at outside of plasma relative to component at coordinates near the midplane, versus length of model ring.

Figure 4. Length - thickness curves for simulated experimental $B_{z}$ data.

Table 2. Diamagnetic flux pickup loop calibration factors from MHD equilibrium model.

Table 3. Numerical factors to convert output from EQUIL computer code to dimensional quantities.

Table 4. Explanation of values that must be input to EQUUIL code.

Table 5. Explanation of calculated values output by EQUIL code. 
Research Support for Plasma Diagnostics on Elmo Bumpy Torus Investigation of diamagnetic diagnostics for the electron rings

\section{INTRODUCTION}

Determination of the parameters of the hot electron rings in EBT is one of the basic goals of the experiment ${ }^{l}$, having a significant roll to play in plasma power balance ${ }^{2}$ and stability ${ }^{3}$ considerations. Diamagnetic flux pickup loops have been used since the beginning of the experiment as a diagnostic for the ring stored energy ${ }^{4}$. A single attempt was made to obtain data needed to establish ring geometry by measurement of the diamagnetic field axial components near the outside of the plasma ${ }^{5}$, but this measurement was not sufficiently useful to be made a part of the standard diagnostics. In a similar way, diamagnetic measurements have been made on the NBT experiment ${ }^{6}$ and the STM experiment. ${ }^{7}$ The fundamental importance of these diamagnetic measurements prompted studies into the calibration of existing diagnostics and feasibility of additional diamagnetic diagnostics. In this report the results of studies into three aspects of diamagnetic diagnostics will be presented -el imination of intercavity cross talk effects in perpendicular energy signals via data analysis, assessment of possible observation of ring geometry using diamagnetic measurements, and calibration of perpendicular energy diagnostics using current sheet and MHD equilibrium models.

The use of diamagnetic flux pickup loops encircling each EBT cavity to indicate electron ring perpendicular energy $\left(W_{\perp}\right)$ in the corresponding cavity is complicated by the fact that each $w_{\perp}$ signal contains varying contributions due to energy in neighboring cavities. To facilitate use of these $w_{\perp}$ signals in determining ring power distribution among the cavities a method was developed to resolve individual cavity $W_{\perp}$ values from the array of 24 cross coupled $W_{\perp}$ signals. For a wide range of ring geometries the cross coupling can be compensated to about $3 \%$ by the simple method of subtracting $1 / 4$ of the raw $w_{\perp}$ signal from the two adjacent cavities from the raw $W_{\perp}$ 
signal of a given cavity and then multiplying the result by $8 / 7$. A more accurate compensation algorithm has been incorporated in the computer code used to analyze data from plasma turn-downs. This is described in section II of this report.

Although ring perpendicular energy is an important plasma parameter, the confinement properties of that ring -- expressed by ring geometry and "beta" -- are equally important. Satisfactory diagnostics for ring geometry have not yet been achieved on EBT by means of diamagnetic measurements. Early attempts using small relay coils for diamagnetic field measurement lacked sufficient sensitivity to ring geometry to fix model parameters and simulation studies made then were not encouraging. ${ }^{5,8}$ Use of a Hall probe array on the STM experiment for this purpose 7 prompted a fresh look at this possibility for EBT. Also a reported relationship between diamagnetic signals and (presumed) ring axial length for $\mathrm{NBT}^{9}$ prompted further comparisons of model rings and external diamagnetic field components. These studies are described in section III of this report.

Calibration of $W_{\perp}$ signals from the diamagnetic flux pickup loops is somewhat model dependent and of such importance as to merit study by more than one approach. In section IV we present results from preliminary calculations using a bumpy cylinder MHD equilibrium code for calibration of the $W_{\perp}$ signals.

Following the concluding comments and recommendations in section $V$, we present in the appendix the FORTRAN listings and sample inputs and outputs for the computer programs written for use in this work. 


\section{CORRECTION OF PERPENDICULAR ENERGY DIAMAGNETIC}

SIGNALS FOR CROSS TALK BETWEEN SECTORS

The $W_{\perp}$ signals used routinely as an indication of ring plasma energy in each EBT sector are subject to significant cross talk from adjacent sectors. A method to unfold the twenty-four $W_{\perp}$ signals to give twenty-four signals, each proportional to the perpendicular energy in a single electron ring, was developed and subsequently included in the data analysis program. A derivation of the algorithm and its implementation as a universal correction method is given in what follows.

Derivation of voltage-energy calibration in the presence of cross talk

Let the signal output by the integrator connected to the pickup loops on the $i$ 'th sector be $v_{j}$, and let $F_{i}$ be the diamagnetic flux linking one turn of the pickup loop. Then $v_{i}=F_{i} N / t$ where $N$ is the number of turns and $t$ is the integrator time constant (assumed the same for all i). Let the electron ring in each EBT sector be modeled by two current sheets. Let the inner current sheet have total current magnitude $I_{i l}$ and the outer current sheet have total current magnitude $I_{i 2}$. Let the mutual inductance coupling current sheet $I_{i 1}$ and pickup loop $j$ be $M_{j i 1}$, and let that linking $I_{i 2}$ and pickup loop $j$ be $M_{j i}$ ?. The total flux linking one turn of pickup loop $i$ is thus

$$
F_{i}=\sum_{j=1}^{24}\left(M_{i j 1} I_{j 1}-M_{i j 2} I_{j 2}\right)+F_{c}
$$

where the minus sign is used so that all $M$ and $I$ values can be positive with the outer and inner current sheets oppositely directed. $F_{c}$ is the diamagnetic flux due to plasma not represented by the current sheets, i.e., the toroidal core plasma.

Given a specific geometry for a current sheet model, $M_{i j 1}$ and $M_{i j 2}$ can be calculated. We choose to use the concentric cylindrical current sheet model described in another report 
Based on it, a FORTRAN function DM has been written to calculate the M's. (A listing of the FORTRAN is given in the appendix.)

Lacking any knowledge to the contrary, we make the following key assumption: The geometry of all 24 electron rings is the same; that is, the $M_{i j}$ values depend only on the difference between $i$ and $j$ (modulo 24) not on $i$ and $j$ separately. While this is not exactly true, computer studies show that the $M_{i j}$ are only weakly geometry dependent ${ }^{10}$ so that the assumption does not introduce serious error.

The perpendicular energy in the model is given by

$$
W_{\perp i}=2 \pi r(\Delta r) B_{a v g} \frac{T}{2}\left(I_{i 1}+I_{i 2}\right)
$$

where $B_{a v g}$ is a suitable average value for magnitude of total magnetic field (vacuum plus diamagnetic) over the region occupied by the ring. In $(v-1)$ we have a set of 24 equations in 49 unknowns, the $I_{i 1}{ }^{\prime} s, I_{i 2} s$, and $F_{c}$. To reduce the unknowns to 24 to allow for solution for the $W_{\perp}$ 's via Eq. (2) we do the following. First $F_{c} \ll F_{i}$ is assumed and $F_{C}$ is set to zero. Second the theoretical formula for drift current ${ }^{C}$ is used to fix the difference of $I_{i 1}$ and $I_{i 2}$ :

$$
I_{i 2}-I_{i 1}=\frac{\Delta B}{2 B}\left(I_{i 2}+I_{i 1}\right)
$$

where $\Delta B$ is the difference between the magnetic field at the inner current sheet and that at the outer, and $B$ is the mean value. This provides the additional 24 relations needed to solve eq $(V-1)$ for the $I_{j 1}$ and $I_{j 2}$ values. (The term $D F=(1+\Delta B / 2 B)$ is used in the computer codes to represent this "drift factor".) If we let $I_{i}=\left(I_{i 1}+I_{i 2}\right)$ then $I_{i 1}=I_{i}(1-\Delta B / 2 B)$ and $I_{i 2}=I_{i}(1+\Delta B / 2 B)$ so that Eq. (1) becomes

$$
\begin{aligned}
F_{i} & =\sum_{j=1}^{24}\left[M_{i j 1}(1-\Delta B / 2 B)-M_{i j 2}(1+\Delta B / 2 B)\right] I_{j} \\
& =\sum_{j=1}^{24} c_{i j}{ }^{I} j
\end{aligned}
$$


Now from the assumed identity of the geometrical factors for all sectors one has the property that $C_{i j}$ is a symmetric circulant matrix:

$$
\begin{aligned}
& c_{i j}=c_{j i} \\
& c_{i}+n, j+n=c_{i j}, \text { addition mod } 24 .
\end{aligned}
$$

Thus there are only 13 independent matrix elements for $c_{i j}$. Such a matrix can be inverted by Fourier techniques to give an inverse matrix $D_{i j}$ having the same properties. Thus we have

$$
I_{i}=\sum_{j} D_{i j} F_{j}
$$

and through Eq. (2) the separated ring perpendicular energies.

FORTRAN subroutines have been written to evaluate the $c_{i j}$ and $D_{i j}$ and to calculate (normalized) $I_{i}$ 's given a set of $F_{j}$ 's. These are listed in the appendix.

Correction matrix for diamagnetic flux signals

This same technique can be used to correct the $v_{i}$ values to those that would be obtained if only flux from the $i$ 'th ring contributed. Let such corrected values be labeled $w_{j}$. Then

$$
\begin{aligned}
w_{i} & =C_{i j} I_{i} N / t=C_{i j} \sum_{j} D_{i j} v_{j} \\
& =\left(d^{-1}\right) 11 \sum_{j=1}^{24} d_{i j} v_{j}
\end{aligned}
$$

where $d_{i j}=1$. There are only 12 independent elements to the correction matrix $C_{i j}$ which can be represented in terms of the numlal ized matrix $d_{i j}$ having ones for all diagonal elements. The normalizing factor is the diagonal element of the inverse of the $d_{i j}$ matrix. Let the twelve independent elements of $d_{i j}$ be labeled as $f_{i}=d_{1}, j+1, i=1,2 \ldots 12$ and let $f_{0}=\left(d^{-1}\right)_{11}$. Then the correction algorithm to yicld the signals due to the rings in a single sector only is 


$$
\begin{aligned}
w_{i}= & f_{0}\left(v_{i}+\left(v_{i}+1+v_{i-1}\right) f_{2}+\left(v_{i}+2+v_{i}-2\right) f_{3}\right. \\
& \left.+\ldots+\left(v_{i}+11+v_{i}-11\right) f_{12}+\left(v_{i}+12\right) f_{13}\right)
\end{aligned}
$$

where addition of indices is modulo 24.

Results of a few representative runs are given in Table 1. One sees that for the model parameters tested one can use a universal "average" set $f_{i}$ to correct for cross talk between sectors and still achieve an accuracy of at least $2 \%$ of the largest of the uncorrected readings. Since the precision of the $v_{i}$ values is not better than $2 \%$, this fixed, average $f_{i}$ set was programmed into the EBTOFF data reduction routine used on the PDP-10. Thus EBTOFF now provides a cross talk correction option for analys is of plasma turn down data. A listing of the FORTRAN for this revised EBTOFF is given in the appendix.

Hand calculation algorithm

Note that nearly all the correction for cross talk comes from the two adjacent sectors. In fact, since the next nearest pair of sectors has the opposite sign $\left(f_{3}>0 ; f_{j}<0, i>3\right)$ from the remaining ones, only about another $1 \%$ of error will be introduced if only the nearest neighbor sector corrections are made. For hand calculations to $3 \%$ accuracy, simply subtract one-fourth of each neighboring sector $W_{\perp}$ voltage signal from the one whose corrected value is desired; then multiply this result by 1.15 to obtain the value that would have resulted if only that sector's ring had produced flux to link the pickup loop. 


\begin{tabular}{|c|c|c|c|c|c|c|}
\hline $\begin{array}{c}\text { ring } \\
\text { thickness }\end{array}$ & 2.0 & 2.0 & 4.0 & 2.0 & \multirow{4}{*}{ 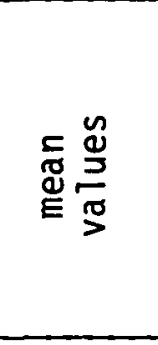 } & \multirow{4}{*}{ 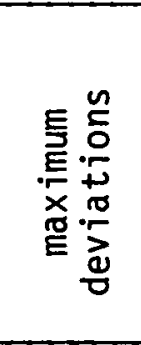 } \\
\hline $\begin{array}{c}\text { ring } \\
\text { mean radius }\end{array}$ & 13.32 & 13.32 & 13.32 & 12.22 & & \\
\hline $\begin{array}{l}\text { drift } \\
\text { factor }\end{array}$ & 1.065 & 1.065 & 1.129 & 1.058 & & \\
\hline $\begin{array}{l}\text { ring } \\
\text { length }\end{array}$ & 5.0 & 10.0 & 10.0 & 10.0 & & \\
\hline$f_{0}$ & 1.1424 & 1.1461 & 1.1448 & 1.1538 & 1.1468 & 0.007 \\
\hline$f_{2}$ & -0.2475 & -0.2505 & -0.2494 & -0.2565 & -0.2510 & 0.0055 \\
\hline$f_{3}$ & 0.0176 & 0.0188 & 0.0184 & 0.0213 & 0.0190 & 0.0023 \\
\hline$f_{4}$ & -0.0066 & -0.0068 & -0.0067 & -0.0071 & -0.0068 & 0.0003 \\
\hline$f_{5}$ & -0.0013 & -0.0012 & -0.0012 & -0.0011 & -0.0012 & 0.0001 \\
\hline$f_{6}$ & -0.0010 & -0.0010 & -0.0010 & -0.0010 & -0.0010 & 0 \\
\hline$f_{7}$ & -0.0006 & -0.0006 & -0.0006 & -0.0006 & -0.0006 & 0 \\
\hline$f_{8}$ & -0.0004 & -0.0004 & -0.0004 & -0.0004 & -0.0004 & 0 \\
\hline$f_{9}$ & -0.0003 & -0.0003 & -0.0003 & -0.0003 & -0.0003 & 0 \\
\hline$f_{10}$ & -0.0002 & -0.0002 & -0.0002 & -0.0002 & -0.0002 & 0 \\
\hline$f_{11}$ & -0.0001 & -0.0001 & -0.0001 & -0.0001 & -0.0001 & 0 \\
\hline$f_{12}$ & -0.0005 & -0.0005 & -0.0005 & -0.0005 & -0.0005 & 0 \\
\hline$f_{13}$ & -0.0006 & -0.0006 & -0.0006 & -0.0006 & -0.0006 & 0 \\
\hline
\end{tabular}

Table 1. Data from typical model ring calculations for perpendicular energy signal correction coefficients. 
III. EXAMINATION OF RELATIONSHIP OF EBT ELECTRON RING GEOMETRY TO DIAMAGNETIC FIELD COMPONENTS WHICH CAN BE OBSERVED FROM OUTSIDE THE PLASMA

The fact that diamagnetic flux loop signals, which are used as a ring energy diagnostic, are insensitive to geometry is an indication that determination of ring geometry from diamagnetic field measurements will be difficult. A single attempt was made during the EBT-I period to obtain data to establish ring geometry by measurement of the diamagnetic field axial component at several points near the outside of the plasma ${ }^{5}$. This measurement was not sufficiently useful to be made part of the standard diagnostics.

Diamagnetic measurements have also been made recently on the NBT experiment ${ }^{6}$ and the STM experiment ${ }^{7}$. In order to understand the NBT results for the radial component of the magnetic field near the midplane versus ring energy ${ }^{9}$ and to assess the possibility of successfully applying the techniques used on STM to EBT, a re-examination of the relationship of parameters for a current sheet model of the rings to the diamagnetic field components was carried out. The details follow.

Previous ring field simulations and revised simulation code

In late 1976 a set of measurements of diamagnetic field axial components near the outside of the plasma was made using small relay coils as pickups. The resulting data was noisy and not able to give a definitive fit to the ring model parameters. This prompted a simulation study of the fields due to model rings to search for possible locations where field component measurements could discriminate between different ring geometries. (This study has been reported elsewhere 5,8 .) The computer program used for this study output "arrow plots" which showed diamagnetic field versus position for given values of ring model parameters. The results were pessimistic for determination of ring model parameters by field component measurement at accessible locations. The lack of sensilivily or rield components to model parameters is due to the fact 
- that field values a distance $R$ from the center of a cylindrical current sheet having length $L$ and radius $A$ varies with $A$ and $L$ as $(A / R)^{2}+(L / R)^{2}$ compared to one. Thus the requirement that measurements of field components be made outside the region containing the plasma (in order to prevent the probes' modifying the ring geometry itself) was responsible for the lack of success of the observations using the relay coils.

Reported use of $\mathrm{Hall}$ probes to obtain high precision magnetic field readings on the STM and NBT experiments prompted a restudy of feasibility of use of an array of diamagnetic field component measurements to determine ring geometry on EBT. The original "arrow plot" computer code was employed again, but this time including the theoretical $\triangle B / B$ drift current effect ${ }^{10}$ to reduce the number of free model parameters. A revised field simulation code (FLDEO) was written to output the field components at fixed positions as functions of ring model parameters. (This code is listed in the appendix.) FLDEQ was used to simulate the NBT experimental data as well as to look again at the possibility of ring geometry determination for EBT using high precision field measurements.

Simulation of NBT radial diamagnetic field measurements

The NBT experiment used a Hall effect device, rather than a relay coil, to measure the plasma diamagnetic field. The Hall probe was oriented to give no output due to the vacuum field, hence its signal was the diamagnetic component normal to the vacuum field. This arrangement was simulated using the FLDEQ code by looking at the radial component of the magnetic field due to a concentric cylindrical current sheet model when the field point was $1 \mathrm{~cm}$ from the midplane and $5 \mathrm{~cm}$ from the outer current sheet.

The simulated signal for the magnetic field reproduces qualitatively the variation of the signals reported for NBT from a Hall effect detector as the ring energy is increased ${ }^{9}$. The qualitative result is compatible with an increase in ring axial extent (length) with increase in energy while maintaining a constant energy density. The simulated $B_{r}$ signal is plotted versus axial extent assumed for the ring, in NBT geometry, in Fig. 1 . The location of maximum $B_{r}$ at 


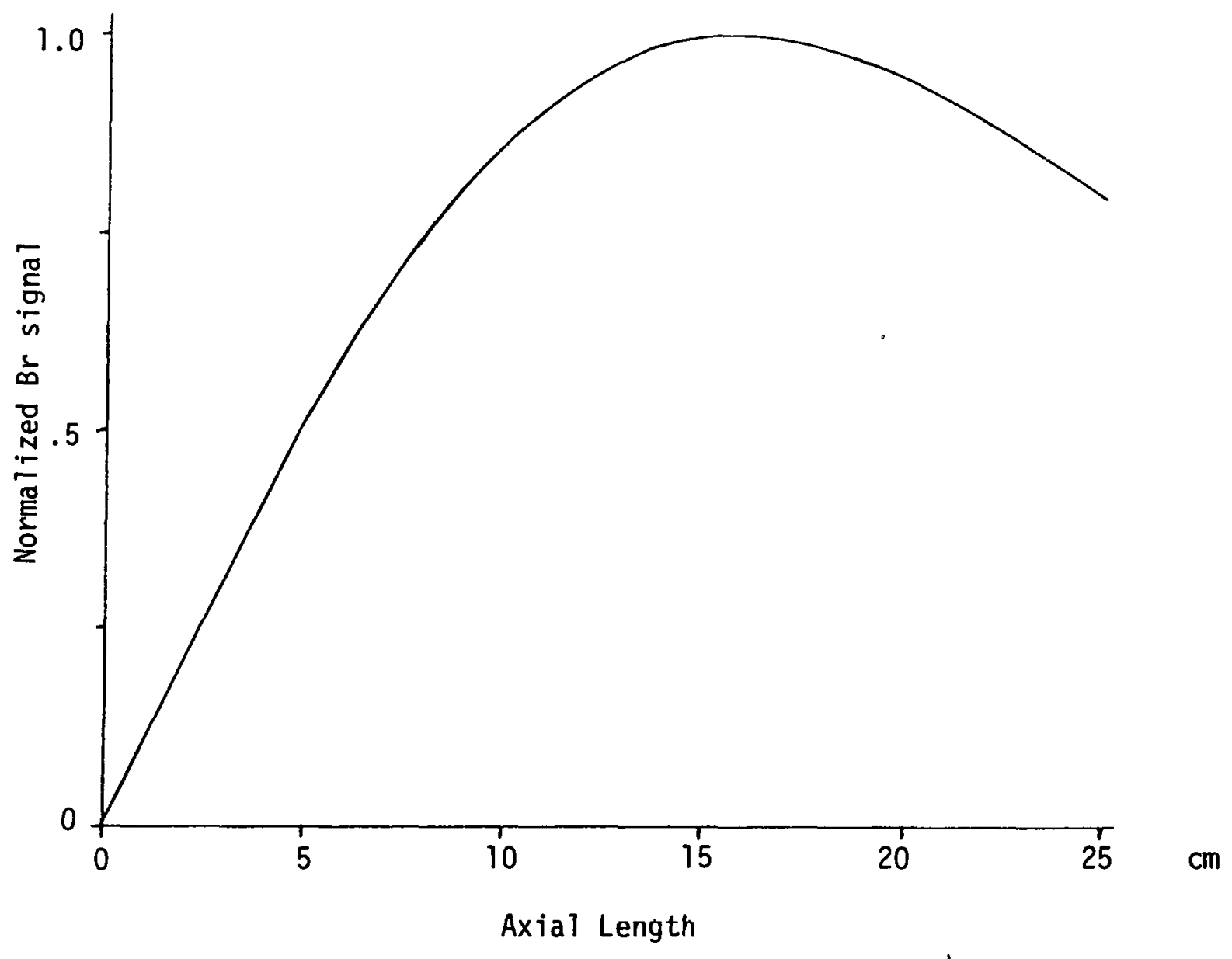

Fig. 1. Simulated radial diamagnetic field component versus length of model ring for a detector $1 \mathrm{~cm}$ away from midplane and $5 \mathrm{~cm}$ away from edge of ring. (NBT conditions) (Adjacent cavity effects included) 
about $16 \mathrm{~cm}$ for total length does not vary significantly with changes in assumed values for drift current effects and ring thickness.

Next the possibility of a similar variation of radial field with ring energy was explored for EBT conditions. Plots for $B_{r}$ versus ring axial extent are given in Fig. 2 for EBT-I geometry for several possible detector locations at the outside of the EBT cavity. The maximum in signal occurs for larger ring lengths than in the NBT case primarily because the detector locations are farther from the model rings. Although it would be interesting to look for this fall off of field with increasing energy for EBT, it is not likely to be observed unless the rings are longer and nearer the outside of the machine than anticipated.

Finally we note that this result of decrease in magnetic field with increase in current sheet length is exactly what one would anticipate on a purely intuitive basis. For a constant energy density in the ring one has current sheets in the model with constant surface current densities. Zero length for the current sheet gives zero field. As the energy and length increase, the field at a fixed outside location increases at first, but as the length increases sufficientiy the "ends" of the ideal solenoid become more distant, ultimately leading to continuously decreasing fields.

EBT ring geometry from external field measurements

The previous studies using "arrow plots" gave little hope for determination of ring parameters by external field measurements. . In order to see what one might be able to do with more precise values for field components using Hall probes a study was carried out, using the FLDEQ simulation program. This study attempted to find how parameters of the current sheet model for EBT rings could be related by measuring diamagnetic field components at the outside edge of the cavit.y. If one assumes only relative calibration between detectors is available and not absolute field values then one can determine if the data is compatible with the model but cannot fix the model parameters. The ratios between detector signals are predicted to be nearly constant for a wide variation of choices for ring length and thickness, provided the radial location of the ring is set near the heating resonance and the drift current effect is near 


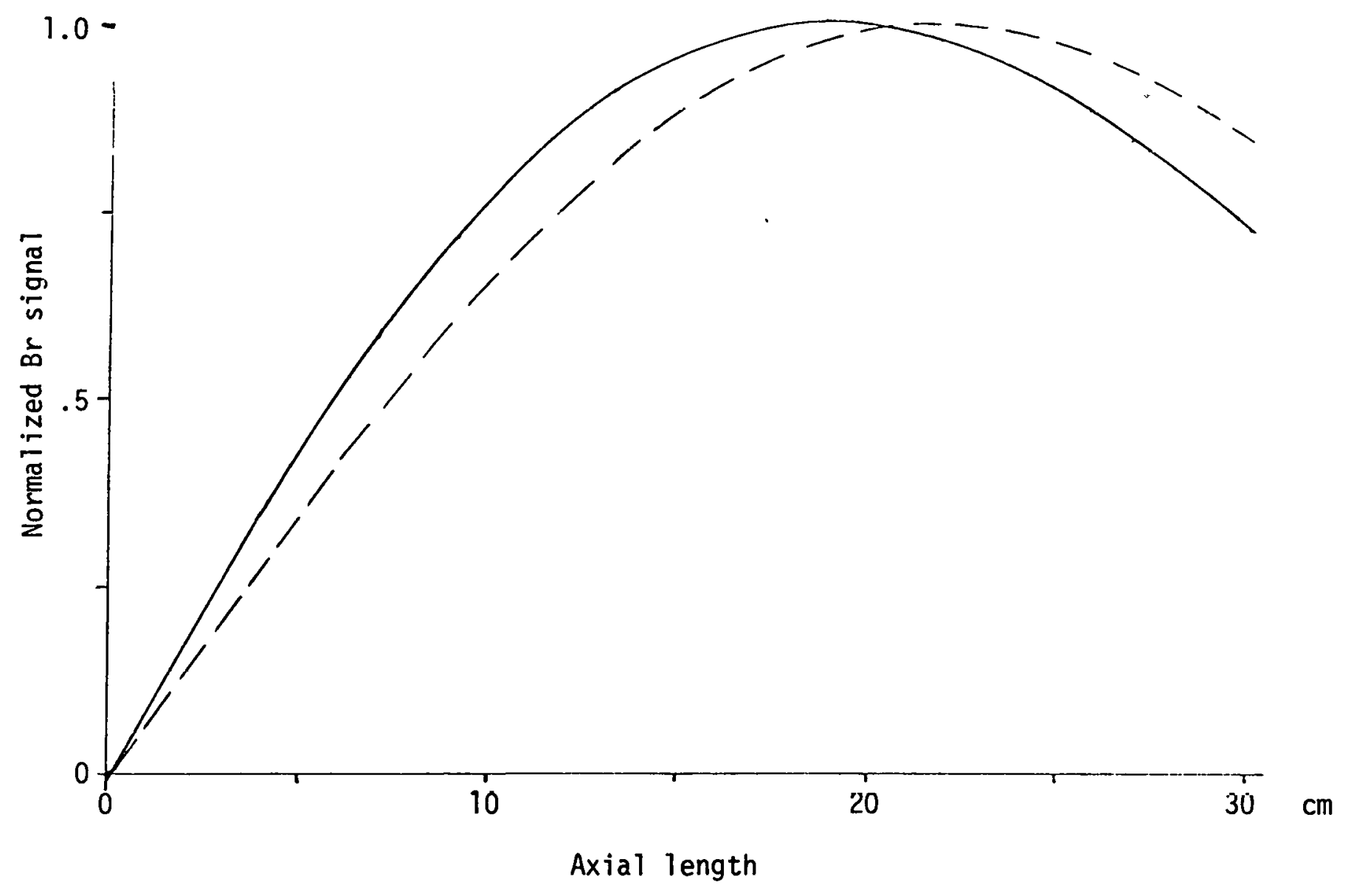

Fig. 2. Simulated radial diamagnetic field versus length of model ring. Solid line for detector at coordinates $(1,30)$, dashed 1 ine for detector at coordinates $(10,30)$ with respect to cavity center. (Ring model thickness $2 \mathrm{~cm}$ assumed)(EBT-I geometry--adjacent cavity effects included) 
the theoretical value. If an absolute calibration could be obtained for field component measurements as well as for the flux loop signals used to measure perpendicular energy then a determination of length, given thickness, could perhaps be made since the perpendicular energy measurement is less sensitive to length and thickness of the ring than some field component measurements. An attempt was made to make this connection between field and flux signals with the data taken in 1976, but some discrepancy was present in the relative calibration which prevented reaching any conclusions.

Simulated data was obtained for field components at several detector locations versus model ring length with other model parameters fixed. The field values were ratioed to the values obtained at the location nearest the midplane in order to eliminate an assumption of absolute calibration for experimental data. The resulting curves are plotted for one choice of ring thickness and radius in Fig. 3. Note that the slopes of the curves are small. Thus in the presence of experimental uncertainty accurate determination of length is difficult even with the model parameters of thickness, radius, and drift current effect known.

Since the other model parameters are not known a priori one can consider cases with both length and thickness unknown. Then for each field component a curve of length versus thickness can be made. An example is given in Fig. 4 using simulated $B_{r}$ readings for a particular length and thickness. In this case the curves are nearly parallel so that the point of common intersection could not be found accurately in the presence of experimental uncertainties, al though model length could be determined more accurately than thickness.

There is a need for field measurements at a combination of precision, absolute calibration and locations that would fix the parameters of the ring model -- not only to evaluate these parameters but alsu to determine the validity and usefulness of the model in further plasma calculations (from the goodness of the fit of the model to the data). The STM results indicate a more complicated ring model will be needed for good fits ${ }^{7}$. A possible approach is to use a MHD equilibrium model such as is dcscribed in the next section of this report. 


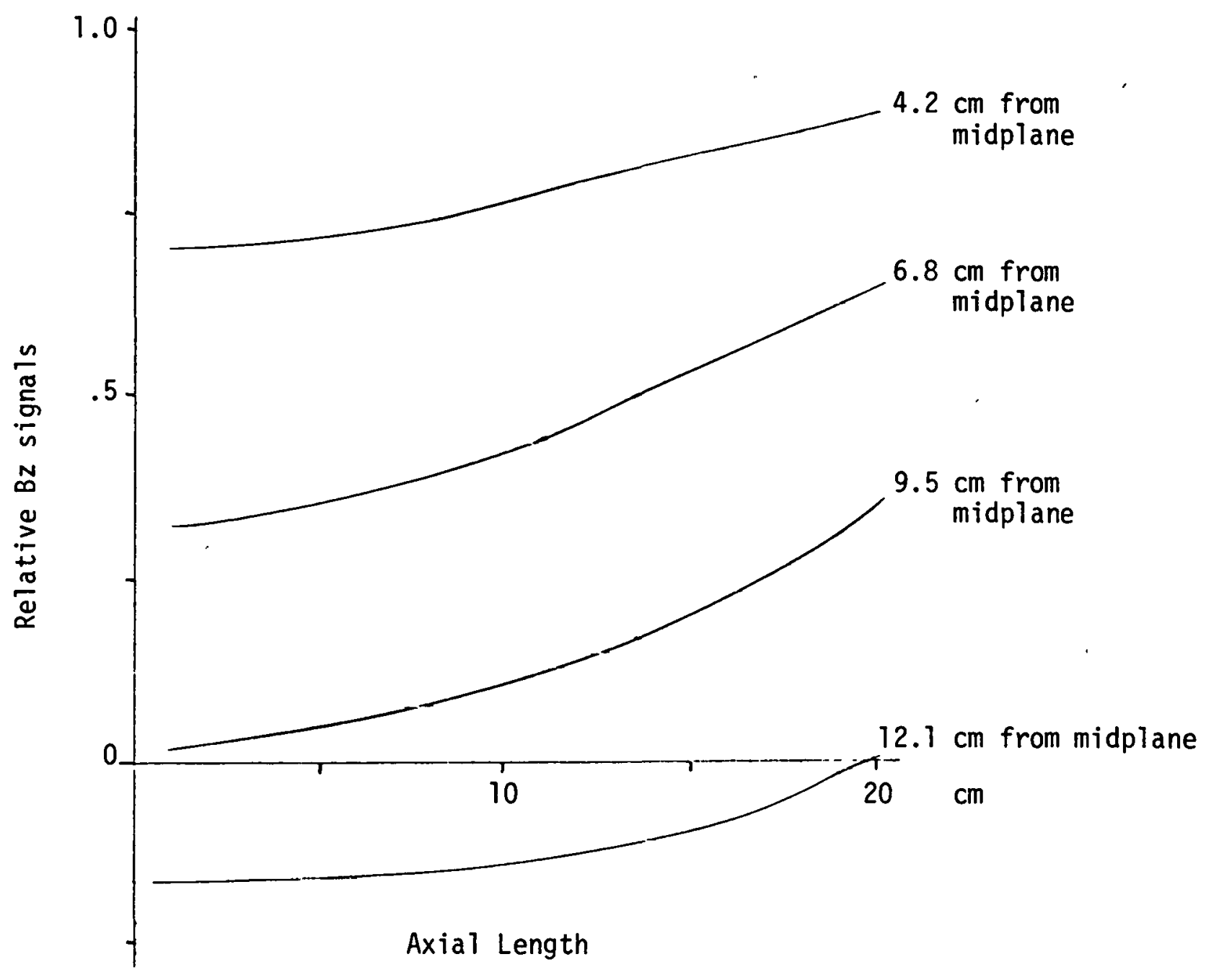

Fig. 3. Simulated axial diamagnetic field components at outside of plasma ( $23.5 \mathrm{~cm}$ from cavity center) relative to component at coordinates $(1.6,23.5)$ near the midplane, versus length of model ring. (Ring thickness $2 \mathrm{~cm}$, mean radius $13.3 \mathrm{~cm}$ assumed-EBT-I geometry, adjacent cavity effects included) 


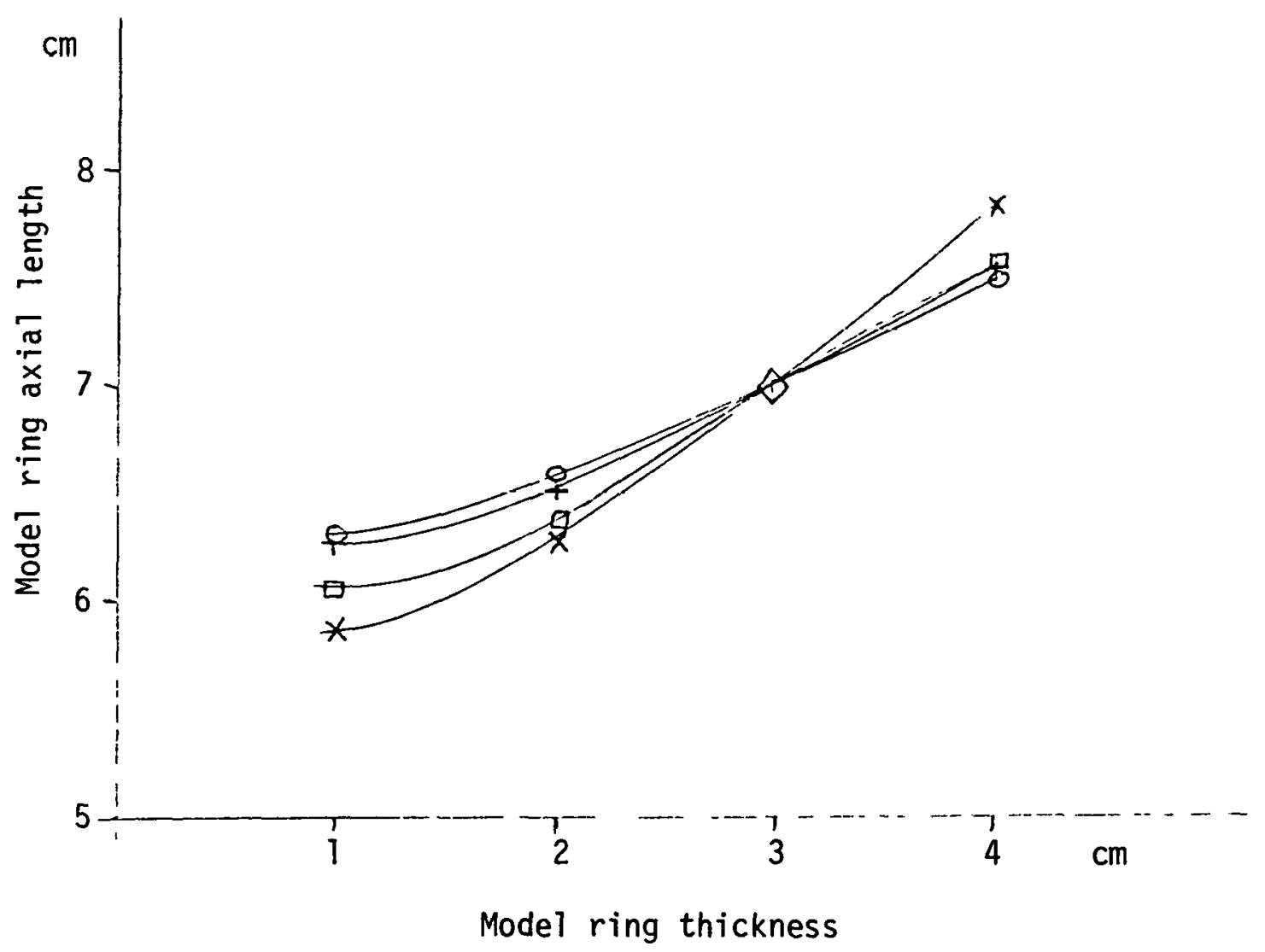

Fig. 4. Length - thickness curves for simulated experimental Bz data for detectors at:

signal from detector at $(1.6,23.5)$ 


\section{IV. "BUMPY CYLINDER" MHD EQUILIBRIUM CODE MODEL FOR CALIBRATION} OF ELECTRON RING ENERGY DIAGNOSTIC - COMPARISON TO CURRENT SHEET MODEL

The concentric cylindrical current sheet model that has been used to provide a calibration for the diamagnetic flux loops' perpendicular energy signal has been studied extensively. ${ }^{10}$ Although the calibration results obtained are quite insensitive to the model parameters (a fact attributed in part to the near Helmholtz coil arrangement of the pickup loops), which should imply similar calibration results would be obtained with other models, two questions still remain as to the validity of the result. The first question is on the adequacy of the handling of the drift current effect for the current sheets. The second is what is the proper choice of average magnetic flux density to use to multiply total magnetic moment to obtain perpendicular energy. Both of these questions are answered automatically if a MHD equilibrium model is used in place of current sheets.* In this section we will describe the modifications made to an existing MHD code, the normalization factors associated with the code output, and the problems and limitations of the code. The results of the MHD equilibrium code being applied to typical ring situations will be discussed and compared to the analogous current sheet results.

The burnpy cylinder MHD equil ibrium code

We were provided a copy of the FORTRAN of the bumpy cylinder MHD code written by Hedrick ${ }^{11}$ to serve as the basis for this work. The code uses a model of pressure as a separable function of flux, $\psi$, and field magnitude $B$ with

\footnotetext{
*Remaining questions as to valid range of model parameters must be answered through the use of other diagnostic methods. Testing of these models has been done by assuming reasonable dimensions for electron rings centered near the rings' heating resonance.
} 


$$
g(\psi)=\left\{\begin{array}{l}
\left(\psi-\psi_{1}\right)^{2}\left(\psi+\psi_{1}-2 \psi_{2}\right)^{2} /\left(\psi_{2}-\psi_{1}\right)^{4}, \psi_{1} \leq \psi \leq \psi_{2} \\
1, \psi_{2} \leq \psi \leq \psi_{3} \\
\left(\psi-\psi_{4}\right)^{2}\left(\psi+\psi_{4}-2 \psi_{3}\right)^{2} /\left(\psi_{3}-\psi_{4}\right)^{4}, \psi_{3} \leq \psi \leq \psi_{4} \\
0, \text { otherwise }
\end{array}\right.
$$

as the flux function and

$$
\begin{aligned}
& P_{\perp}=\frac{1}{2} S\left(B_{C}{ }^{2}-B^{2}\right) g(\psi) \\
& P_{11}=\frac{1}{2} S\left(B_{C}-B\right)^{2} g(\psi)
\end{aligned}
$$

as the pressure functions. $S$ is a positive constant less than one and $B_{C}$ is a cutoff field value - pressure is zero for $B_{.}>B_{C}$. The code chooses the $\psi_{1}, \psi_{2}, \psi_{3}, \psi_{4}$, values at proper flux coordinates to give fixed (input) values for the radial position of the pressure profile in the midplane. The resultant equilibrium ring is thus a function of six input parameters to the code: four radial values $r_{j}$ corresponding to the flux values $\psi_{j}$; the cutoff field $B_{c}$; and the constant $S$. The code calculates the equilibrium by iteration on the nonlinear MHD equation

$$
\Delta^{*} \psi_{p}+\nabla(1 n \sigma) \cdot \nabla \psi_{p}=-\frac{r^{2}}{\sigma} \frac{\partial p_{\Pi}}{\partial \psi}-\nabla(7 n \sigma) \cdot \nabla \psi_{c}
$$

where $\sigma=1+\left(p_{\perp}-p_{\Pi}\right) / B^{2}$ and $\psi=\psi_{p}+\psi_{c}$ with $\psi_{c}$ the vacuum flux. The right hand side and $\nabla(1 n \sigma)$ values are calculated using previous solutions for $\psi$, then Eq. (11) is solved by an S.0.R. finite difference algorithm and the process repeated. The code fixes the boundary conditions for Eq.(11) by using a multipole expansion of the field due to the plasma. ${ }^{11}$

There are several auxilary input parameters required by the code: number of sectors to represent an infinite bumpy cylinder, number of terms in multipole expansion, S.O.R. acceleration parameter, and outer loop solution mixing parameter. In addition the number of iterations to be performed on both inner and outer loops must be specified. Only a few of the many possible combinations of these 
auxilary parameters have been used, the choices being guided by trial runs and the experience of other users of the code. 12

Several modifications were required to the FORTRAN of the MHD equilibrium code (titled EQUIL) in order to obtain the necessary output for calibration of the perpendicular energy diamagnetic signals. Most of the added code was placed in subroutine BATS to provide, on the final iteration, a numerical integration of pressure over space to give energy, and to provide an output of perpendicular pressure versus position in a format which gives a pressure map on the line printer. An output of total flux linking a specified circle of constant radial coordinate was also included. A number of smaller changes were made to input/output to make the code compatible with the UM computer network FORTRAN system. Certain sections of the code whose results were not needed for the present purpose were bypassed to reduce time required for execution, and some changes were made in the control of the iterations and the extent of the output. Since the code is over 2000 lines long a complete listing is not included with this report, but listings of the main program, which describes the modifications in comments, and of subroutine BATS, which contains the major additions, are given in the appendix.

Normalization of variables in EQUIL code - specification of input values - interpretation of output values

All length variables in EQUIL are assumed to be in centimeters. All plasma variables are normalized to the magnitude of maqnetic flux density at the center of the midplane, $B_{0}$. Further, factors of $\mu_{0}$ that would be required for SI units are omitted. The FORMAT statements in the code specify how the input variables must be entered, but the input variables and their interpretations are repeated in the output. Since the interpretation of variables given in the computer output is not always clear, and since an understanding of these is necessary for use of the code and interpretation of the results, the input parameters and output values are briefly described in the appendix where a sample output is given. 
The normalization of the output values produced by EQUIL was carefully traced through the FORTRAN listing to be sure all the numerical constants were taken into account. Since the code only treats one-half a mirror section due to symmetry the total ring energy is a factor of two times the value obtained by numerical integration in the code. As a result the values given in Table 2 were obtained. In particular we note that the ring "beta" relative to the field at the center of the midplane, $B_{\perp}=2 p_{\perp} \mu_{0} / B_{0}^{2}$, is just twice the computed value of PERP; the perpendicular energy of the ring in Joules is ten times the computed value WPER multiplied by $B_{0}{ }^{2}$ in $(T e s l a)^{2}$; the flux linking a circle of radius corresponding to the index $L$ in $S I(L)$ in Webers equals the $S I(L)$ value times $6.28 \times 10^{-4}$ times $B_{0}$ in Tesla. Note that local ring beta is typicaliy a factor of $2 \frac{1}{2}$ times greater than $B_{\perp}$ defined with respect to $B_{0}$. General observations on EQUIL output

Sample output from representative runs of the MHD equilbrium program EQUIL are given in the appendix. Some general comments on qualitative results and limitations on their reliability will be presented here. First we note that the pressure model built into the code implies that, for a fixed radial profile for the ring, the higher the beta the longer the ring in the toroidal direction. Whether or not this implication of the model is also true for the actual ring is significant for ring diagnostics, since a ring long enough to be "high" beta is too long to be adequately represented by a circular cylinder model. In EQUIL runs we have made to date we have achieved less than $20 \%$ beta for rings when the length was forced to be about $10 \mathrm{~cm}$.

We note that for the runs of EQUIL made to date that had beta values high enough to achieve a local minimum in $B$ versus $r$, the $W_{\perp}$ values that resulted should produce diamagnetic flux signal voltages $(>500 \mathrm{mV}$ ) that are greater than those observed for EBT-I turn-downs $(<300 \mathrm{mV})$. However, no systematic study has been made on this topic.

There remain matters of numerical precision to be resolved with the EQUIL code itself. The code is written in single precision 


\begin{tabular}{|c|c|c|c|c|}
\hline $\begin{array}{c}\text { beta } \\
\%\end{array}$ & 2 & 8 & 18 & 23 \\
\hline \hline $\begin{array}{c}\text { radial } \\
\text { shape }\end{array}$ & triangle & trapezoid & triangle & trapezoid \\
\hline$r_{1}$ & 11 & 11 & 11 & 11 \\
\hline$r_{2}$ & 13 & 12 & 13 & 12 \\
\hline$r_{3}$ & 13 & 14 & 13 & 14 \\
\hline$r_{4}$ & 15 & 15 & 15 & 15 \\
\hline \hline$\left(\frac{w_{\perp}}{V_{0} 1 t}\right)$ & 32 & 32 & 30 & 28 \\
\hline
\end{tabular}

Table 2. Diamagnetic flux pickup loop calibration factors from MHD equilibrium model. $\left(B_{0}=5000(G)\right)$. 
FORTRAN and executed on a 32 bit word computer. Since the solution is done by iteration, roundoff errors are less of a problem, but a test case should be run in double precision. The size of the finite difference mesh was checked at two values, and though the results changed, the finer mesh moved the calibration factor for the diamagnetic flux signal toward a smaller energy per volt. The number of iterations on a given run was increased successively until only small changes in results occurred for additional iterations in both outer and inner loops. We note that increasing the number of iterations also reduces the energy per volt factor. We also observe that the values for pressure converged much more rapidly than the values for diamagnetic flux. This is due to pressure being determined by the total flux on which the diamagnetic value is only a perturbation. The number of multipole terms in the boundary condition expansion was fixed at 10 and the number of sectors to approximate an infinite bumpy cylinder was fixed at 7 . Obviously a great deal more effort could be spent assessing the effects of these numerical matters, but the qualitative conclusions are not expected to change.

Current sheet model for bumpy cylinder

In order to make a direct comparison of diamagnetic flux signal calibration in a MHD and a current sheet model, a program was written, similar to the one used to calculate the mutual inductances for the bumpy torus, to provide the calibration factor for a bumpy cylinder with an arbitrary number of sectors. This code (BUMCAL) is 1isted in the appendix. The code outputs normalized tiux linkage for single current sheets. The drift factor effect for the concentric current sheet model is then calculated by hand. The input values given to the program are the number of sectors, the current sheet radius, the current sheet width, and the separation between adjacent sectors (all in centimeters). The output is a value APT which is the normalized flux linkage for a pickup loop in a position similar to the diamagnetic flux loops on EBT (radius $28 \mathrm{~cm}$, location $9.5 \mathrm{~cm}$ from midplane). The normalization in the code is such that to obtain the dimensional flux linking one turn of the pickup loop one must multiply the value of APT by $\mu_{0} R I / 2$ where $R$ is pickup coil radius and $I$ is total current 
for the sheet. Thus the formula to obtain the flux pickup loop calibration factor is

$$
\frac{W_{\perp}}{\text { Volts }}=\frac{B_{\text {avg }}}{\left(\mu_{0} / 4 \pi\right)} \frac{r(\Delta r) t}{R N} \frac{1}{\left[(1+(\Delta B / 2 B)) A P_{\text {out }}-(1-(\Delta B / 2 B)) A P_{i n}\right]}
$$

where $B_{\text {avg }}$ is the proper "average" value of total magnetic flux density over the model ring to convert dipole moment to energy. $\Delta r$ is ring thickness, $r$ is ring mean radius, $N$ is number of turns on the pickup coil, $t$ is integrator time constant, $\Delta B$ is change in magnetic field across the ring thickness and $B$ the mean value.

One case was run for comparison to the MHD values. For it $R=28 \mathrm{~cm}, r=13 \mathrm{~cm}, \Delta r=2 \mathrm{~cm}, L=10 \mathrm{~cm}$ and BUMCAL gave $A P_{\text {out }}=1.0076$ and $A P_{i n}=0.7394$. The values assumed for $\triangle B / B$ and $B_{\text {avg }}$ have a significant bearing on the result. To agree with the procedure used for the EBT current sheet model the value taken for $\triangle B / B$ corresponded to the vacuum field in the midplane (as read from the output for a low beta case from EQUIL). If $B_{\text {avg }}$ is taken as the value near the center of a corresponding low beta run of EQUIL then $B_{\text {avg }}=0.255(T)$ for a field of 5000 Gauss at the center of the midplane. Substituting these values in Eq. ( 12 ) gives a numerical value for the calibration factor of 26 (Joule/volt). Obviously there is room for considerable uncertainty in the $B_{\text {avg }}$ value used as well as in $\triangle B / B$. No other cases have been checked, but experience with the bumpy torus current sheet model shows that little change is to be expected for different thickness $\Delta r$ or length $L$ as long as the other values remain the same.

Comparison of MHD equilibrium model and current sheet model flux loop energy calibration factors

Four cases have been run with EQUIL using input values that yield rings that can reasonable be compared with the cylindrical current sheet model. Each had a length of about $10 \mathrm{~cm}$ and was approximately cylindrical in geometry (as can be seen in the EOUIL sample output in the appendix). The radial cross section, beta 
values, and flux loop calibration factors are summarized in Table 3 . We note that pickup loop calibration factors exceeded the current sheet model value of 26 (Joule/volt) by a range of 10 to $20 \%$.

A $20 \%$ agreement between as crude a model as cylindrical current sheets compared to a MHD equilibrium is encouraging. The difference is no doubt due in part to the choice of $B_{\text {avg }}$ and $\triangle B / B$ for the current sheet model. A concern for the accuracy of the MHD model results needs to be mentioned however. In each case listed in Table 3 the radial increment for the finite differences was $0.25 \mathrm{~cm}$. This put only 16 points across the ring. The case of $2 \%$ beta and triangular radial profile was also run with a $0.5 \mathrm{~cm}$ radial increment. A result of 39 (Joule/volt) was obtained, which is $20 \%$ higher than the result for $0.25 \mathrm{~cm}$ increments. A further reduction in increment size could reduce the calibration factor to a value more nearly in agreement with the current sheet model. Time did not allow such runs of EQUIL to be made during the period of this subcontract.

A word of caution must be given about using these bumpy cylinder flux pickup loop calibrations for the $W_{\perp}$ signals on EBT. First, al though the loop placement was chosen to be as near to the EBT value as possible, there is still a difference between the toroidal and cylindrical geometries. Second, the EQUIL code runs and BUMCAL runs were made using a separation between adjacent mirror coils of $11.5 \mathrm{~cm}$. The separation at $15^{\circ}$ for a $150 \mathrm{~cm}$ major radius torus would be $39 \mathrm{~cm}$. The proper equivalent separation for a bumpy cylinder for comparison of calibration factors is not clear, but it is clear that adjacent sector cross talk is a bigger factor for the bumpy cylinder, all other effects being equal. However, the current sheet model for EBT gives values for $W_{\perp}$ signal calibration not far different from those found for the bumpy cylinder. ${ }^{10}$ 


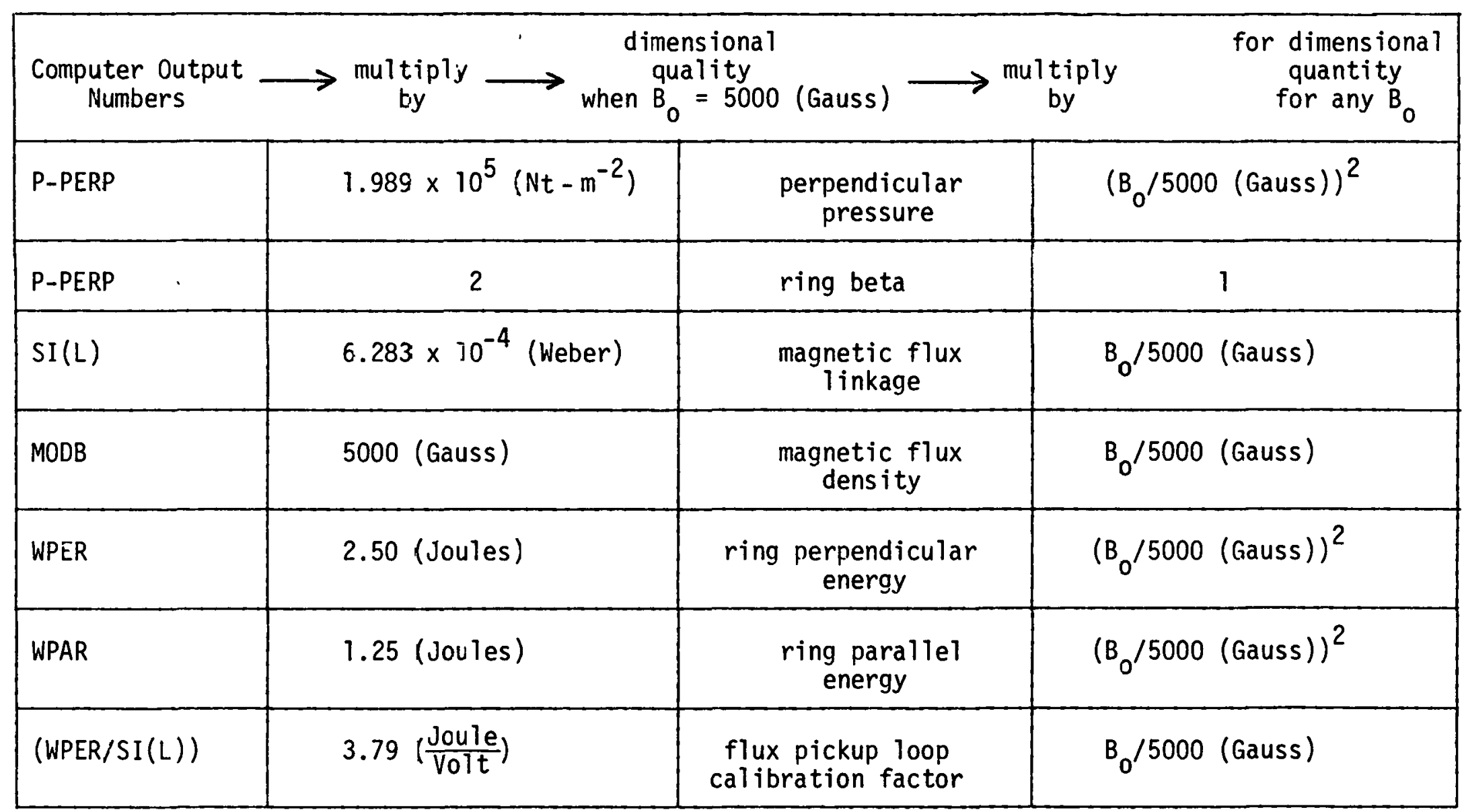

Table 3. Numerical factors to convert output from EQUIL computer code to dimensional quantities. 


\section{CONCLUDING COMMENTS AND RECOMMENDATIONS}

The work discussed above is by no means the last word on diamagnetic diagnostics for EBT electron rings. However, important advances have been made in understanding these diagnostics, which we will point out again along with giving our recommendations for additional work in these areas.

The cavity cross talk compensation algorithm for the perpendicular energy signals described in section II is simple and has proven successful in use. The implementation in the EBTOFF code is applicable to EBT-I/S only, however a similar program could easily be written for other machines. One must caution users that the "universal" set of correction numbers written into EBTOFF works best for rings with mean radii near $13 \mathrm{~cm}$. Accuracy will be reduced if the machine is run in a mode that would produce rings significantly larger or smaller. In any event, the test of accuracy is the corrected signal output for a cavity with zero input power (which should be near zero).

The examination given to the possibility of obtaining ring geometrical data from diamagnetic field component measurements leaves the projected outcome of such an experiment with a great deal of uncertainty. It is the feeling of the author that the best possible set of diamagnetic data should be obtained. If this is not definitive in itself, itcanbecorrelated to non-diamagnetic diagnostics as they become available. Further work is needed on the use of al ternate models for ring geometry, including parameterizations of 3-D MHD equilibria.

The 2-D bumpy cylinder MHD equilibrium calculations have confirmed the basic validity of the use of a current sheet model for calibration of the diamagnetic perpendicular energy diagnostic. There still remain a sizeable number of calculations and code modifications to be done to finally establish the best values and check out possible numerical problems in the code. As 3-D MHD equilibria are generated for geometrical modeling they can also be used to check the $w_{\perp}$ calibration. As yet optimization has not been attempted on the pickup coil sizes, locations and orientations. 
While not a major task, this needs to be considered, especially for application on any new or modified plasma experiment, such as EBT-P. 


\section{REFERENCES}

1. N. A. Uckan, ed., Proceedings of the Workshop on EBT Ring Physics: Dec. 3-5, 1979: Oak Ridge, Tenn., Oak Ridge National Laboratory, CONF-791228, April 1980.

2. N. A. Uckan, Op. cit., section 6, pp. 317-380.

3. N. A. Uckan, Op. cit., section 7, pp. 381-490.

4. R. A. Dand1, et. al., Summary of EBT-I Experimental Results, ORNL/TM-6457, Oak Ridge National Laboratory, October 1978, pp. 9-12.

5. K. H. Carpenter, "Diamagnetic Measurements for Experimental Determination of EBT Ring Paramters", in N. A. Uckan, op. cit., p. 147.

6. M. Fujiwara, et. al., "The Ring Formation in Nagoya Bumpy Torus", in N. A. Uckan, op. cit., pp. 123-141.

7. B. H. Quon, et. al., "Spatially Resolved Measurements of the Diamagnetic Field," Bulletin of the APS, Vol. 25 (October 1980), p. 994.

8. K. H. Carpenter, "Modeling the Electron Annulus in EBT from Diamagnetic Field and Flux Measurements," in Fusion Energy Division, Annual Progress Report For Period Ending December 31, 1976, ORNL-5275, Oak Ridge National Laboratory, June 1977, pp. 14-16.

9. G. R. Haste and C. L. Hedrick, ORNL Foreign Trip Report, ORNL/FTR-767 Oct. 8, 1979.

10. K. H. Carpenter, R. A. Dand1, M. W. McGuffin, Cal ibration of a Diamagnetic Diagnostic for Stored Energy of High Temperature Electron Annuli in Elmo Bumpy Torus (EBT), ORNL/TM-7076, to be issued.

11. D. B. Nelson, C. L. Hedrick, "Macroscopic Stability and Beta Limit in the Elmo Bumpy Torus," Nuclear Fusion, Vol. 19 (1979), p. 283.

12. R. C. Goldfinger, private communication. 
APPENDIX - FORTRAN Listings and Inputs and Outputs

Cross talk compensation programs

The routines written to achieve the unfolding of intercavity cross talk between $W_{\perp}$ signals have their FORTRAN 1istings given on the following pages. These listings are in the form of a compressed format file used with the UM computer network IBM-CMS software. Subroutines called, but not in the listing, were used in prior work at ORNL and are available on the FED PDP-10 computer.

A11 the main programs listed prompt for input interactively or else read as input a file produced by one of the other main programs. All output is via the NAMELIST method for easy data identification. Outputs used in determining the universal correction values programmed in EBTOFF are given in the pages following the FORTRAN listings. 
FILE: AIMI CPR A UNIVERSITY OF MISSOURI COMPUTER NETWORK

\begin{tabular}{|c|c|c|c|c|c|c|c|}
\hline : REA & & AIMI & $E X E C$ & A 1 & TEMP & $07 / 21 / 80$ & $09: 55: 02$ \\
\hline$\varepsilon 1$ & $\varepsilon 2$ & LTAIMI & EXEC & A 1 & & & \\
\hline$\varepsilon 1$ & $\varepsilon 2$ & CAIMI & $E \times E C$ & A 1 & & & \\
\hline$\varepsilon 1$ & $\varepsilon 2$ & AIOC & FORTRAN & A 1 & & & \\
\hline$\varepsilon 1$ & $\varepsilon 2$ & BMNORM & FORTRAN & A 1 & & & \\
\hline$\varepsilon 1$ & $\varepsilon 2$ & DM & FORTRAN & A 1 & & & \\
\hline$\varepsilon 1$ & $\varepsilon 2$ & EBTOFT & FORTRAN & A 1 & & & \\
\hline$\varepsilon 1$ & $\varepsilon 2$ & MIJE 1 & FOETRAN & A 1 & & & \\
\hline \&1 & $\varepsilon 2$ & SYMCIR & FORTRAN & A 1 & & & \\
\hline$\varepsilon 1$ & $\varepsilon 2$ & TAIMI & FORTRAN & A 1 & & & \\
\hline$\varepsilon 1$ & $\varepsilon 2$ & TDM & FORTRAN & A 1 & & & \\
\hline$\varepsilon 1$ & $\varepsilon 2$ & TSTSYM & FORTRAN & A 1 & & & \\
\hline$\hat{u} 1$ & $\varepsilon 2$ & ZEROIN & FORTRAN & A 1 & & & \\
\hline$: R \equiv A$ & $D$ & LTAIMI & $E \times E C$ & A 1 & TEMP & $07 / 21 / 80$ & $09: 40$ \\
\hline
\end{tabular}

LOAD TAIMI MIJE 1 AIOC SYMCIR DM ZEROIN SLFL AS 1 SASIMP SGAUS 8 (NOMAP GEN:1OD TAI

:READ CAIMI EXEC A 1 TEMP $07 / 21 / 80 \quad 09: 40: 43$

FORTGI TAIMI (NOPRINT NOTERM

FORTGI MIJE 1 (NOPRIHT NOTERM

FORTGI RIOC (NOPRINT KOTERM

FORTGI DM (HOPRINT NOTERM

FORTGI SYMCIR (NOPRINT NOTERM

FORTGI ZEROIN (NOPRINT NOTERM

:READ AIOC FORTRAM AI TEMP $07 / 21 / 80 \quad 09: 40: 43$ SUBROUTINE AIOC (AIO,EF)

C K.H.CARPENTER 11 JUL80.

C APPIIES INVERSE MUTUAL INDUCTANCE MATRIX BM TO INPUT WPER SIGNAL

C VALUES EF TO GIVE UNFOLDED WPER VALUES AIO (NORMALIZED).

C NORMALIZATION OF WPER FOR I'TH CAVITY IS:

$\mathrm{C}$

$\mathrm{C}$

$\mathrm{C}$

C

$\mathrm{C}$

$\mathrm{C}$

$\mathrm{C}$

C WP $(I)=(A I O(I)-A I O(K)) * B V(I) / C P H I / N T U R N /(M U O / T W O P I)$ WHERE BV(I) IS "AVERAGE" MAGNETIC FLUX DENSITY OVER ANNULUS, CPHI IS VALUE FIUX IIKKING PICKUP COIL IS MULTIPIIED BY TO OBTAIN EF(I), AND NTURN IS TOTAL NO. OF TURNS IN SERIES IN PICKUP COIIS ON CAVITY I. AIO(K) IS RESIDUAL VALUE FOR CAVITY WITH NO AMNUIUS. FOR DETAILS SEE KHC 9JUL8O.

COMMON/CMIJE 1/BM( 13$), A M(13), V 1$

DIMENSION AIO (24), EF (24)

C MULTIPLIES INPUT VECTOR EF BY MATRIX BM TO OBTAIN OUTPUT

C VECTCR AIO.

C BM IS A SYMMETRIC, CIRCULANT MATRIX OF DIMENSION 24. DO $100 \quad I=1,24$ $I i=\operatorname{MOD}(I, 12,24)$

$I F(N . E Q .0) N=24$

$A I O(I)=B M(1) * E F(I)+B M(13) * E F(N)$

DO $50 \mathrm{~J}=2,12$

$M 1=M O D(I+J-1,24)$

$I F(N 1.22 .0) N 1=24$

$N 2=\operatorname{MOD}(25 \div I-J, 24)$

$I F(N 2 . E O .0 ; N 2=24$

$A I D(I)=A T O(I)+B M(J) *(E F(N 1)+E F(N 2))$

50 CONTINUE

100 CONTINUE

R.ETURK 
END

:READ BMNORM FORTRAN A1 TEMP $07 / 21 / 80 \quad 09: 40: 43$

C BMNORM K.H.CARPENTER 16JUL8O

C PROGRAM TO OUTPUT NORMAIIZED ARRAY OF BM WITH BM( 1$)=1$

C AND AN ARRAY NORMAIIZED BY MULTIPIYING BY AM( 1 ).

DIMENSION AIO(24), EF(24), BM(13), AM(13),BN(13),BMN(13)

NAMELIST/NORM/BN,BMN,AL, RT, DF, BO, GHZ, RR, XR, BZ

NAMELIST/TAIOUT/AI, RT, DF, BO, GHZ, EF, AIO,BM, AM, V1, RR, XR, BZ, IERR

5 READ $(3, T A I O U T, E N D=100)$

DO $10 \mathrm{~K}=1,13$

$B N(K)=B M(K) / B M(1)$

$B M N(K)=B M(K) * A M(1)$

10 COKTINUE

WRITE $(7$, NORM)

GO TO 5

100 STOP

END

:READ DM FORTRAN A1 TEMP 07/21/80 09:40:44

FUNCTION DM(DEG,RI,RO,CO,AL,DF,RE, ZO, AMR, IERR)

C K.H.CARPENTER 8 JUL8O

C

RETURNS NOFMAIIZED MUTUAL INDUCTANCE VAIUE BETWEEN

DIAMAGNETIC PICKUP LOOPS AND EBT ANNULUS IN CURRENT

SHEET MODEL. ARGUMENTS ARE :

DEG = ANGLE IN DEGREES BETWEEN CAVITY WITH ANNUIUS

AYD CAVITY WITH PICKUP LOOPS

RI = RADIUS OF INNER CURRENT SHEET

RO = RADIUS OF OUTER CURRENT SHEET

CO = OUTWARD DISTANCE FROM CENTER OF CURRENT SHEET TO CENTER OF PICKUP LOOP

$A L=$ IENGTH OF CURRENT SHEETS

$D F=$ DRIFT FACTOR $(1+D B / B / 2)$

RB = RADIUS OF PICKUP LOOPS

$Z O=$ HALF OF DISTANCE BETWEEN PICKUP LOOPS

AMR = DISTANCE FROM CENTER OF MACHINE TO CENTER OF PICKUP IOOPS

RESUIT IS INDEPENDENT OF UNITS USED FOR DISTANCE,BUT

UNITS MUST BE THE SAME FOR AIJ. ARGIIMFNTS.

THE ARGUMENTS ABOVE ARE UNCHANGED ON RETURN.

IERR = ERROR INDICATOR. IF IERR=0, NO ERROR.

ON RETURN DM CONTAINS THE VAIUE OF THE NORMAIIZED

MUTUAL INDUCTANCE BETWEEN THE PICKUP LOOPS AND THE CURRENT

SHEETS. THE NORMALIZATION IS:

$M=D M * N * T * M U O /(2 * P I)$ WHERE

$N=$ TOTAI TURNS IN PICKUP IOOPS

$T=R O-R I$

VOLTAGE SIGNAL FROM PICKUP LOOPS ( 2 IN SERIES WITH TOTAL

TURNS $M$ ) DUE TO THIS ANNULUS IS EQUAL TO M*TC*JM*AI WHERE

TC IS INTEGRATOR TIME CONSTANT AND

JM IS MAGNETIC DIPOLE MOMENT PER UNIT VOLUME

FOR ARNULUS ELECTRONS (MEAN SURFACE CURRENT).

DOUBIE PRECISION DPI

COMMON/CFB/FB, R, X, R1, AL 2, RS, R1S, R 1R4, RPR 1S2, RMR 1S

COMMON/CSLFL/FI, B, XB, ZB, ADEG, CX, SX, XBR, BSX, BCX

DATA DPI/3.141592653539793DO/ 
FILE: AIMI CPR A UNIVERSITY OF MISSOURI COMPUTER NETWORK

DATA NG/4/, NS/8/

$I E R R=0$

NG $1=N G$

C PICK UP ARGUMENTS AND PUT IN COMMONS:

$\triangle D E G=D E G$

$A L 2=A L / 2.0$

$B=R B$

C SET FOR OUTER CURRENT SHEET

$\mathrm{R} 1=\mathrm{RO}$

C CALCULATE VALUES FOR ROTATIONAL TRANSFORM

$A R A D=D E G * D P I / 180 . D 0$

$C A=\operatorname{COS}(A R A D)$

$S A=S I N(A R A D)$

$\mathrm{ZC}=\mathrm{ZO} * \mathrm{CA}$

$\mathrm{TZC}=2 \cdot * \mathrm{ZC}$

$\mathrm{ZS}=\mathrm{ZO} * \mathrm{SA}$

TZS $=2 . * \mathrm{ZS}$

C SET XB,ZB FOR IST COII

$\mathrm{ZB}=\mathrm{ZC}+\mathrm{AMR} * \mathrm{SA}$

$X B=-Z S+A M R * C A-A M R+C O$

C NO INTEGRATION REQUIRED IN SLFI FOR SYMMETRIC CASE

IF ( ( ADEG.EQ.0.OR.ADEG.EQ.180.).AND.CO.EQ.0.)NG 1 =0

CALL SLFL(NG $1, N S)$

$A M 1=F L$

C SET XB,ZB FOR 2ND COIL

$\mathrm{ZB}=\mathrm{ZB}-\mathrm{TZC}$

$X B=X B+T Z S$

CALI SIFL (NGI, NS)

$A M 1=A M 1+F I$

C SET FOR INNER CURRENT SHEET

$\mathrm{R} 1=\mathrm{RI}$

CALI SLFL (NG1, NS)

$A M 2=F I$

C SET FOR 1ST COIL AGAIN

$Z B=Z B+T Z C$

$X B=X B-T Z S$

CNIL SLFI(NG 1, ,S )

$\triangle M 2=A M 2+F L$

$D M=(D F * A M 1+(D F-2) * A M 2) * R B * R. B / A I 2 /(R O-R I)$

RETURN

END

:READ EBTOFT FORTRAN A1 TEMP $07 / 21 / 80 \quad 09: 48: 14$

C ESTOFT K.H.CARPENTER 2 TJULBO

C PROGRAM TO OUTPUT NORMAIIZED ARRAY OF AIO WTTH

C WITH AION $(K)=A I O(K) \star A M(1)$.

DIMENSION AION (24), AIO 24$), \operatorname{EF}(24), B M(13), A M(13), B N(13), B M N(13)$

NAMEIIST/NORM/AION, AIO,AI, RT, DF, BO, GHZ, RR, XR, BZ

NAMELIST/TAIOUT/AL,RT, DF, BO, GHZ, EF, AIO,BM, AM, V I, RR, XR, BZ, IERR

$5 \quad \operatorname{READ}(3, T A I O U T, E Y D=100)$

DO $10 \quad K=1,24$

$A I O N(K)=A M(1) * A I O(K)$

10 CONTINUE

WRITE ( 7, NORM )

GO TO 5

100 STOP 
END

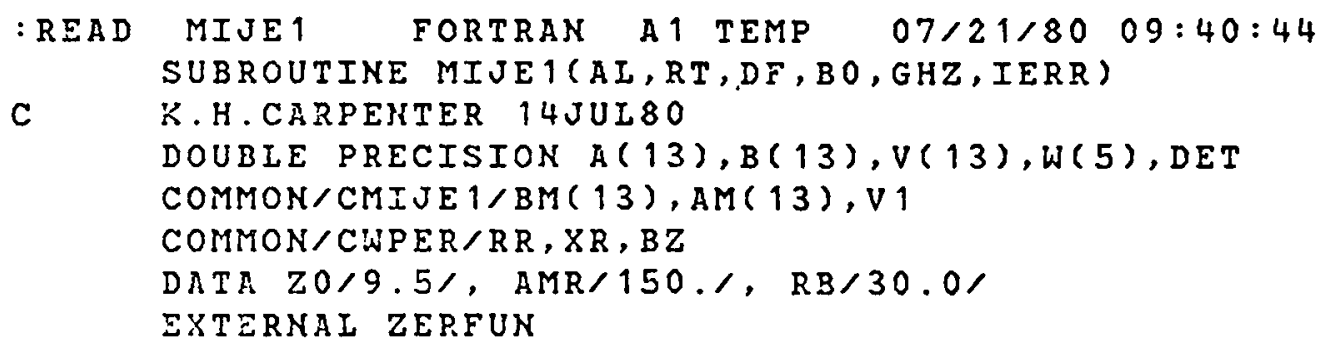

\section{INPUT ARGUMENTS:}

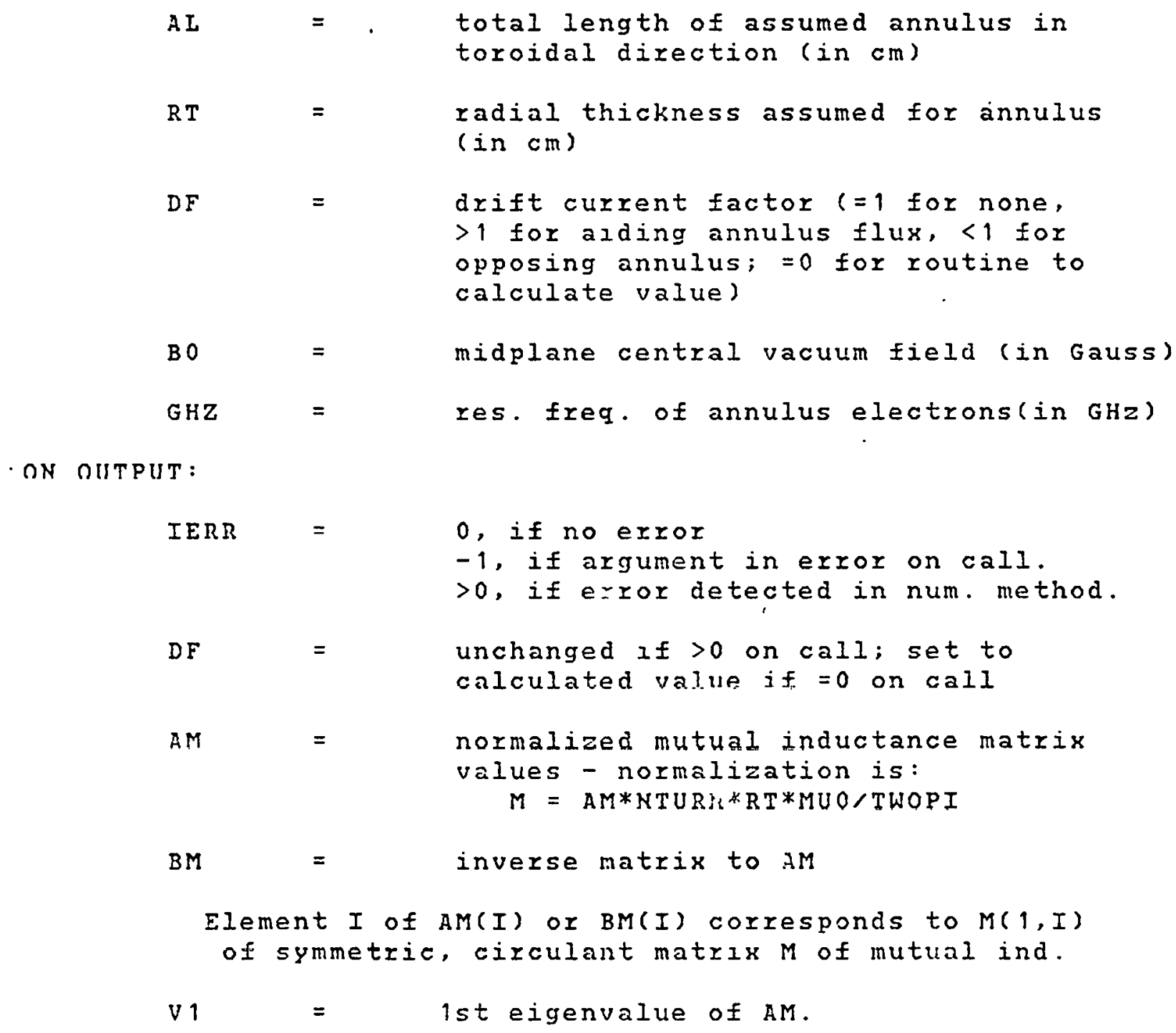




\section{$\mathrm{C}$}

$\mathrm{C} * * * * * * * * * * * * * * * * * *$

$\mathrm{C}$

C : TEST INPUT ARGUMENTS FOR RANGE:

IF (GHZ.IE.O.OR.BO.LE.O..OR.AL.IE.O.OR.RT.LE.O.)GO TO 100

C

$\mathrm{C}$

$\mathrm{C}$

$\mathrm{C}$

FIND RING MEAN RADIUS AND CENTER FROM RESONANCE AT

GHZ AND COLESTOCK FIEID MODEL

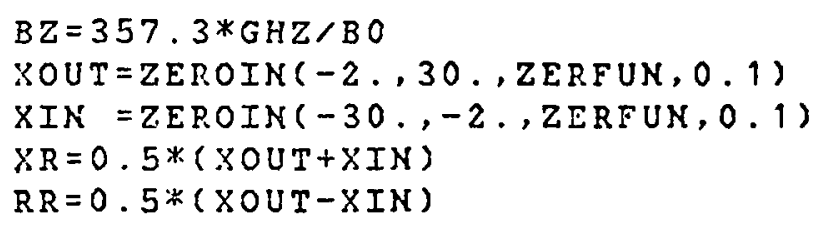

$\mathrm{C}$

IF DF<O, CALCULATE DF FROM COLESTOCK FIELD MODEL AND FORMULA $D F=1 .+0.5 * D E L B / B$

$I F(D F . L E .0) D F=1 .+0.5 *(P A T(X O U T-0.5 * R T)-P A T(X O U T+0.5 * R T)) / B Z$

C

C SET FIXED PARAMETERS FOR CALL TO DM

$R I=R R-0.5 * R T$

$R O=R I+R T$

$\mathrm{CO}=-X \mathrm{R}$

C INITIAIIZE LOOP

$I E R R=0$

$D E G=-15.0$

C CALCULATE AM MATRIX ELEMENTS

DO $50 \quad I=1,13$

$D E G=D E G+15.0$

$A(I)=D M(D E G, R I, R O, C O, A L, D F, R B, Z O, A M R, I E R)$

$A M(I)=A(I)$

$I E R R=I E R R+I E R$

50 CONTINUE

C INVERT AM TO GET BM

$I F L G=1$

CALI SYMCIR(A, V,B,W,DET, 24, IFLG)

IF (IFLG.NE. 3) IERR =IERR + 200

$V 1=V(1)$

DO $60 \quad I=1,13$

$60 \quad B M(I)=B(I)$

RETURN

100 IERR $=-1$

RETURK

END

FUNCTION ZERFUN(X)

COMMON/CWPER/RR, XR,BZ

ZERFUN $=B Z-P A T(X)$

RETURN

END

FUNCTION PAT $(X)$

C Colestock fit to midplane field restricted to zero angle.

c (agrees with measured values. For agreement with calculated

c values, multiply values by 1.0176.$)$

T $2=0$. 


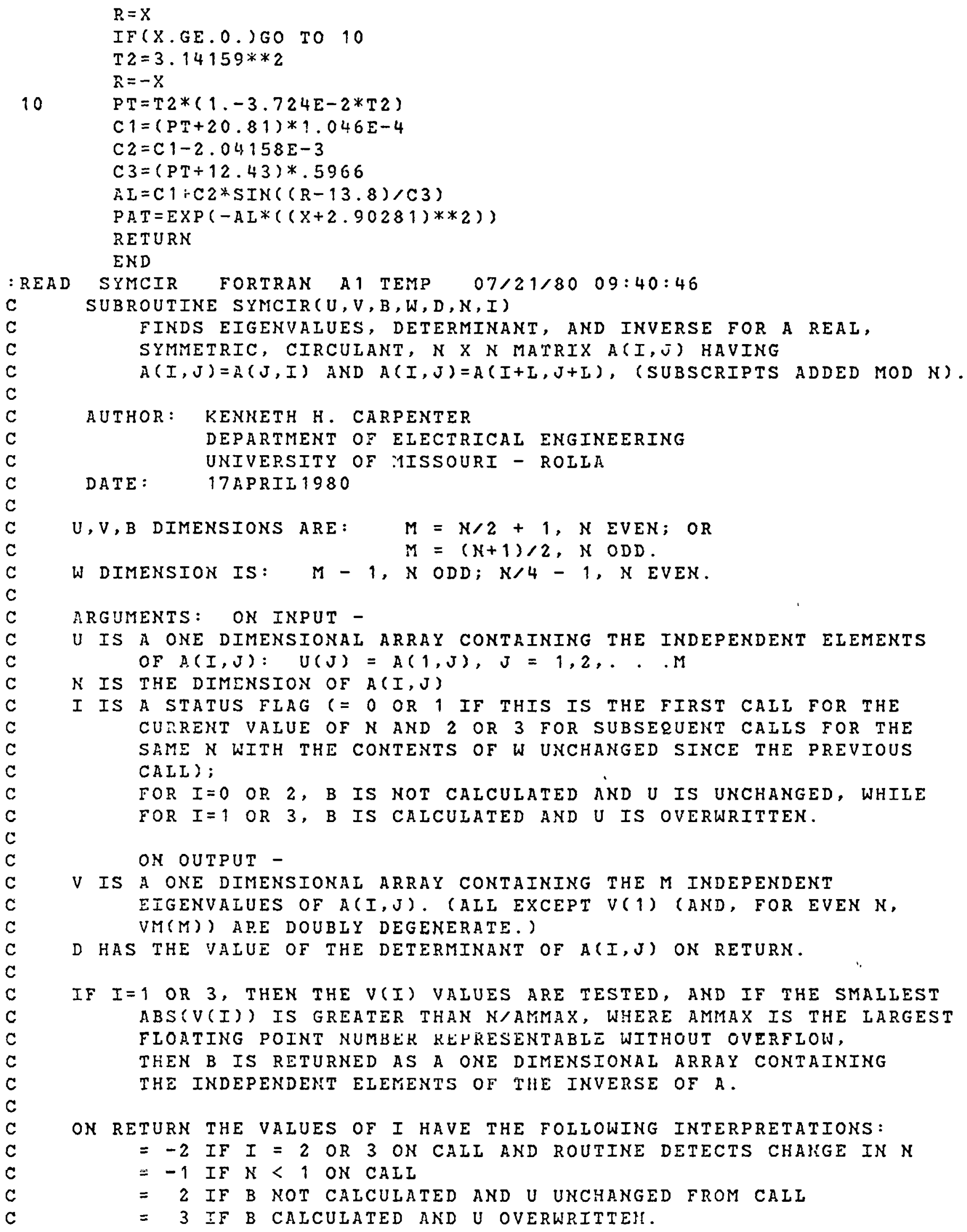


C

\section{c}

C

CS

CS

C

$\therefore$

$\operatorname{cs}$

CS $\quad W(1)=\operatorname{COS}(P N)$

$W$ IS, A ONE DIMENSIONAL WORK ARRAY USED BY THE ROUTINE TO STORE COSINE VALUES; W SHOUID NOT BE CHANGED BETWEEN CAIIS.

ENTRY POINTS DEFINED IN THIS ROUTINE: SYMCIR, CCCOS, CCCCOS

THE FOLLOWING IS A DOUBLE PRECISION VERSION. TO CONVERT TO SINGLE PRECISION, REMOVE THE "CS" CHARACTERS FROM THE LINES BEGINMING WITH "CS", AND ADD "CD" CHARACTERS TO THE FIRST OF THE FOLLOWING LINES.

THIS VERSION USES THE SYMMETRY OF THE MATRIX TO REDUCE THE AMOUNT OF COMPUTATION, BUT DOES NOT USE AN FFT APPROACH. THIS VERSION WILI BE THE MOST EFFICIENT IF $N$ IS PRIME OR CONTAINS A IARGE PRIME FACTOR. IF $N$ IS A PRODUCT OF SMALL PRIMES IT WILI BE MORE EFFICIENT TO IGNORE THE SYMMETRIC NATURE OF THE MATRIX AND USE THE FFT METHOD TO INVERT THE GENERAL CIRCULANT MATRIX.

\section{SUBROUTINE SYMCIR (U, V,B,W, D,N,I)}

REAL U(1), $V(1), B(1), W(1), D$

DOUBLE PRECISION U(1), $V(1), B(1), W(1), D$

REAL

DOUBLE PRECISION CCCOS, AN, A, T, PN, AMMAX, ONE, VM, VMZ, SINT, SIN 1

COMMON/CCCCOS/NO, NO2, NO4, IFOUR, IODD, IUP, IUPP

THE FÓLLOWING VALUES MUST BE SET TO THE LARGEST ALLOWABIE FIOATING POINT VALUE FOR THE COMPUTER BEING USED:

DATA AMMAX/1.E37/

DETA AMMAX/1.D37/

DATA $T / 2.0 /, O N E / 1.0 /$

DATA $T / 2.0 D 0 /, 0 N E / 1.0 D O /$

TEST $N$ AND I AND BRANCH:

IF (K.GE.1)GO TO 10

$I=-1$

RETURY

IF $(N-2) 300,400,20$

IF (I.GT.1)GO TO 100

INTTTATTTF. COSTNF. ARRAY FOR THIS $N$ :

$\mathrm{NO}=\mathrm{N}$

$N O 2=N / 2$

$N O 4=N / 4$

$I F O U R=\operatorname{MOD}(N, 4)$

IODD $=$ ITOD $(N, 2)$

CS $\quad P N=T * T * T * A T R H(1.0) / F L O A T(N)$

$P N=T * T * T * D \Lambda T \Lambda N(1.0 D O) / D B L E(F L O A T(N))$

$I=N / 4-1+I F O U R / 2$

$I F$ (IODD.E\&.1)L $=(N-1) / 2$

IF(L.IT.1)GO TO 50

$W(1)=D \cos (P N)$

IF(L.IT.2)GO TO 50

$\operatorname{SIN} 1=\operatorname{SIN}(P N)$

$\operatorname{SIN} 1=\operatorname{DSIN}(P N)$

$\operatorname{IF}(L . E Q .2) G O$ TO 40

$S I N T=S I N 1$

DO $30 \mathrm{~K}=2$, I 


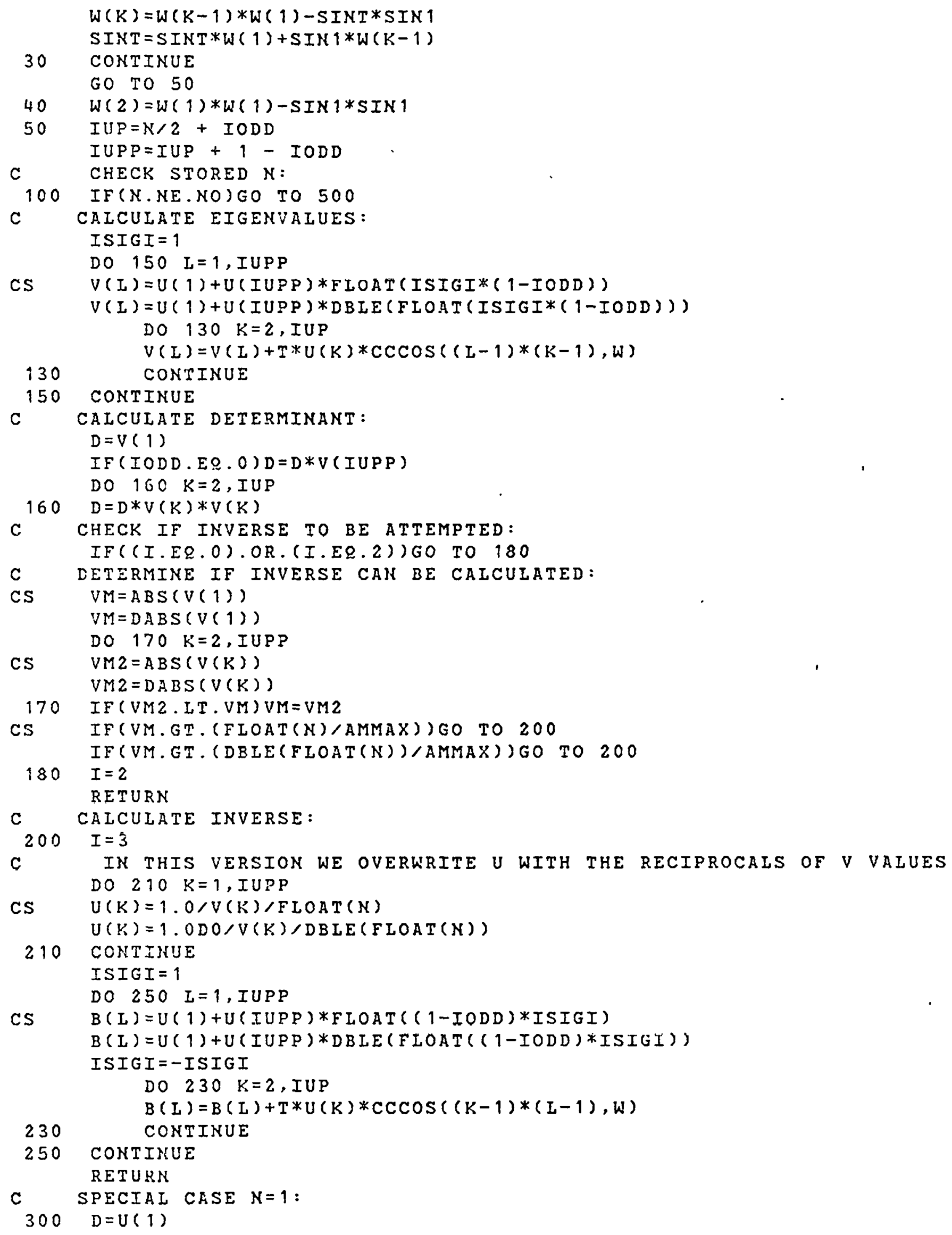




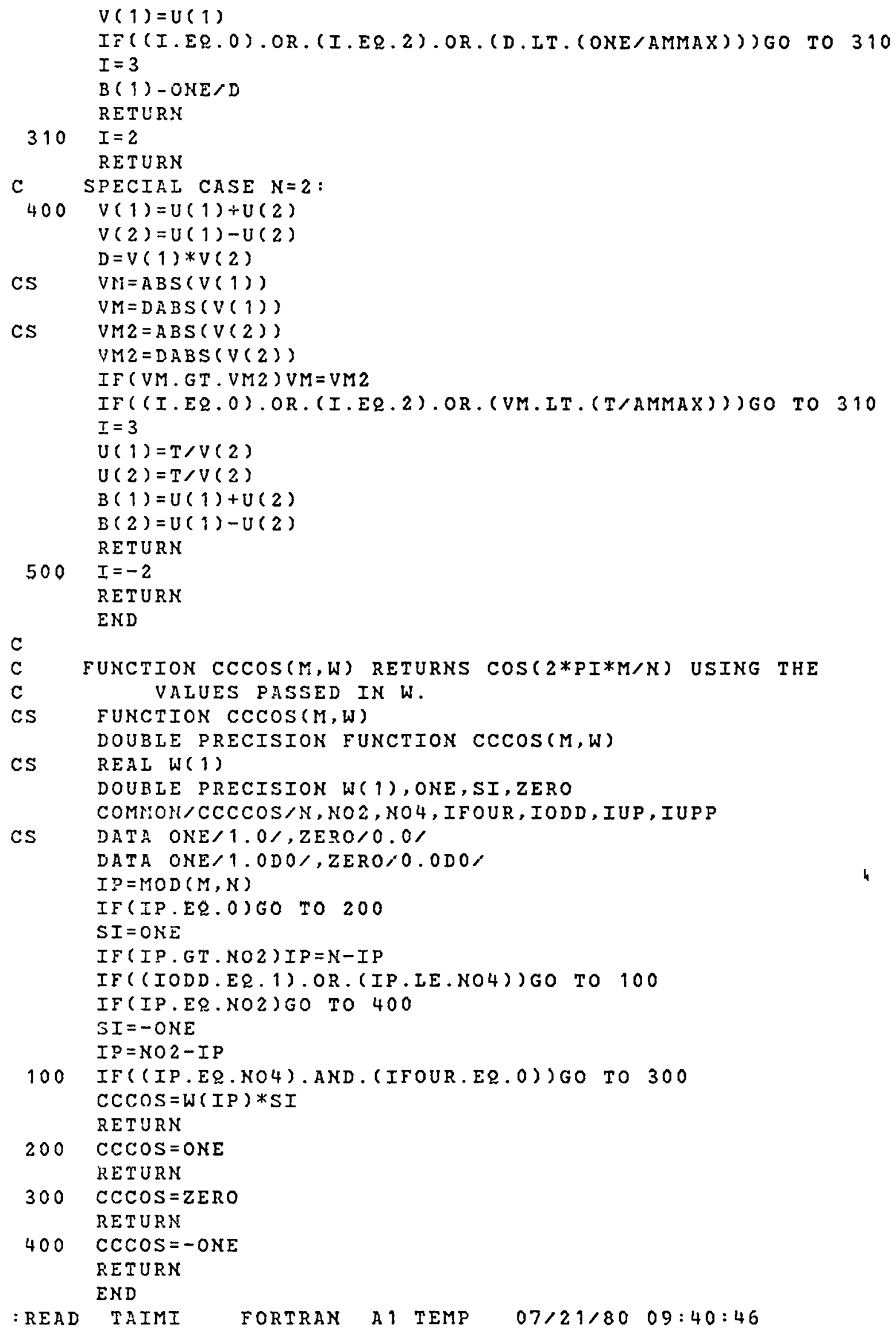


C PROGRAM TAIMI K.H.CARPENTER 14JUL 80

C PROVIDES A TEST DRIVER FOR ROUTINES MIJE 1 AND AIOC. DOUBLE PRECISION A(13), B( 13$), V(13)$, W( 5$), D E T$ COMMON/CMIJE1/BM( 13 ), AM( 13$), V 1$

COMMOM/CNPER/RR, XR, BZ DIMENSION AIO ( 24$), E F(24)$

KAMEIIST/TAIOUT/AI, RT, DF, BO, GHZ, EF, AIO, BM, AM, V 1, RR, XR, BZ,IERR

10 WRITE $(5,20)$

20 FORMAT(' TAIMI: ENTER AI,RT,DF,BO,GHZ,IOUT: (-1/ TO STOP)')

READ ( 5, *) AI, RT, DF, BO, GHZ, IOUT

IF(AL.LT.O.)STOP

WRITE $(5,30)$

30 FORMAT' ' ENTER EF ARRAY')

$\operatorname{READ}(5, *) \mathrm{EF}$

CAII MIJE1 ( $A L, R T, D F, B O, G H Z, I E R R$ )

IF IIERR.NE.O)GO TO 40

$C R I I$ AIOC (AIO,EF)

40 WRITE(IOUT, TAIOUT)

GO TO 10

$E N D$

$\begin{array}{lllll}\text { :READ TDM FORTRAN A } 1 \text { TEMP } & 07 / 21 / 80 & 09: 40: 46\end{array}$

C PROGRAM TDY TESTS FUNCTION DM

C TO USE: INPUT DATA TO PROMPT, ENTER - 1 / TO STOP.

NAMELIST/TDMOUT/DMO, IERR, DEG, RI, RO, CO, AL, DF, RB, ZO, AMR

10 WRITE $(5,20)$

20 FORMAT( $/$ ENTER DEG, AL,DF,RI,RO,RB,ZO,AMR,IOUT: (-1/ TO STOP)')

$R E A D(5, \pitchfork) D E G, A I, D F, R I, R O, R B, Z O, A M R$

IF (DEG.EQ. -1.0$) S T O P$

$D M O=D M(D E G, R I, R O, C O, A L, D F, R B, Z O, A M R, I E R R)$

WRITE (IOUT, TDMOUT)

GO TO 10

END

- READ TSTSYM FORTRAN A1 TEMP 07/21/80 09:40:47

C PROERAM TSTSYM

C THIS IS A TEST MAIN PROGRAM TO CALL SYMCIR

C DOUBIE PRECISION VERSION ONLY GIVEN HERE.

DOUBLE PRECISION U(10), $V(10), B(10), W(10), D, C C C O S$

10 WRITE $(6,20)$

¿O FORMAT(' ENTER $N, I, U(K), K=1, M-I 2, G 10.5$ ')

READ $(5,30) \mathrm{N}, \mathrm{I}$

30 FORMAT(IZ)

$\mathrm{J}=\mathrm{N} / 2+1$

$\operatorname{READ}(5,35)(U(K), K=1, J)$

35 FORMAT(G10.5)

CAIL SYMCIR (U, V,B,W,D, $N, I)$

WRITE(S, 40)U, V,B,W,D, N,I

40 FORMAT( $8(5 \mathrm{D} 13.5 /), \mathrm{D} 13.5, \mathrm{I} 5, \mathrm{I} 5)$

DO $60 \mathrm{~K}=1, \mathrm{~N}$

$D=\operatorname{Cccos}(K, W)$

WRITE $(6,50) D$

50 FORMAT (D15.5)

60 CONTINUE

- IF(1. $(1.0)$ GO TO 10

STOP

EYID 


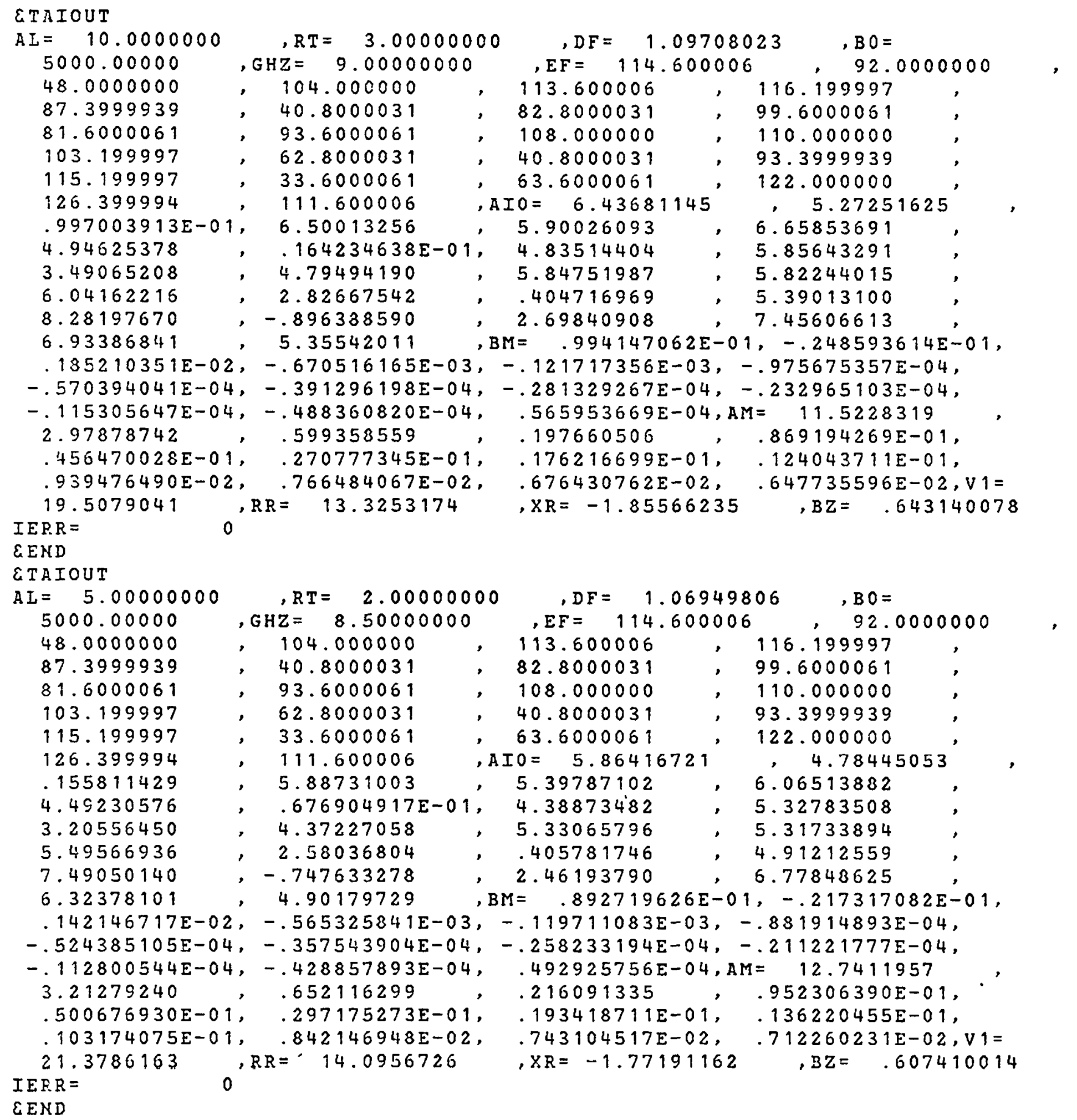

Output from runs of TAIMI as main program, using actual $W_{\perp}$ data for input as "EP". 


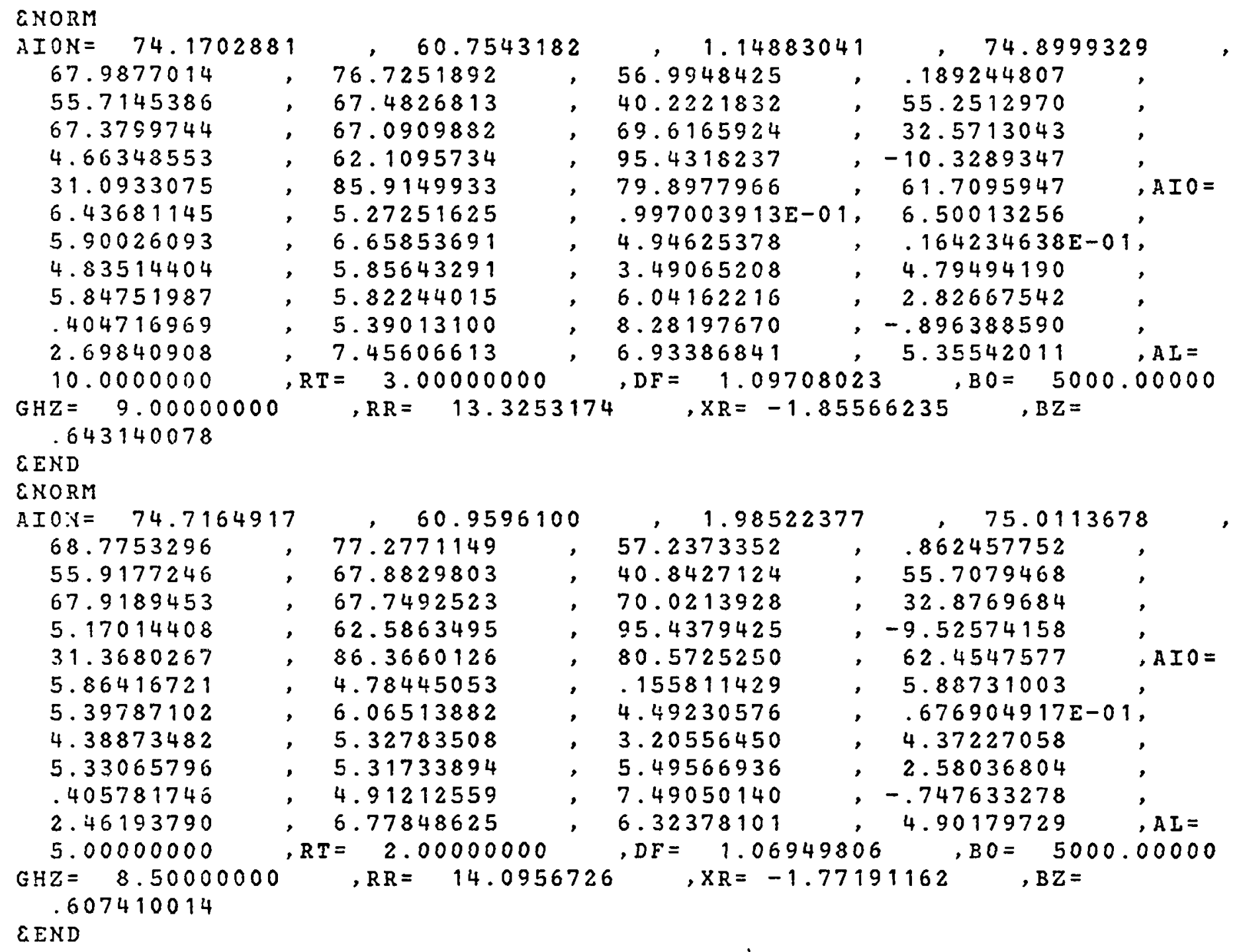

Output from run of EBTOFT using output from TAIMI on previous page as innut. 
The following four pages list outputs from a run of TAIMI as the main program made to test effect of different ring parameters on compensation for cross talk. 
ETAIOUT

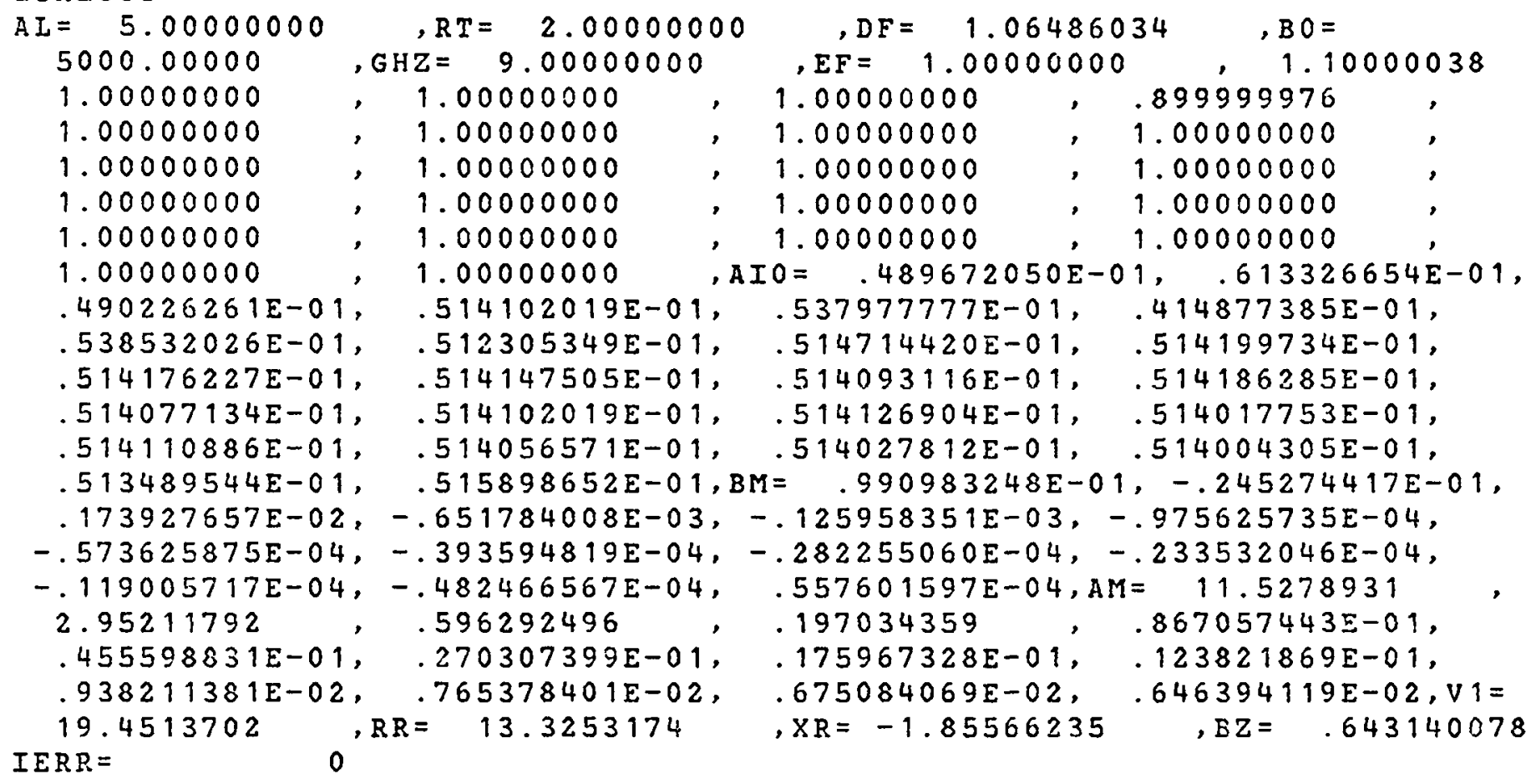

EEND

ETAIOUT

$A L=10.0000000$

5000.00000

1.00000000

1.00000000

1.00000000

1.00000000

1.00000000

1.00000000

$.489381552 E-01$,

$.538667664 \mathrm{E}-01$,

$.513809100 \mathrm{E}-01$,

$.513703778 \mathrm{E}-01$,

$.513744541 \mathrm{E}-01$,

$.513095930 E-01$,

$.188937155 \mathrm{E}-02$,

$-.570778648 \mathrm{E}-04$,

-.113690639E-04,

2. 97735882

$.455484614 E-01$,

$.937622041 E-02$,

19.4652710

IER R =

,$R T=1.00000000$ , $\mathrm{GHZ}=9.00000000$

1.00000000

1.00000000

1.00000000

1.00000000

1.00000000

1.00000000

$.513734594 E-01$,

$.511788167 \mathrm{E}-01$,

$.513780303 E-01$,

$.513734594 \mathrm{E}-01$,

$.513688885 E-01$.
,
,
,
,

, $\mathrm{DF}=$

1.03247261

, $\mathrm{BO}=$

$, E F=1.00000000,1.10000038$

$1.00000000, .899999976$

$1.00000000,1.00000000$

$1.00000000,1.00000000$

$1.00000000,1.00000000$

1.00000000

1.00000000

AIO $=.488801561 \mathrm{E}-01, .613665842 \mathrm{E}-01$,

$.538087636 \mathrm{E}-01, \quad .413803384 \mathrm{E}-01$,

$.514373221 \mathrm{E}-01, .513827354 \mathrm{E}-01$,

$.513724610 \mathrm{E}-01, .513819903 \mathrm{E}-01$,

$.513760410 \mathrm{E}-01, .513649844 \mathrm{E}-01$,

$.513660125 E-01, .513641834 E-01$,

$.515681058 \mathrm{E}-01, B M=.998100638 \mathrm{E}-01,-.250309035 \mathrm{E}-01$,

$-.677948818 \mathrm{E}-03$,

$-.392881921 \mathrm{E}-04$,

$-.492614199 \mathrm{E}-04$,

.598560870

$.270160288 \mathrm{E}-01$. $.764355063 \mathrm{E}-02$,

$-.120861834 E-03,-.979338074 E-04$,

$-.280924869 E-04,-.234509789 E-04$,

$.570950069 \mathrm{E}-04, \mathrm{AM}=11.4863062$

$.197297215, .867392421 E-01$,

$.175858475 E-01, .123718567 \mathrm{E}-01$, $.675517693 \mathrm{E}-02, \quad .646110252 \mathrm{E}-02, \mathrm{~V} 1=$

$, X R=-1,85560235$

0

$R R=13.3253174$

,$B Z=.643140078$

EEND

ETAIOUT

$A L=10.0000000 \quad, R T=4.00000000$ $5000.00000 \quad, G H Z=9.00000000$

1.00000000

1.00000000

1.00000000

1.00000000
1.00000000
1.00000000
1.00000000
1.00000000

,$E F=\quad \begin{aligned} & 1.12904544 \\ & , E F=1.00000000\end{aligned}$

1.00000000

1.00000000

1.00000000

1.00000000
, $\mathrm{BO}=$

1. 10000038
.899999976
1.00000000
1.00000000
1.00000000 


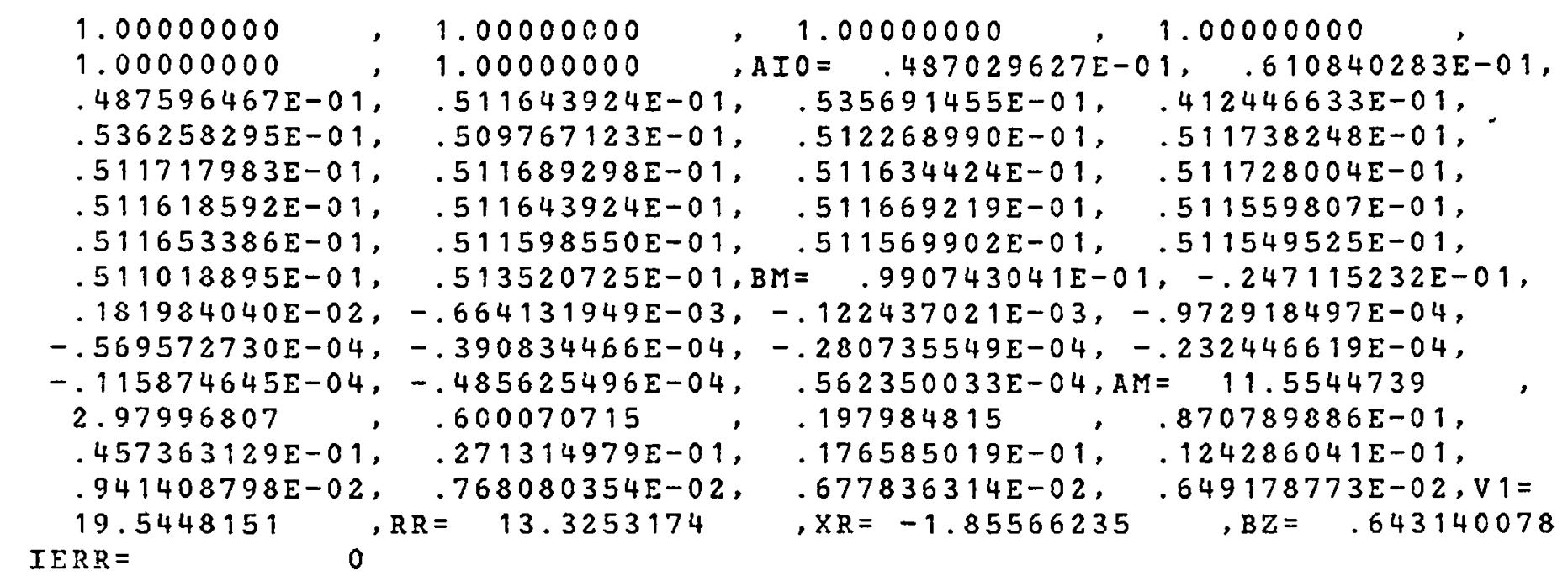
$\varepsilon E N D$

:READ TAI DATAO AI EBT1 07/16/80 12:15:41

ETAIOUT

$A L=10.0000000$

5000.00000

1.00000000

1.00000000

1.00000000

1.00000000

1.00000000

1.00000000

$.489022546 \mathrm{E}-01$, $.538182296 \mathrm{E}-01$, $.513383328 E-01$, $.513288192 \mathrm{E}-01$, $.513323620 \mathrm{E}-01$, $.512678027 E-01$, $.187515398 \mathrm{E}-02$, $-.570504761 \mathrm{E}-04$, $-.115145758 \mathrm{E}-04$,

2. 97769383

$.455883741 \mathrm{E}-01$, $.937997550 E-02$, 19.4812469

IERR =

, $\mathrm{RT}=2.00000000$ , $\mathrm{GHZ}=9.00000000$ 1.00000000

1.00000000

1.00000000

1.00000000

1.00000000

1.00000000

$.513313822 E-01$. $.511381589 E-01$, $.513359345 \mathrm{E}-01$, $.513313822 \mathrm{E}-01$, $.513268262 \mathrm{E}-01$. $.515246019 \mathrm{E}-01, \mathrm{BM}=$

$-.675019575 \mathrm{E}-03$,

$-.392017682 \mathrm{E}-04$,

-.489770027 E-04, .598870754 $.270383172 E-01$, $.765311718 \mathrm{E}-02$, $R R=13.3253174$

\footnotetext{
,$$
\text { , }
$$$$
\text { , }
$$$$
1.00000000
$$$$
1.00000000
$$$$
, D F=1.06486034
$$$$
\text { , } \mathrm{B} \mathrm{O}=
$$
, $E F=1.00000000$ 1.00000000 1.00000000 1.00000000 1.00000000 , AIO $=.488445349 \mathrm{E}-01, .613095909 \mathrm{E}-01$, $.537605137 \mathrm{E}-01, .413531289 \mathrm{E}-01$, $.513949655 \mathrm{E}-01, .513406843 \mathrm{E}-01$, $.513304099 \mathrm{E}-01, .513398610 \mathrm{E}-01$, $.513339490 E-01, .513228439 E-01$, $.513239279 \mathrm{E}-01, .513220802 \mathrm{E}-01$. $B M=.996612906 E-01,-.249662362 E-01$, $-.121180856 \mathrm{E}-03,-.978387106 \mathrm{E}-04$, $-.281514222 \mathrm{E}-04,-.233308092 \mathrm{E}-04$, $.568088872 \mathrm{E}-04, \mathrm{AM}=11.5000076$ $.197425544, .868030787 \mathrm{E}-01$, $.175970830 \mathrm{E}-01, .123852938 \mathrm{E}-01$, $.674944371 \mathrm{E}-02, \quad .647038594 \mathrm{E}-02, \mathrm{~V} 1=$ $, \mathrm{XR}=-1.85566235 \quad, \mathrm{BZ}=.643140078$

$\varepsilon E Y D$

\&TAIOUT

P. $=10.0000000$

5000.00000

1.00000000

1.00000000

1.00000000

1.00000000

1.00000000

1.00000000 0

$.703197718 \mathrm{E}-01$, $.770562887 \mathrm{E}-01$, $.736609101 \mathrm{E}-01$, $.736469030 E-01$.
, $\mathrm{RT}=2.00000000$ ,$G H Z=9.00000000$

1. 00000000

1.00000000

1.00000000

1.00000000

1.00000000

1.00000000

$.736503601 \mathrm{E}-01$.

$.734175444 \mathrm{E}-01$,

$.736563570 E-01$, $.736503601 \mathrm{E}-01$,

\section{,}

,

,

,

, 1.00000000

,$D F=1.00000000$

, $\mathrm{BO}=$ $, E F=1.00000000,1.10000038$ $1.00000000 \quad .899999976$ 1.00000000 1.00000000 1.00000000 1.00000000 1.00000000 1.00000000 1.00000000 $A I 0=.702444315 \mathrm{E}-01, .877200961 \mathrm{E}-01$, $.769810081 \mathrm{E}-01, .595809072 \mathrm{E}-01$, $.737339258 \mathrm{E}-01, .736650825 \mathrm{E}-01$, $.736492276 \mathrm{E}-01, .736621022 \mathrm{E}-01$, $.736537576 \mathrm{E}-01, .736385534 \mathrm{E}-01$. 


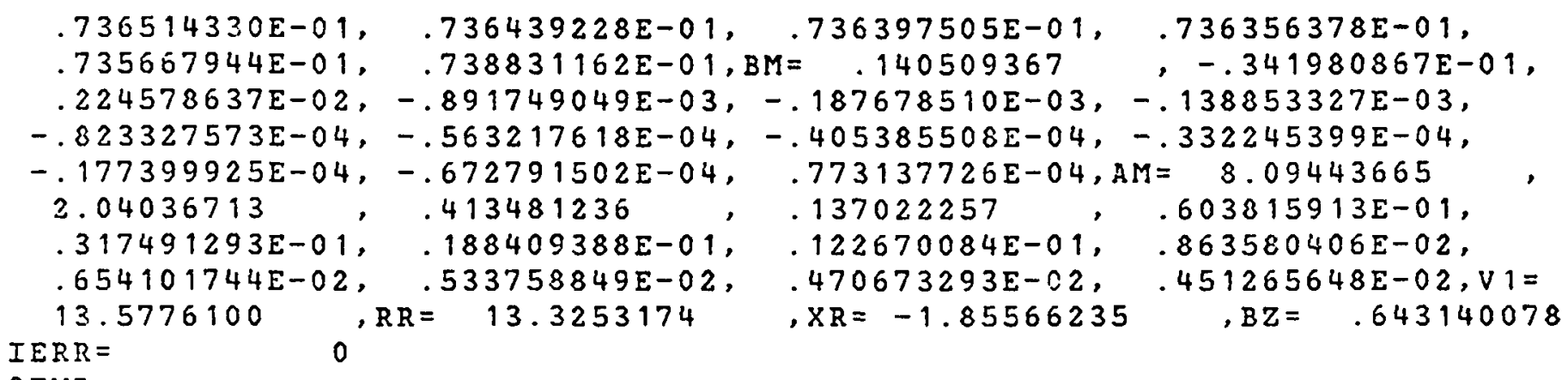

EEND

ETAIOUT

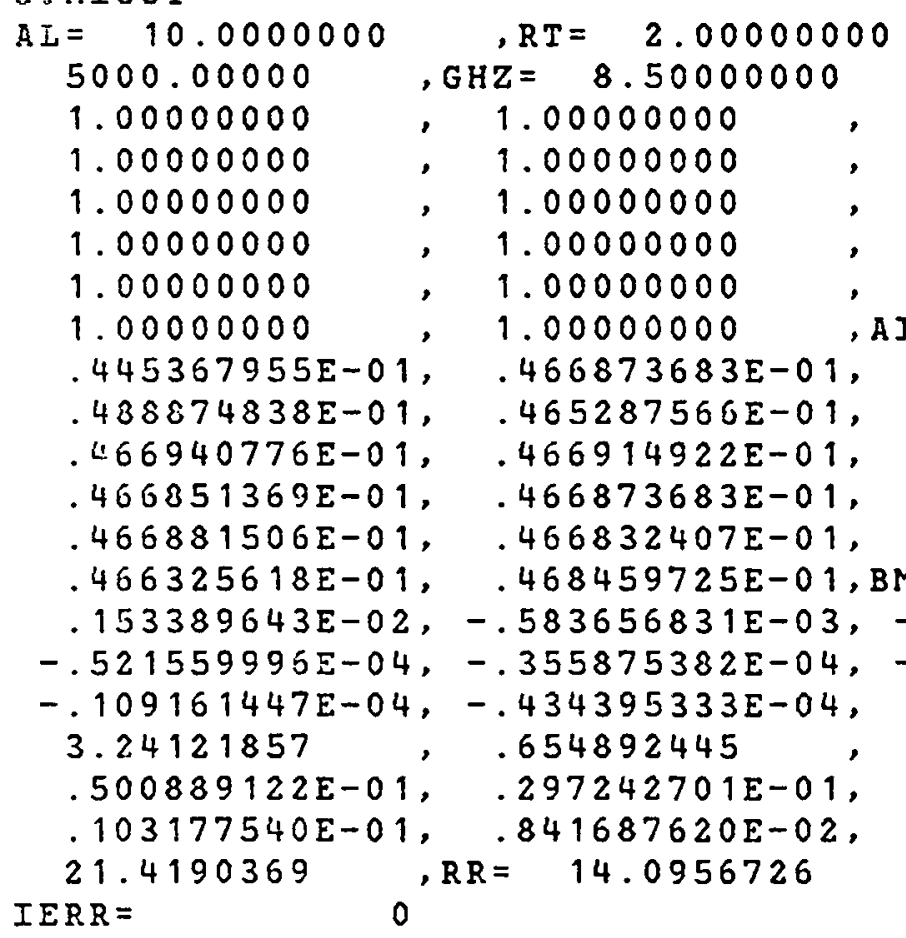

,$D F=\quad \begin{aligned} & 1.06949806 \\ & E F=1.00000000\end{aligned}$ ,$E F=1.00000000$ 1.00000000 1.00000000 1.00000000 1.00000000 1.00000000 AIO $=.444872528 \mathrm{E}-01, \quad .556690805 \mathrm{E}-01$. $.488379486 \mathrm{E}-01, .377056561 \mathrm{E}-01$, $.467421748 \mathrm{E}-01, \quad .466963686 \mathrm{E}-01$, $.466865823 E-01, \quad .466949418 E-01$, $.466895960 \mathrm{E}-01, \quad .466797911 \mathrm{E}-01$, $.466806516 E-01, .466783643 E-01$, $M=.897013545 \mathrm{E}-01,-.220893584 \mathrm{E}-01$, $-.115707313 E-03 ;-.882687164 E-04$, $-.256969215 E-04,-.211314182 E-04$, $.500975148 \mathrm{E}-04, A M=12.7181473$ $.216522872, .953212380 E-01$, $.193403512 \mathrm{E}-01, .136210918 \mathrm{E}-01$, $.742683187 \mathrm{E}-02, .712139904 \mathrm{E}-02, \mathrm{~V} 1=$ $, \mathrm{XR}=-1.77191162 \quad, \mathrm{BZ}=.607410014$

$\varepsilon E N D$

ETAIOUT

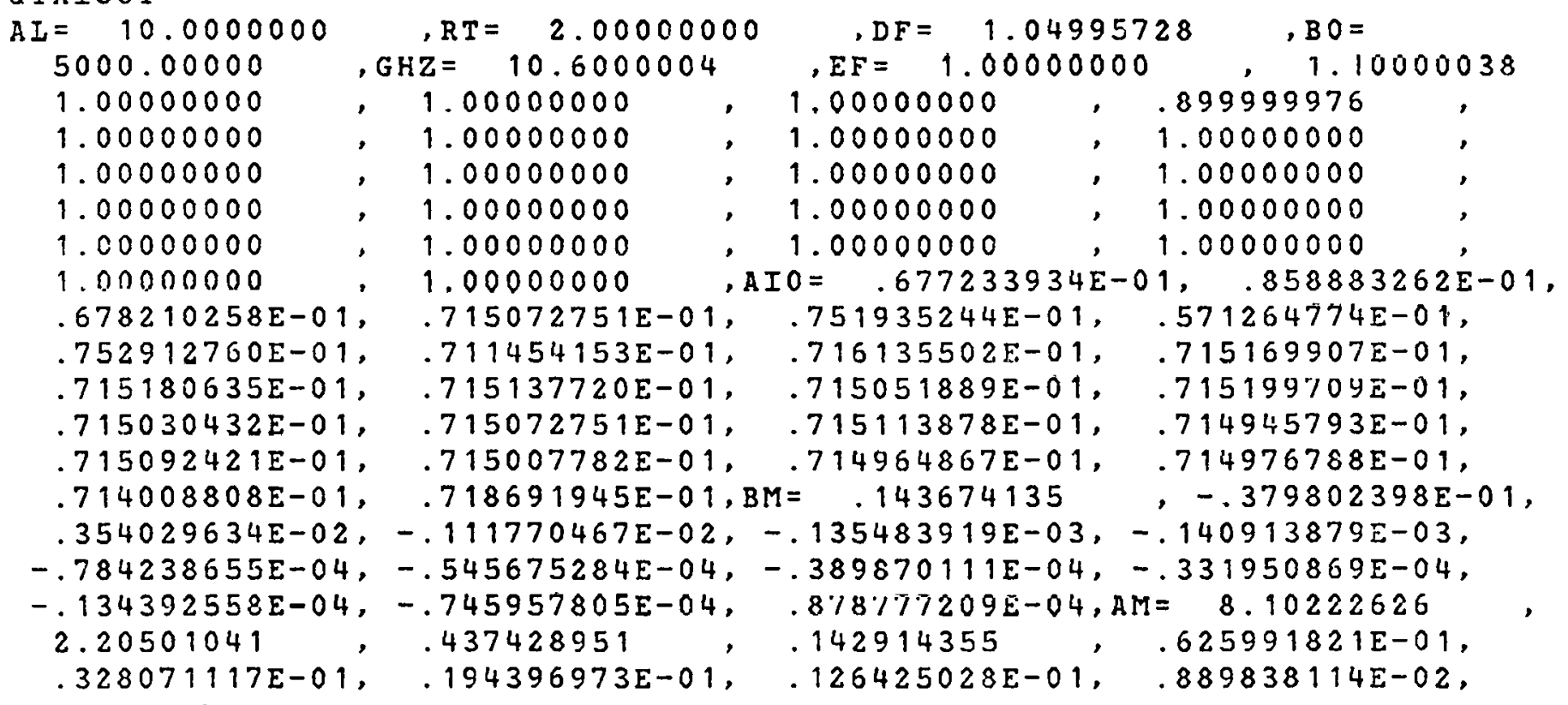




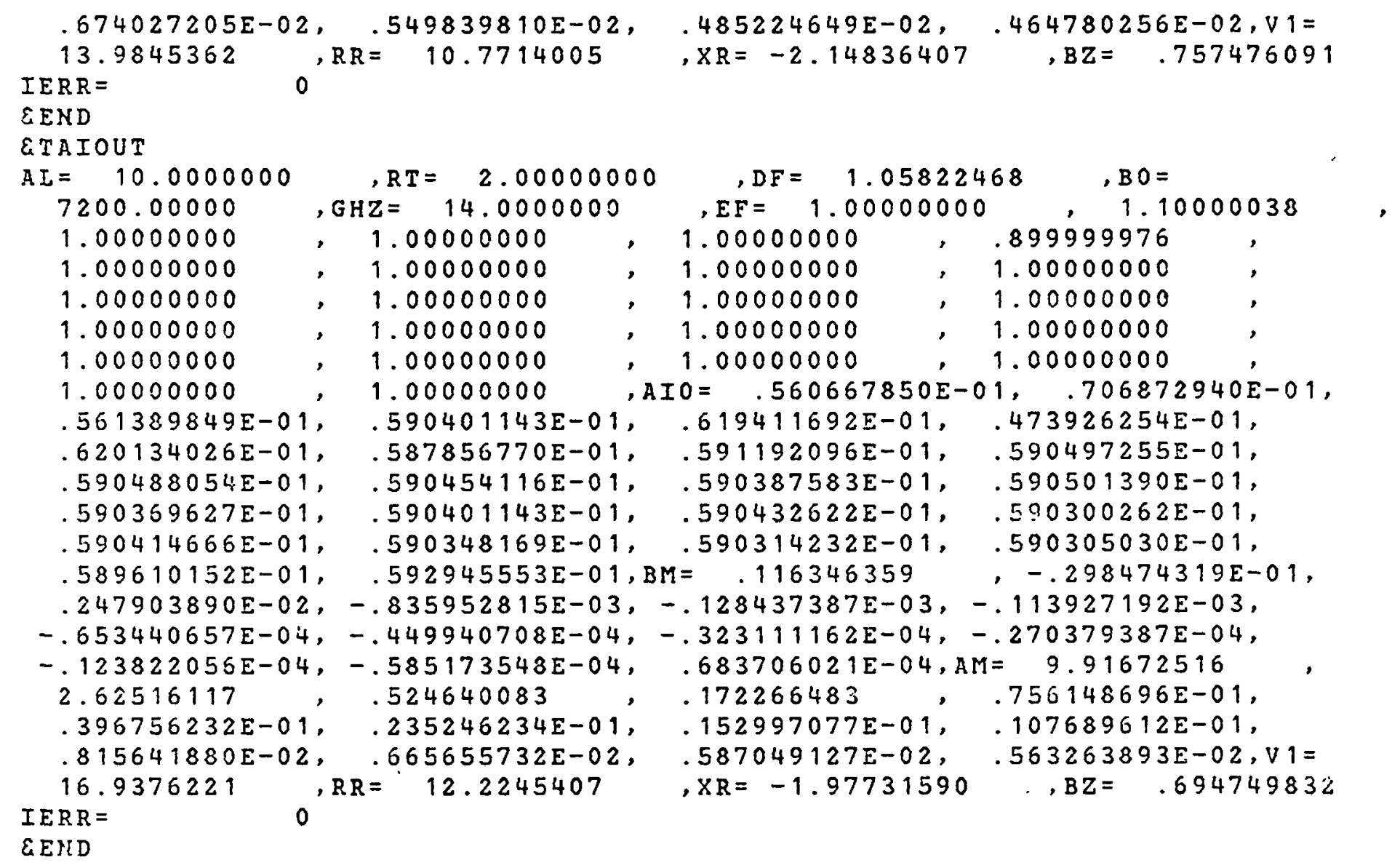


The following two pages list the output from program BMNORM when the output from TAIMI on the preceding four pages is the input. 


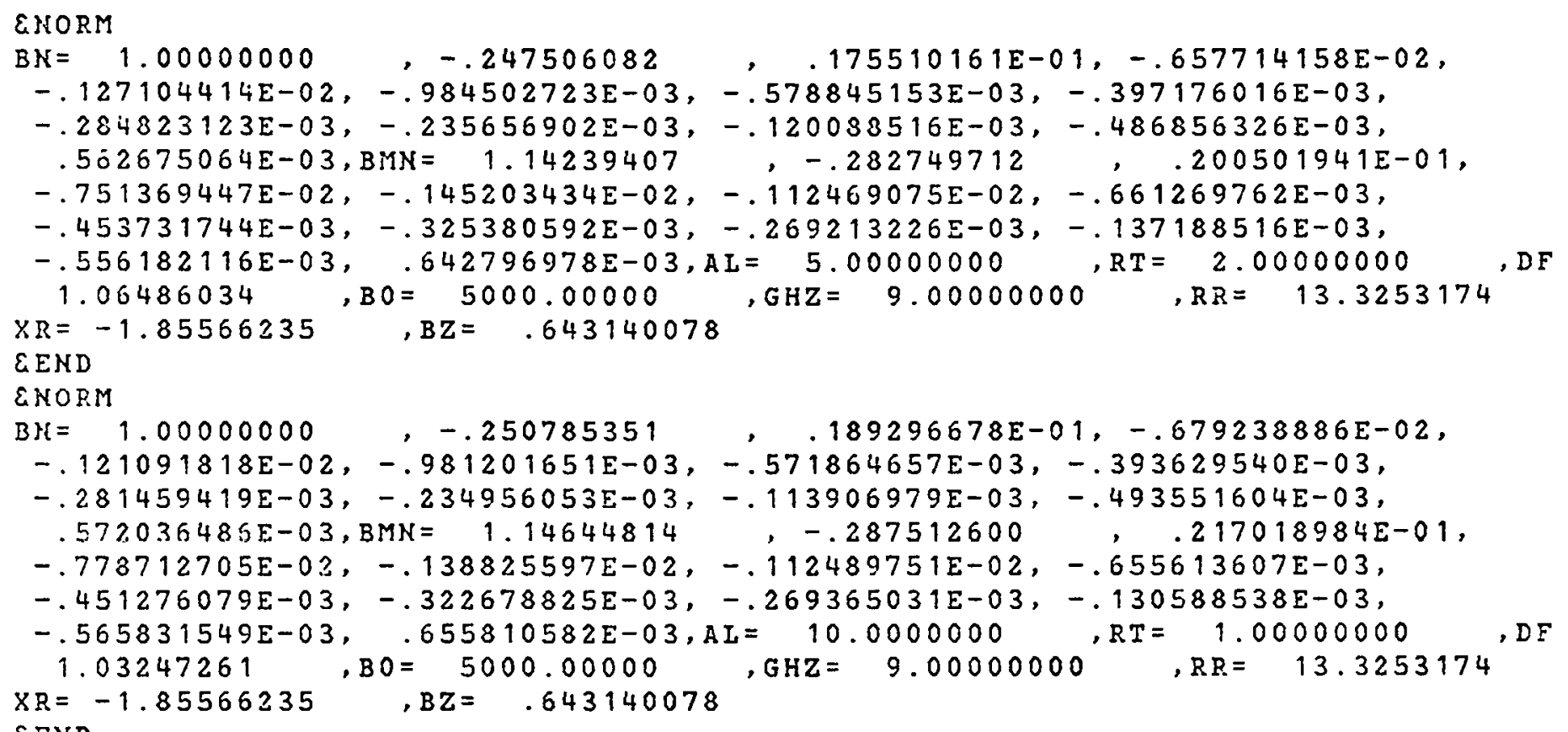

EEND

EKORM

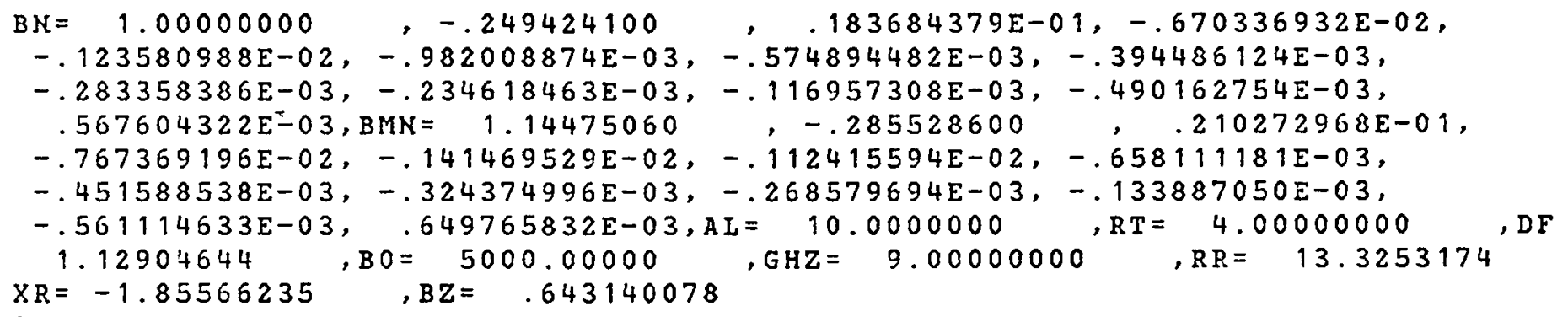

$\varepsilon E N D$

ENOIM

$B N=1.00000000,-.250510812, .188152678 \mathrm{E}-01,-.677313656 \mathrm{E}-02$,

$-.121592684 E-02,-.981712248 E-03,-.572443474 E-03,-.393349910 E-03$,

$-.282470835 \mathrm{E}-03,-.234101011 \mathrm{E}-03,-.115537085 \mathrm{E}-03,-.491434475 \mathrm{E}-03$, $.570019474 \mathrm{E}-03, \mathrm{BMN}=1.14610481, \quad-.287111878, .215642825 \mathrm{E}-01$,

$-.776273012 \mathrm{E}-02,-.139358058 \mathrm{E}-02,-.112514570 \mathrm{E}-02,-.656080898 \mathrm{E}-03$,

$-.450820429 E-03,-.323741464 E-03,-.268304255 E-03,-.132417699 E-03$,

$-.563235721 \mathrm{E}-03, .653302530 \mathrm{E}-03, A \mathrm{~L}=10.0000000 \quad, \mathrm{RT}=2.00000000, \mathrm{DF}$ $1.06486034 \quad, \mathrm{~B} 0=5000.00000 \quad, \mathrm{GHZ}=9.00000000 \quad, \mathrm{RR}=13.3253174$ $X R=-1.85566235 \quad, B Z=.643140078$

$\varepsilon E K D$

ENOR.M

$-.133570097 \mathrm{E}-02,-.988213811 \mathrm{E}-03,-.585959050 \mathrm{E}-03,-.400839839 \mathrm{E}-03$,

$-.288511161 \mathrm{E}-03,-.236457825 \mathrm{E}-03,-.126254861 \mathrm{E}-03,-.478823204 \mathrm{E}-03$, $.550239114 \mathrm{E}-03, \mathrm{BMN}=1.13734341,-.276814222, .181783736 \mathrm{E}-01$,

$-.721820444 E-02,-.151915173 E-02,-.112393941 E-02,-.666437205 E-03$,

$-.455892878 \mathrm{E}-03,-.328136608 \mathrm{E}-03,-.268933829 \mathrm{E}-03,-.143595244 \mathrm{E}-03$,

$-.544586685 \mathrm{E}-03, .625811284 \mathrm{E}-03, \mathrm{AL}=10.0000000, \mathrm{RT}=2.00000000$ $1.00000000, \mathrm{BO}=5000.00000 \quad, \mathrm{GHZ}=9.00000000 \quad, \mathrm{RR}=13.3253174$ $\mathrm{XR}=-1.85566235 \quad, \mathrm{BZ}=.643140078$ $\varepsilon E N D$ 


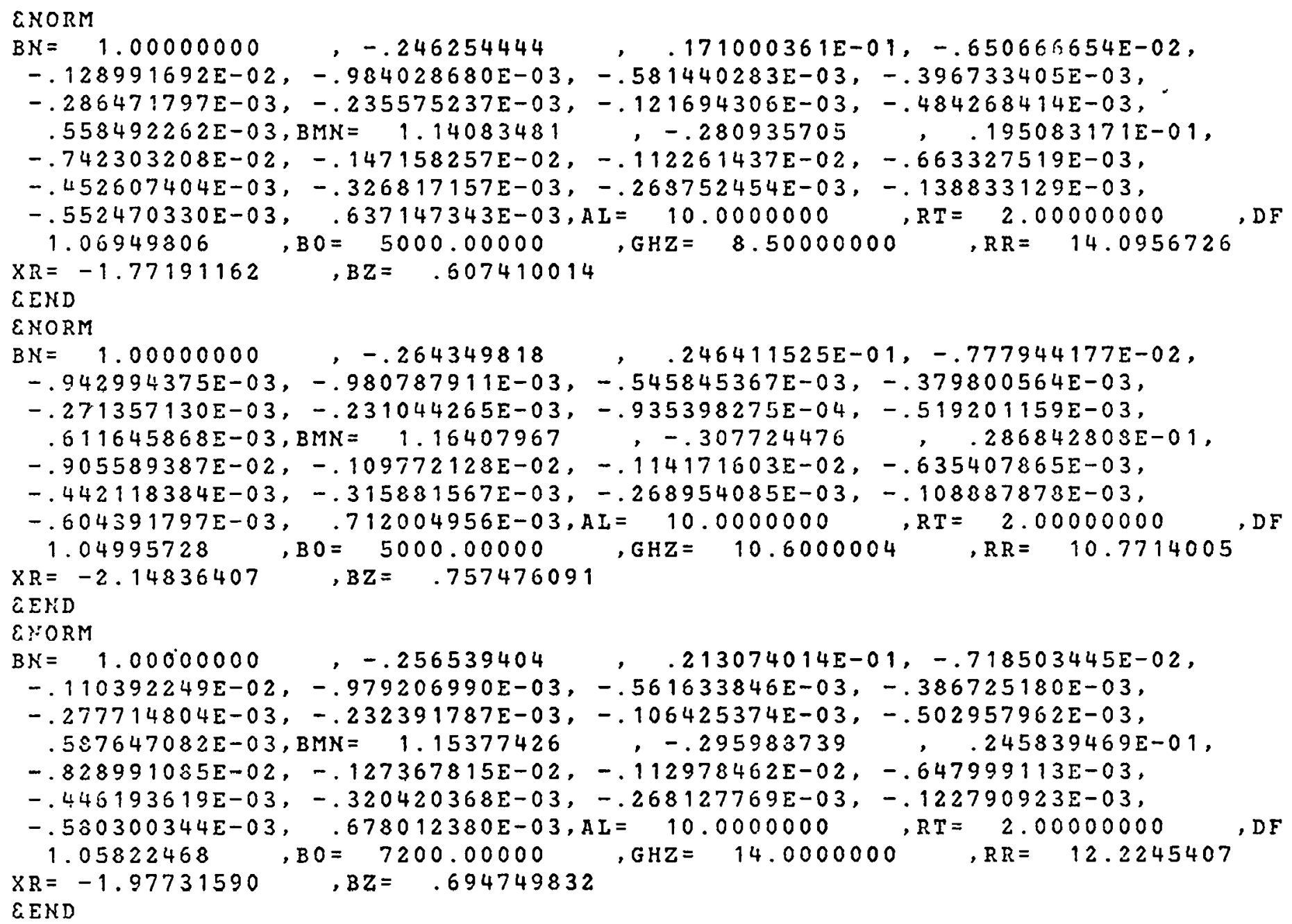




\section{EBTOFF program}

The EBTOFF program runs on the Fusion Energy Division PDP-10 computer at Oak Ridge National Laboratory. It is an interactive program which needs to be run from a graphics terminal. The program prompts for input. The modification made during the work described in this report was to include correction for intercavity cross talk on $W_{\perp}$ signals as an option. A sample output plot for $W_{\perp}$ with this option in effect is given on the next page. On the following pages the FORTRAN listing of EBTOFF, as modified, is given. 
W PER. [IN RDC COUNTS] VS. CAVITY NO. [ $1=N 1,24=W 6]$

[EBTOFF V5 J WTS FROM A36AG6.WTS TURN DOWN. EBT I, 50/0, N3, 55, - ?

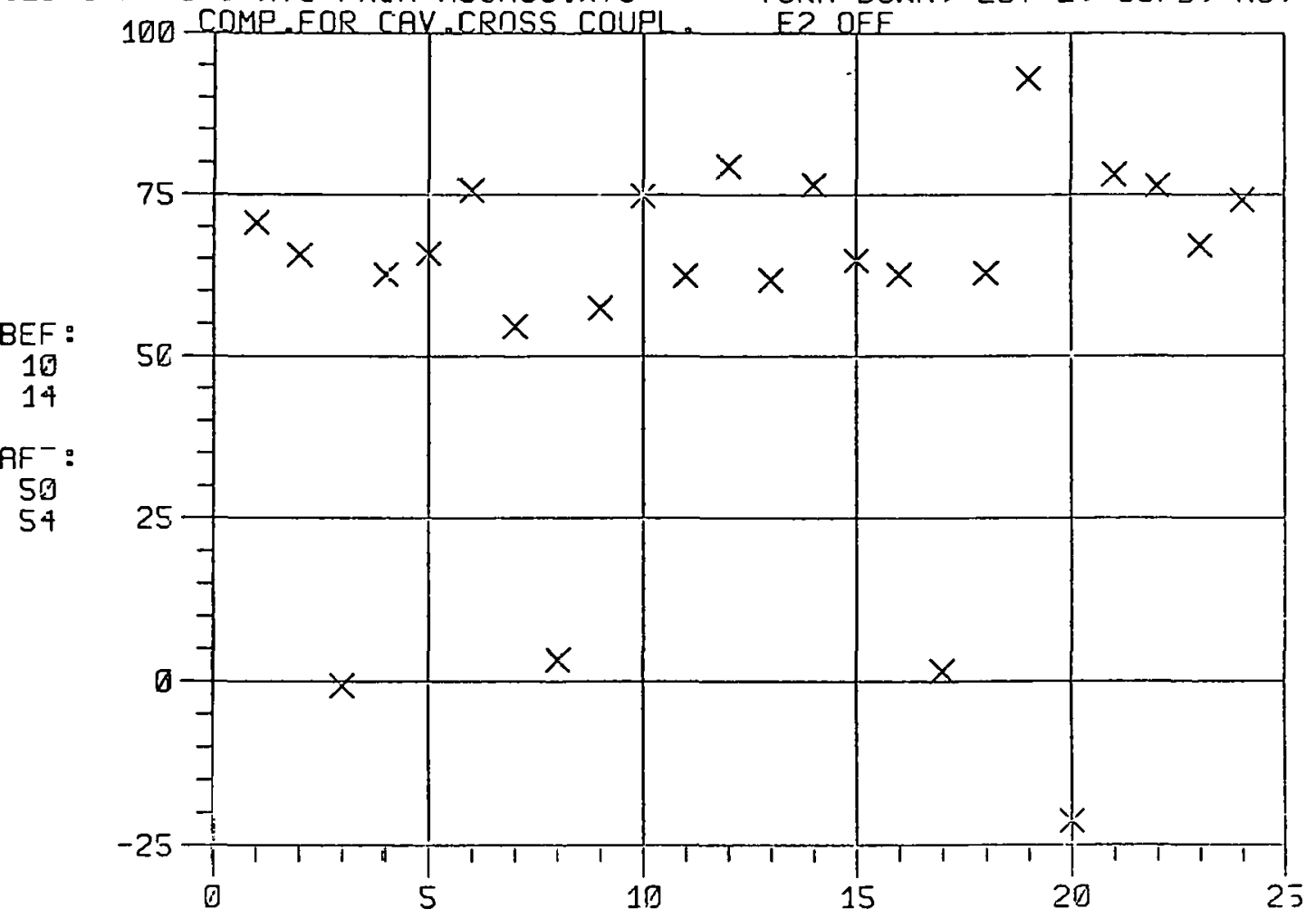

A33EAF, EBB EBTOAT V5I $3 / 11 / 80-14: 27: 56$

$S-D P R O=$

1 FGG 
PROGRAM EBTOFF !K.H.CARPENTER $15 S E P P O$

$c$
$C$
$C$
$c$
$c$
$c$
$c$
$c$
$C$
$c$
$c$
$c$
$c$
$c$
$c$
$c$
$c$

28JULBO:KHC: VERSION 5 : Added compensation for cavity cross coupling for WPER

1DRPRQO:KHC : Write of L.PER to EBTOFF. DAT cidded.

10MAR30:KHC: VERSION 4 : Pidded weights to W-Per curve. for correction of unequal gains.

11APRT9:KHC: VEPSION 3 : Added BEF \& AFT values to plot, and added looping on curve choice, and co:rected DO 1 imits on BEF \& AFT loops.

1EFER79:KHC: VERSION 2 : Ficiled choice of curves $1,2,3$ ind plot at BEF time only if greciter thun PirT

Outputs plot or print of lij-Per. in $A D C$ units

as determined from diamaginetic loops on turn-down

of microlidue polver.

Subroutincs called are in EED $10 B$ or TEK AG2

LCFD with EDD1OB.REL and ADETEK.REL

FARPMETER MAYX $=256, \mathrm{M}: I D=24$, M $M Y Y P=257$

LOGICAL LDIFF

DOUELE PRECISION DUT

COMMQT /CEEB IO/IN, FILNA (2), DATIM(4), VERSNO, ISLOPR, IFASPR, IVRD.

1 IFAD, IFPR, ISAMPF, IDPPS, NOWDC, IBUF (342)

COMMON/CADEOU/IPLTU IFOR PLOT UNIT NO. USING TEKADE

DIMENSION IDAR (NID), IFPDAT (TIAK, MID), PLOTND (MAXP), XAK(4)

DIMIENSION WTS(24), ITIU(4)

DATA WTS $/ 24: 41.0 /$, IWT/O/

D.97A IUIIIT/50/,XAX/-1.,24.,0.,1./

DATA IVERS $/{ }^{\circ}$ (15) $)$

C OPEN UYIT 17 FOR ASCII OUTFUT OF RESULTS:

OPEN (UNIT $=17$, DEVICE $=$ 'DSK',FILE $=$ 'EBTOFF, DRT', ACCESS $={ }^{\prime}$ APPEND')

1

INITIALIZE FOR PLOTS AND TYPE HEADER OUT

IOLDCR $=0$

IPLTU $=-1$

CALL IHITT(1)

CALL SETRUF ( 1 )

CALL ANTIODE

CALL SLP(1)

5 TYPE 10

10 FORMATC" EBTOFF VS - LANT TO ENTER FILE SPEC. OR TIME?:'\$) ACCEPT 20.MODEIN

20 FORMAT (A1)

IF (TIODEIN.EQ.'T') GO TO 50

TYPE 30

30

FORMAT(" EBB FORMAT FILE SPEC.:"\$)

FICCEPT 40, IDAR

40 FORMAT (24.A5)

OPEN (UN IT I IUNIT D DIALOG = IDAR, ACCESS ='SEQ IN', MDDE =' IMAGE')

CALL UHIT(IUNIT)

GO TO 80

50 TYPE 60

GU FURMAT(" ENTER MD-DA-YR HR: MIISE (6G):'\$)

ACCEPT 70, MONTH, IDAY, IYEAR, IHR, IMIN, ISEC

70 FORMAT ( $6 G)$

CALL FECHD (IUNIT, MOIITH, IDAY, IYEAR, IHR, IMIN, ISEC)

C

INPUT FILE NOW OPENED - TYFE COMMENTS

80 CALL TYCOM

82 TYPE 85 


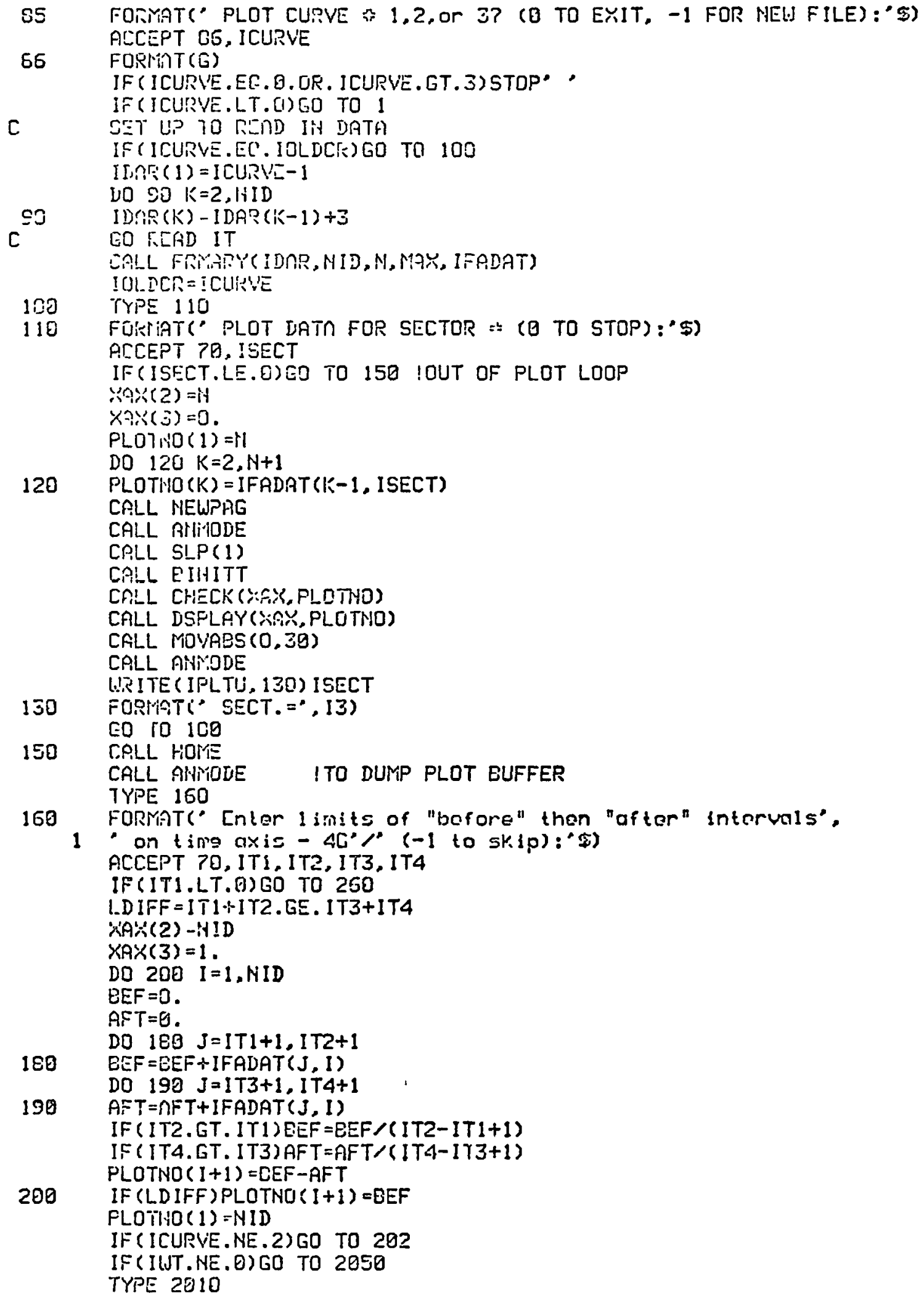




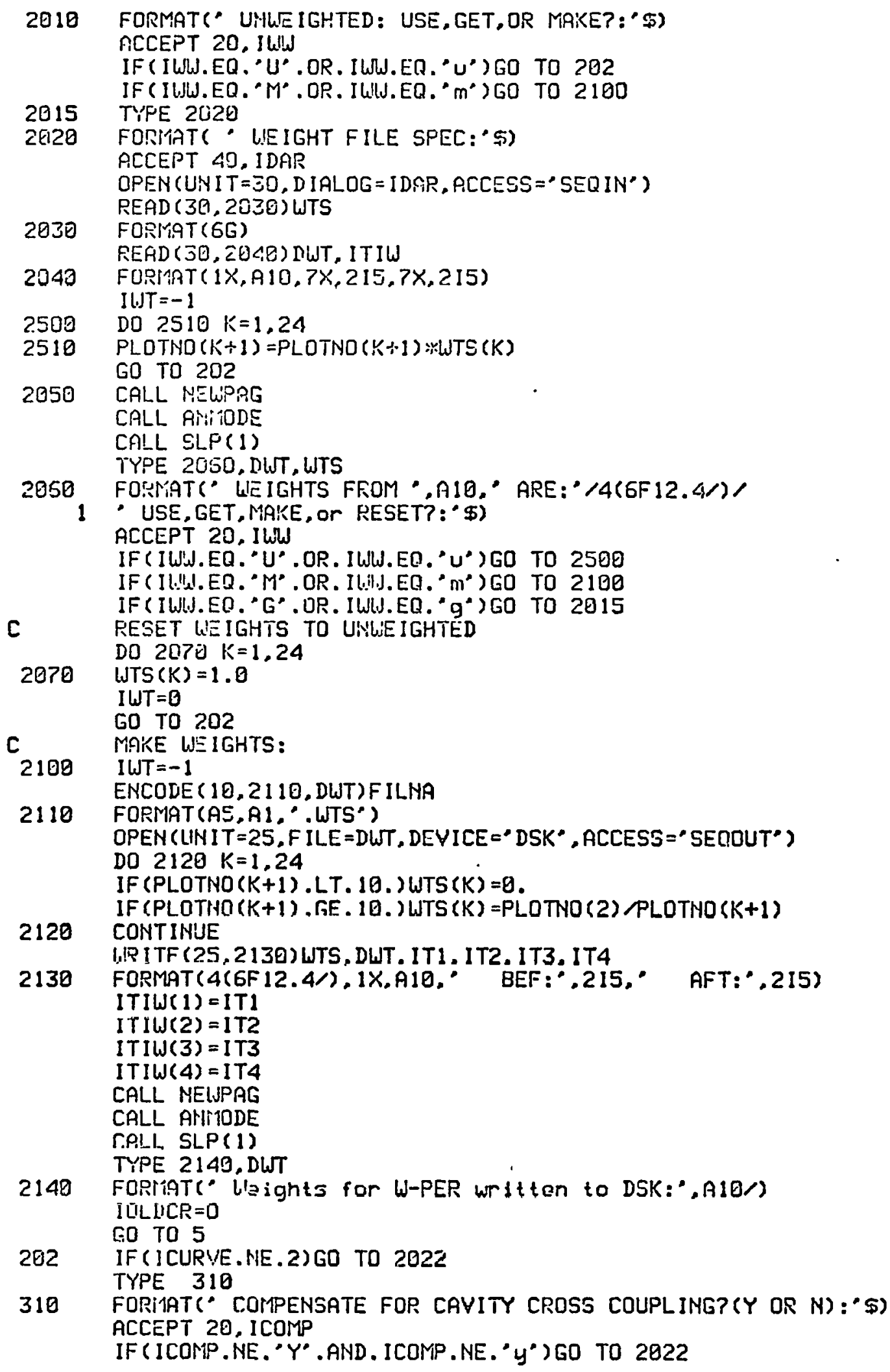


FORMATT(S' PRESSURE (IN ADC COUNTS) VS. CAVITY NO. (1-N1, 24=W5) -

1 - (EBTOFF', A5)

IPLTU $=-1$

CALL NELIPAG

CRLL RAYPIODE

CALL SLP(1)

TYPE 235

235 FORIAAT(' PRESSURE YS CAVITY OUTPUT TO LPT')

$$
\text { GO TO } 82
$$

240 WRITE (IPLTU, 250) IVERS

250 FORMGT ( $\Phi^{\circ}$ POLER (IN ADC CCINTS) VS. CAVITY NO. (1=N1, 24=L!5)

$1>^{\prime \prime}$ (E.BTOFF',AS)

IPLTU $=-1$

CALL NELLPFIG

CPLL ANHTDLE

CALL SLP(1)

TYFE 255

255 FGRYIAT (' POLER VS CAVITY DUTPUT TO LPT')

GO TO 82

260 IPLTU $=-1$

CALL HELWPAG

CALL PNII IDDE

CALL SLP(1)

GO TO 82

END

c
c
c.

SUSROLITIHE AIOCP (AIO,EF)

C K.H.CARFENTER 28JUL8O

Sans code as AIO Except that COMDN/CMIJE1/ removad

and BIM( (3) added to "DIMEISSION" statement, and values

placed in "DATA" statement for universal normal lzed correction. DIMENSION AIO(1), EF(1), BMI (13)

DATA BM/1.1A5,-0.2853,0.0229.

$1-0.6930 .-0.0011,-0.0811,-0.0007,-0.0095$.

$2-0.0003,-0.0002,-0.0001,-0.0006,-0.0007 /$

Data values chosen to correct to approximately $5 \%$ accurocy PLOTH output values to those that would be obtained if only flux from each cavity's own annulus linked it.

Values are valid to $5 \%$ for all reasonable EBT-I/S annuli. SUBROUTIHE AIOC (AIO,EF)

K.H.CARPENTER 11 JULBO.

APPLIES INVERSE MUTUAL INDUCTANCE MATRIX BM TO INPUT L.JPER SICNAL: VALUES EF TO GIVE UNFOLDED WPER VALUES RIO (MORMALIZED). MORMALIZATION OF LIPER FOR I'TH CAVITY IS:

WP $(I)=(A I G(I)-A I O(K)) * B V(I)-C P H I / N T U R N /$ HUO/TWOPI

WHERE BV(I) IS "AVERAGE" MAGNETIC FLUX DENSITY OVER ANYULLUS.

CPHI IS VALUE FLUK LINKING PICKUP COIL IS MULTIPLIED EY TO

OBTAIN EF(I), AND MTUFN IS TOTAL MO. OF TURNS IN SERIES

IN PICKUP COILS ON CAVITY I. AIOCK) IS RESIDUAL VALUE FOR

CAVITY WITH HO AHNULUS.

FOP DETAILS SEL KHC 9J!IL8O.

COITIJM/CMIJE1/BM(13), AMT(13),VI

DIIUENSION AIO(24), EF(24)

MIILTIPLIES IHPUT VECTOR EF BY MATRIX BM TO OETAIN OUTPUT

VECTOR AIO.

BM IS A SYMMTETRIC, CIRCULPNT MRTRIX OF DIMENSION 24. 


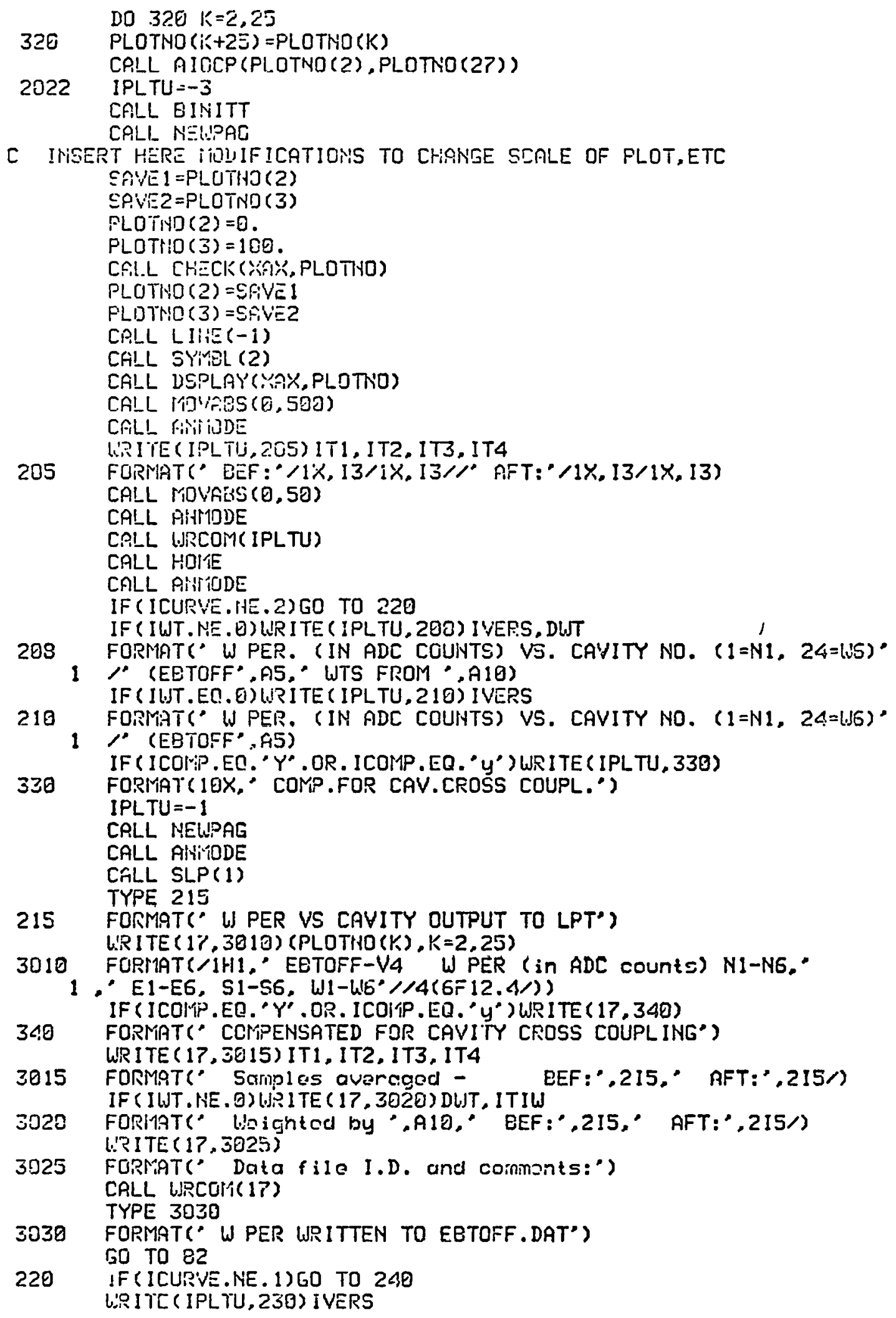




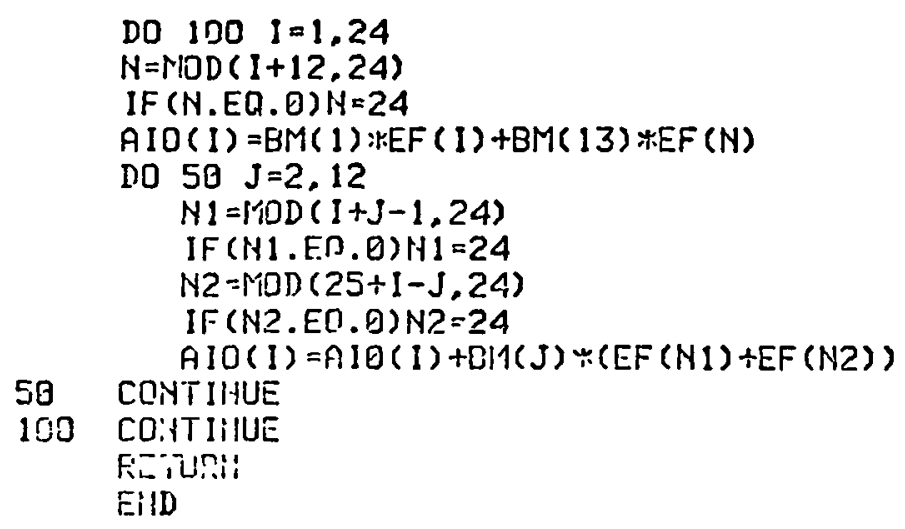




\section{FLDEQ program}

The FLDEO program was used to provide the simulation of the NBT Hall probe versus perpendicular energy data as well as to provide the simulated data for EBT diamagnetic field components as functions of ring parameters. The ma in program and all subroutines are contained in a single FORTRAN file. FLDEO is documented with comment lines in the listing. The program prompts for input. A sample terminal session showing the input dialog and the resultant output produced is given on the next page. The program listing then follows. 
.LOAII FLDEQINOMAP START

EXECUTION BEGIHS...

WHICH PARAMETER DO YOU WISH TO VARY ?: L=LENGIH, R=MEAN RAIIUS, I=THICKASESS: . $\mathrm{L}$

ENTER INITIAL VALUES OF THE PARAMETERS : TOTAL LENGTH: MEAN RAIIUS, THICKNESS, ANI CURT́'E $?$

$.1 \quad 13.331 .937$

ENTER THE UFPER LIMIT OF THE PARAKETER BEING VARIEI:

?

.20

HON MANY VALUES DO YOU WANT CALCULATED (UP TO 100)?

$?$

.20

ENIER FIELU POINT COORIINATES $X, R$ (IN CENTIMEIERS)

?

.1 .525$.

ENIER_ANNULUS OFFSEI. VALUE :

?

.-1.856

INCLUIIE ADJACENT CAYITY EFFECTS ? (Y OR $N$ ):

.$Y$

DO YOU WANT ANOTHER CASE ? (Y OR $N$ ):

.N

$\mathrm{R}$;

IY FILE FI08F001

$(X, R)=(1.50,25.00) \quad$ OFFSET $=-1.856$ ADJACENT INCLUDED ?: $Y$

BZMAX $=0.047467$ BRMAX $=-0.010009 \quad$ AFMAX $=-2.074389$

$\begin{array}{ccccccc}\text { LENGTH } & \text { RADIUS } & \text { THICKNESS } & \text { CR } & \text { BZ } & \text { BR } & \text { AP } \\ 1.000 & 13.330 & 1.000 & 0.937 & 0.083843 & 0.110523 & 0.054503 \\ 2.000 & 13.330 & 1.000 & 0.937 & 0.166958 & 0.219387 & 0.108919 \\ 3.000 & 13.330 & 1.000 & 0.937 & 0.248625 & 0.324994 & 0.163166 \\ 4.000 & 13.330 & 1.000 & 0.937 & 0.328171 & 0.425862 & 0.217159 \\ 5.000 & 13.330 & 1.000 & 0.937 & 0.404952 & 0.520668 & 0.270816 \\ 6.000 & 13.330 & 1.000 & 0.937 & 0.478383 & 0.608288 & 0.324075 \\ 7.000 & 13.330 & 1.000 & 0.937 & 0.547952 & 0.687811 & 0.376853 \\ 8.000 & 13.330 & 1.000 & 0.937 & 0.613222 & 0.758586 & 0.429089 \\ 9.000 & 13.330 & 1.000 & 0.937 & 0.673811 & 0.820196 & 0.480735 \\ 10.000 & 13.330 & 1.000 & 0.937 & 0.729453 & 0.872421 & 0.531734 \\ 11.000 & 13.330 & 1.000 & 0.937 & 0.779936 & 0.915253 & 0.582039 \\ 12.000 & 13.330 & 1.000 & 0.937 & 0.825133 & 0.948927 & 0.631607 \\ 13.000 & 13.330 & 1.000 & 0.937 & 0.864963 & 0.973691 & 0.680430 \\ 14.000 & 13.330 & 1.000 & 0.937 & 0.899425 & 0.990067 & 0.728498 \\ 15.000 & 13.330 & 1.000 & 0.937 & 0.928611 & 0.998655 & 0.775741 \\ 16.000 & 13.330 & 1.000 & 0.937 & 0.952603 & 1.000000 & 0.822190 \\ 17.000 & 13.330 & 1.000 & 0.937 & 0.971540 & 0.994709 & 0.867331 \\ 18.000 & 13.330 & 1.000 & 0.937 & 0.985615 & 0.983473 & 0.912676 \\ 19.000 & 13.330 & 1.000 & 0.937 & 0.995027 & 0.966922 & 0.956724 \\ 20.000 & 13.330 & 1.000 & 0.937 & 1.001900 & 0.945676 & 1.000000\end{array}$

$\mathrm{R}$; 
C

$\mathrm{CZ}$

$\mathrm{CZ}$

$\mathrm{CK}$

$\mathrm{CK}$

$\mathrm{CK}$

$\mathrm{C}$

C

C

C

C

C

C

C

C

C

C

C

C

C

C

C

C

C

C

C

C

C

C

C

C

C

C

C

C

C

C

C

C

C

C

C

C

C
C

C INITIALIZATION.

PROGRAM FLDEQ: F.ZYKAN 24JUL80

F.W.ZYKAN 28AUG80 : OUTPUT NORMALIZED; MAXIMUM FIELD VALUES LISTED.

K.H.CARPENTER OBAUG8O : R1S INSERTED IN COMMON/CFB/ IN MAIN PROG. OUTPUT CHANGED TO UNIT 8; ALTERNATE OUTPUT LOOP INSERTED-AS COMMENTS BEGINNING $\mathrm{CK}$

THIS PROGRAM WILL CALCULATE THE RADIAL AND AXIAL B-FIELDS DUE TO TWO COAXIAL CURRENT CYLINDERS WHOSE CENTERS ARE AT THE REFERENCE, OR PRIMARY ORIGIN. THE PROGRAM IS USER-INTERACTIVE, AND IS DESIGNED FOR USE ON THE IBM VIRTUAL MACHINE/CMS TERMINALS.

THE PROGRAM PROMPTS THE USER FOR THE INPUT DATA, WHICH CONSISTS OF THE CYLINDER (OR ANNULUS) IENGTH, RADIUS, THICKNESS, CURRENT RATIO, AND OFFSET. THESE TERMS REPRESENT THE FOLLOWING : LENGTH--THE TOTAL LENGTH OF THE CYIINDERS IN CM.

RADIUS---THE ARITHHETIC MEAN OF THE RADII OF THE TWO CYIINDERS IN CM.

THICKNESS---THE DIFFEREHCE BETWEEN THE RADII OF THE TWO CYLINDERS IN CM.

CURRENT RATIO---THIS IS THE RATIO OF THE INNER CYLINDER CURRENT DENSITY TO THE OUTER CYLINDER CURRENT DENSITY.

OFFSET-- THE DISTANCE THAT THE ANNULUS IS DISPLACED FROM THE CENTER OF THE EBT CAVITY, DUE TO THE NONUNIFORMITY OF THE MAGNETIC FIEID WHICH THE ELECTRONSFLDOO MOVE THROUGH, IN CM.

THE USER MUST ALSO CHOOSE WHICH PARAMETER IS TO BE VARIED, WHETHER IT IS LENGTH, MEAN RADIUS, OR THICKNESS, AND ALSO HOW MANY VALUES ARE TO BE CALCULATED, ALONG WITH THE UPPER LIMIT OF THE PARAMETER BEING VARIED. THE PROGRAM WILL PROMPT FOR EACH. THE USER MUST ALSO DECIDE WHETHER OR NOT TO INCLUDE THE EFFECTS OF TWO SIMILAR ANNULI WHICH ARE ON EITHER SIDE OF THE 'CENTER' ANNULUS, AND IN A CONFIGURATION LIKE THE CAVITIES IN 'EBT'(15DEGREES OFF OF A LINE FROM THE CENTER OF 'EBT' TO THE CENTER OF THE FIRST ANNULUS, AND EACH $150 \mathrm{CM}$. AWAY FROM THE CENTER OF THE 'EBT' MACHINE).

THE FINAL PIECE OF INFORMATION NECESSARY FOR THE CALCULATIONS IS THE POINT AT WHICH THE USER WANTS THE FIELDS CALCULATED.

THE OUTPUT IS DISPLAYED ON THE CRT TERMINAL, AMD MUST EITHER BE COPIED OR PRINTED FOR A HARD COPY LISTING OF THE DATA OUTPUT.

THE PROGRAM USES A SINGLE-PRECISION ADAPTIVE SIMPSON'S RULE FOR INTEGRATION, AND ALL ELLIPTIC IUTEGRALS ARE DONE IN-IINE.

COMMON/CFB/FB, R, X,R 1, A T,2,RS,R 1S, R 1R4, RPRSQ, RMR ISQ

DIMENSION BZZ $(100), B R R(100), A L(100)$, ANMR $(100), A P P(100)$

$1, \operatorname{ATHK}(100)$

DATA IL,IR,IT,IY/'L','R', 'T','Y',

C $15=\cos (.26179938)$

$\operatorname{S15}=\operatorname{SIN}(.26179938)$

AMR IS THE DISTANCE FROM THE PHYSICAL CENTER OF THE ANNULI TO THE CENTER OF 'EBT'.
FLDOO

FLDOO

FLDOO

FLDOO

FIDOO

FLDOO

FLDOO

FLDOO

FLDOO

FLDOO

FLDOO

FLDOO

FLDOO

FLDOO

FLDOO

FLDOO

FLDOO

FLDOO

FLDOO

FLDOO

FLDOO

FLDOO

FLDOO

FLDOO

FLDOO

FLDOO

FLDOO

FLDOO

FLDOO

FLDOO

FLDOO

FLDOO

FLDOO

FLDOO

FLDOO

FLDOO

FLDOO

FLDOO

FL $D 00$

FLDOO

FLDOO

FLDOO

$F$ L D 00

FLDOO

FLDOO

FLDOO

FLDOO

FLDOO

FLDOO

FLDOO

FLDOO

FLDOO

FLDOO

FLDOO 


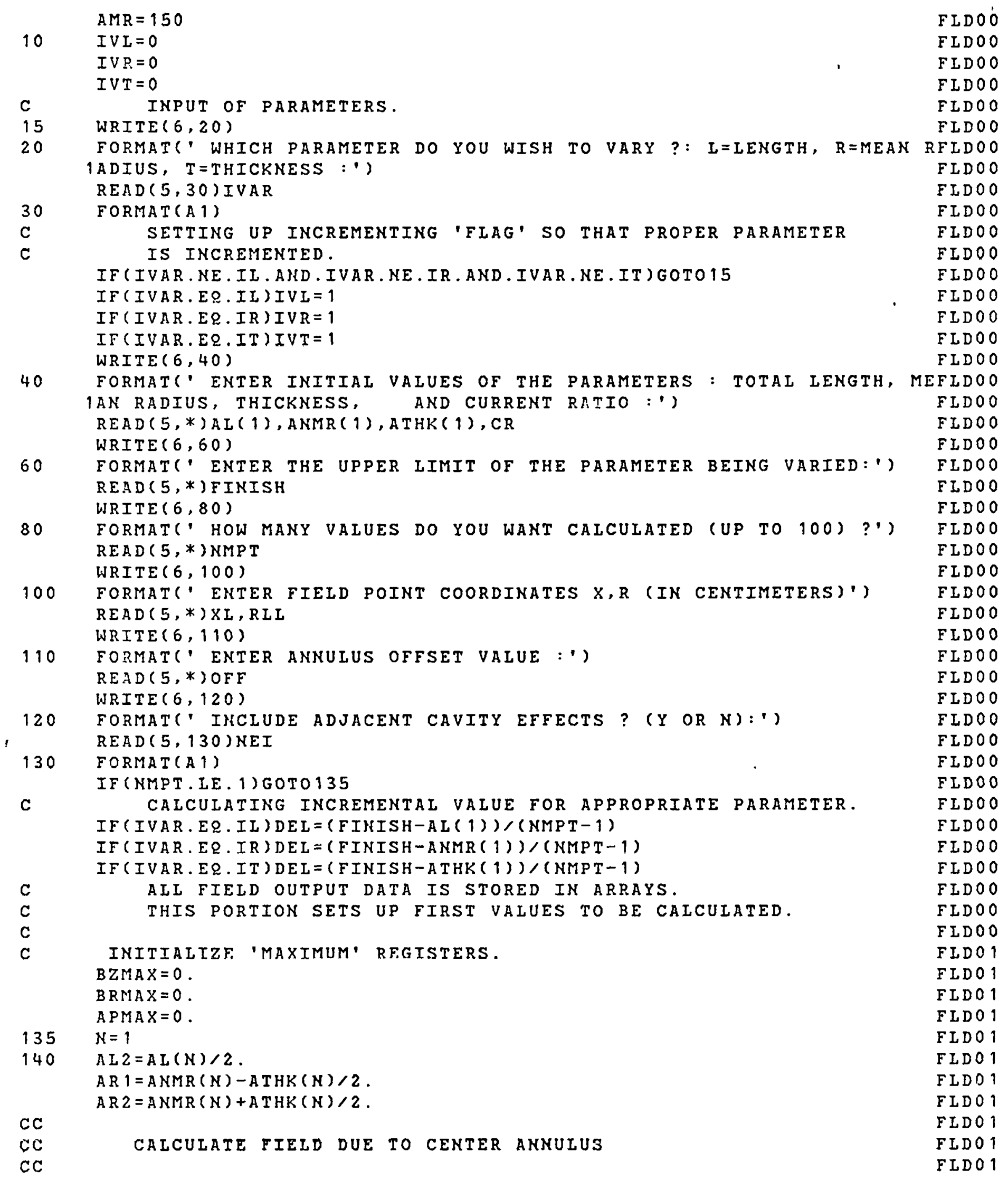




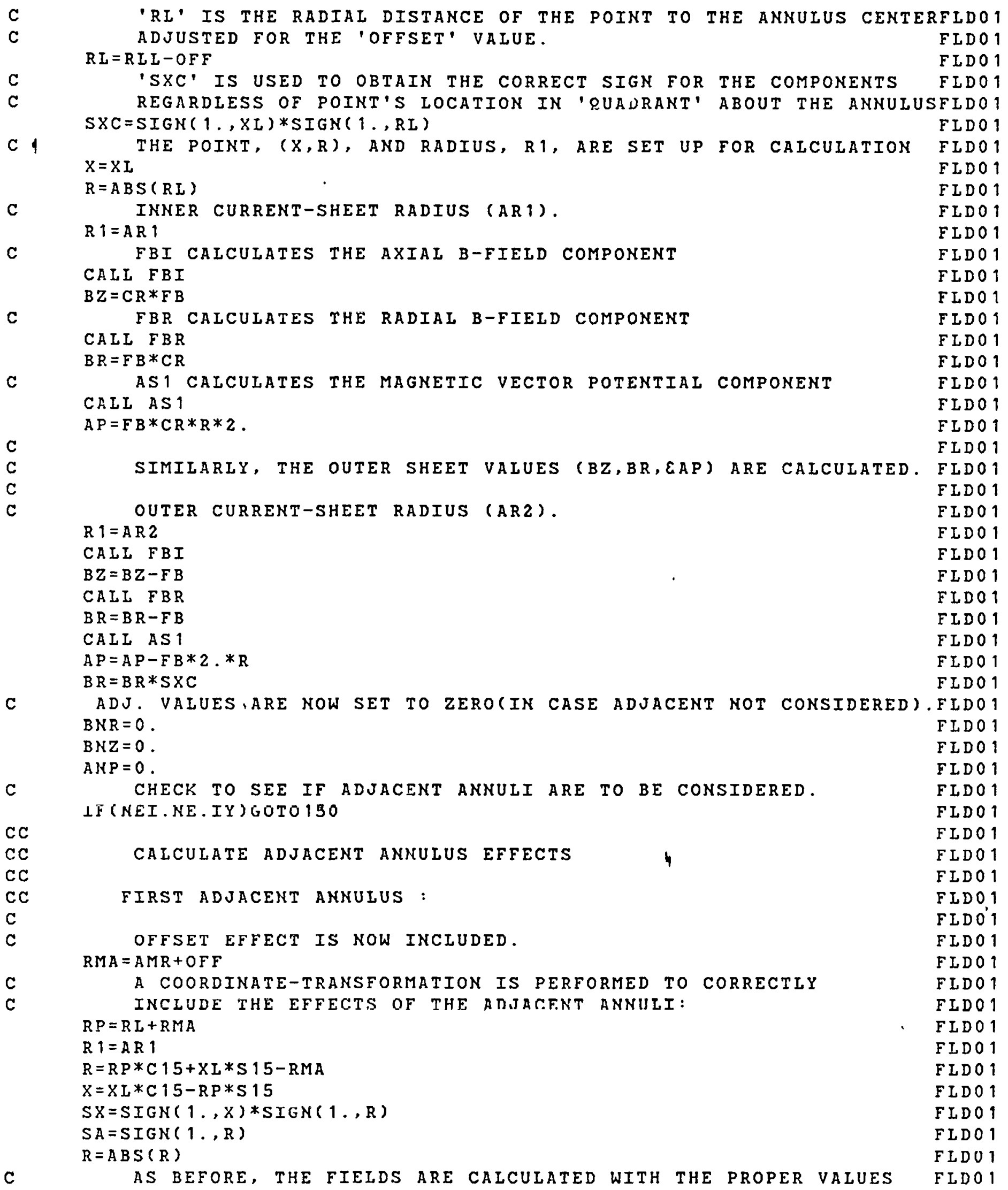


C FOR THE INNER AND OUTER CURRENT SHEETS OF ONE ADJACENT ANNULUSFLDO 1 CALL FBI $B N Z=F B * C R$ CALL FBR $B N R=F B * C R * S X$

CALL AS 1 $A N P=F B * C R * R * 2 . * S A$ $\mathrm{R} 1=\mathrm{AR} 2$ CALL FBI $B N Z=B N Z-F B$ CALL FBR $B N R=B N R-F B * S X$ CALL AS 1 $A N P=A N P-F B * 2 . * R * S A$ FLD 01 FLDO 1 FIDOI FLDO 1 FLDO 1 FLDO 1 FLDO 1 FLNO1 FLDO 1 ELDO 1 FLDO 1 FLDO 1 FLDO 1 C TRANFORMED COMPONENT VALUES ADDED TO THE CENTER-ANNULUS FIELD $B Z=B Z+B N Z * C 15+B N R * S 15$ $B R=B R+B N R * C 15-B N Z * S 15$ $A P=A P+A N P$

$\mathrm{CC}$

$\mathrm{CC}$

$\mathrm{CC}$

$\mathrm{C}$

C

C SECOND ADJACENT ANNULUS:

FLDO 1

FIDO 1

FLDO 1

FLDO 1

FLDO 1

FLDO 1

FLDO 1

AS FOR THE FIRST ADJACENT ANMULUS, THE TRANSFORMED FIELD COMPONENTS FROM THE SECOND ADJACENT ANNULUS ARE ADDED TO THE FIELD TOTALS:

$R=R-X I * S 15 * 2$.

$X=R P * S 15+X L * C 15$

$\mathrm{R} 1=\mathrm{A} \mathrm{R} 1$

$S A=\operatorname{SIGN}(1, R)$

$\operatorname{SX}=\operatorname{SIGN}(1, X) * \operatorname{SIGN}(1, R)$

$R=A B S(R)$

CALI FBI

$B N Z=F B * C R$

CALL FBR

$B N R=F B * C R * S X$

CALL AS 1

$A N P=F B * C R * R * 2$. * SA

$R 1=A R 2$

CNII FBI

$B N Z=B N Z-F B$

CALL FBR

$B N R=B N R-F B * S X$

CALL AS 1

$\mathrm{CC}$

$A N P=A N P-F B * 2 . * R * S A$

FLD 01

FLDO 1

FLDO 1

FLDO 1

FLDO 1

FLDO 1

FLDO 1

FLDO 1

FLDO 1

FLDO 1

FLDO 1

FLDO 1

FLD 01

FLDO2

FLDO2

FI.DO2

FLDO2

FLDO2

FLDO2

$F L D O 2$

FLDO 2

$\mathrm{FLDO} 2$

FLDO2

FIDO2

FINAI SUM OF FIELDS

FLDO2

$\mathrm{CC}$

$\mathrm{C}$

150

ARRAY STORAGE OF SUMS:

FLDO2

$B Z Z(N)=B Z+B N Z * C 15-B N R * S 15$

$F L D O 2$

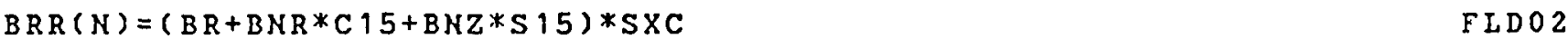

$A P P(N)=A P+A N P$

FIDO2

C COMPARE TO PREVIOUS MAX.

IF (ABS(BZIIAX) . LT.ABS(BZZ(N)))BZMAX $=B Z Z(N)$ IF (ABS (BRMAX) . LT . ABS (BRR $(N))) B R M A X=B R R(N)$

c IF (ABS (APMAX) IT A ABS (APP(N))) APMAX = APP $(N)$ 


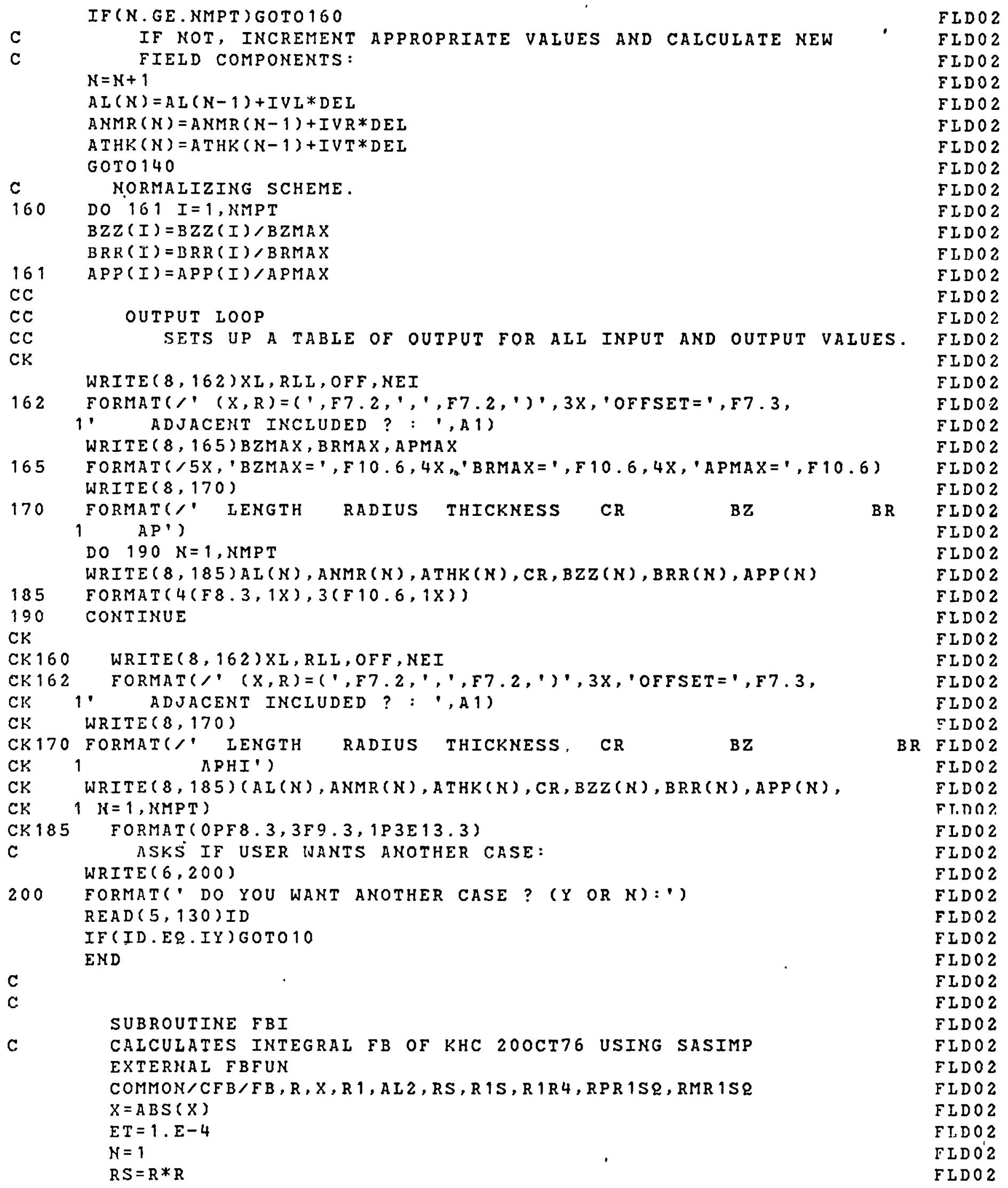




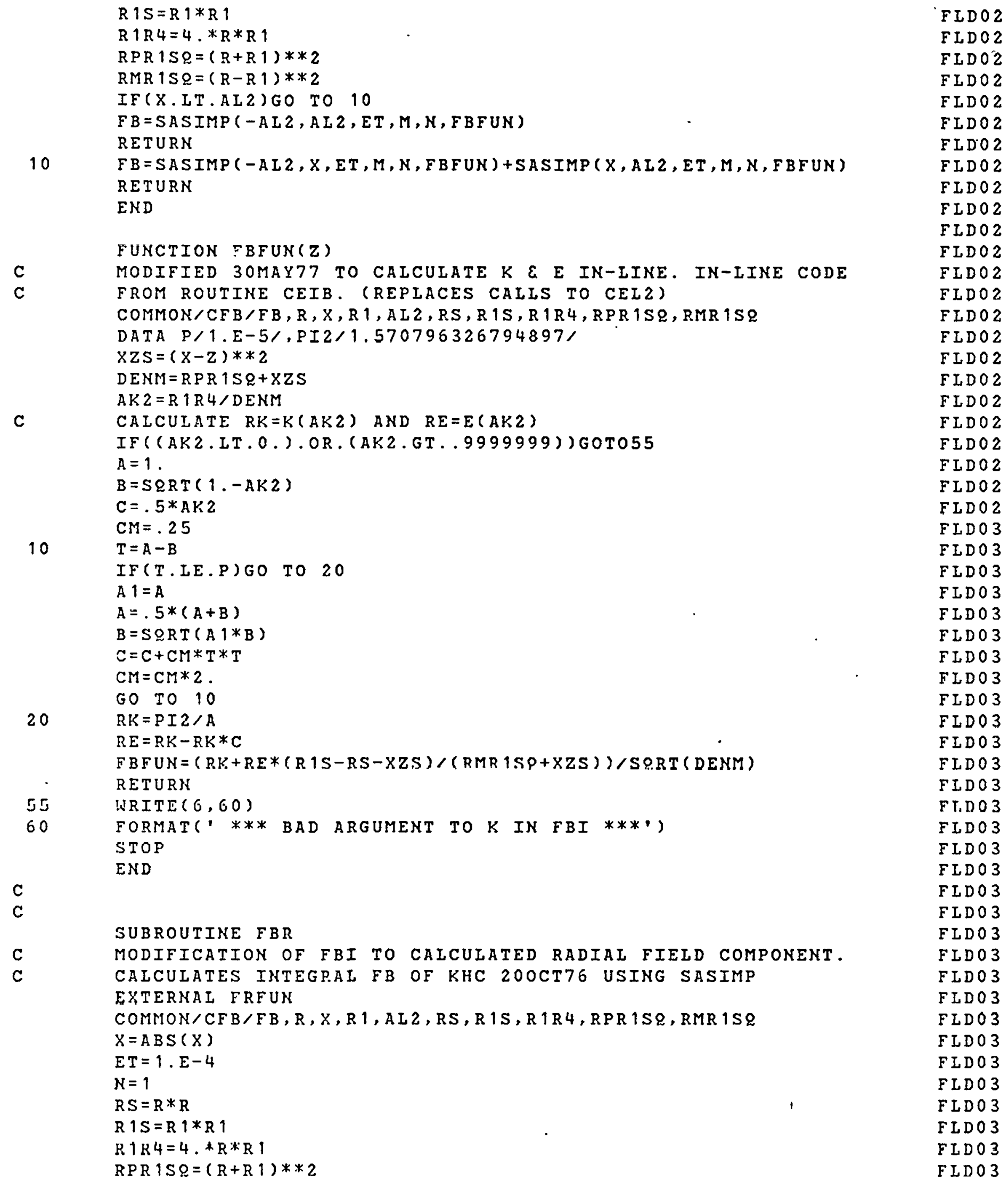

FLDO2

FLDO2

FIDO2

FLDO2

$F L D O 2$

FLDO2

FIDO2

FIDOZ

FIDOZ

FIDOZ

FLDOZ

FLDO2

FLDO2

FLDO2

FLDOZ

FLDO2

FIDO2

$F I D O 2$

FIDO2

FIDOZ

FLDO2

FIDO2

FLDO2

$F L D O 2$

FLDO3

FIDO 3

FIDO3

FIDO 3

FLDO 3

FLDO 3

FIDO 3

FIDO 3

FLDO3

FIDO 3

FLDO 3

FLDO 3

FIDO3

FT.DO 3

FIDO3

FIDO 3

FLDO 3

FLDO 3

FLDO 3

FLDO 3

FIDO3

FLDO 3

FLDO 3

FLDO3

FIDO3

FID03

FLDO 3

FLDO 3

FLDO 3

FLDO 3

FLDO 3 
FIIE: FIDEQ FORTRAN A UNIVERSITY OF MISSOURI COMPUTER NETWORK

10

$\mathrm{RMR} 1 \mathrm{~S} 2=(\mathrm{R}-\mathrm{R} 1) * * 2$

FID 03

IF (X.IT.AL2) GO TO 10

$F \mathrm{LDO} 3$

$A X=.0-A L 2$

- $F B=S A S I M P(A X, A L 2, E T, M, N, F R F U)$

$F \mathrm{LDO} 3$

RETURN

$A X=.0-A I 2$

$F B=S A S I M P(A X, X, E T, M, N, F R F U N)+\operatorname{SASIMP}(X, A L 2, E T, M, N, F R F U M)$

RETURN

END

$F I D O 3$

$\mathrm{FLDO} 3$

FLDO3

$F I D 03$

FLDO3

FLDO3

$\mathrm{CC}$

FUNCTION FRFUN(Z)

C

MODIFIED 3OMAY77 TO CALCULATE K \& E IN-LINE. IN-IINE CODE

C FROM ROUTINE CEIB. (REPLACES CALIS TO CELZ)

COMMON/CFB/FB, R, X,R1, AL2, RS,R 1S,R 1R4, RPR 1SQ, RMR 1SQ

FIDO 3

$F L D O 3$

FIDO 3

$F I D O 3$

DATA $P / 1 . E-5 /, P I 2 / 1.570796326794897 /$

FIDO3

$\mathrm{XZ}=\mathrm{X}-\mathrm{Z}$

$\mathrm{XZS}=\mathrm{XZ} * \mathrm{XZ}$

DENM = RPR 1SQ+XZS

$A K 2=R 1 R 4 / D E N M$

C CALCULATE RK=K(AK2) AND RE=E(AK2)

IF ( (AKZ.LT.0.).OR. (AK2.GT. . 999999))GOTO55

ELDO3

FLD 03

FIDO3

FLDO3

$F I D O 3$

$F L D O 3$

FLDO3

$A=1$.

$B=\operatorname{SeRT}(1 .-A K 2)$

$\mathrm{C}=.5 * \mathrm{AK2}$

$F L D O 3$

$F \perp D O 3$

$\mathrm{CM}=.25$

$10 \quad T=A-B$

IF(T.LE.P)GO TO 20

FLDO3

$F \perp D O 3$

$F \perp D O 3$

$F \perp D O 3$

A $1=A$

$A=.5 *(A+B)$

$B=S Q R T(A 1 * B)$

$\mathrm{C}=\mathrm{C}+\mathrm{CM} * \mathrm{~T} * \mathrm{~T}$

$\mathrm{CM}=\mathrm{CM} * 2$.

$F \perp D 03$

$F L D O 3$

$F \mathrm{LDO} 3$

$F \perp D O 3$

GO TO 10

FLDO3

FLDO 3

$20 \quad \mathrm{RK}=\mathrm{PI} / \mathrm{A}$

$R E=R K-R K * C$

$F R F U=X Z *((.0-R K)+R E *(R 1 S+R S+X Z S) /(R M R 1 S Q+X Z S)) /(R * S Q R T(D E N M))$

RETURN

$53 \quad$ WRLLt $(6,60)$

60 FORMAT('*** BAD ARGUMENT TO K IN FBR ***') STOP

END

FLDO3

FLDO3

FLDO 3

FLDO3

FT. DO 3

$F L D O 3$

$F \perp D O 3$

FLDO3

C

C

FUNCTION SASIMP(A $1, B, E E, M, N, F U N)$

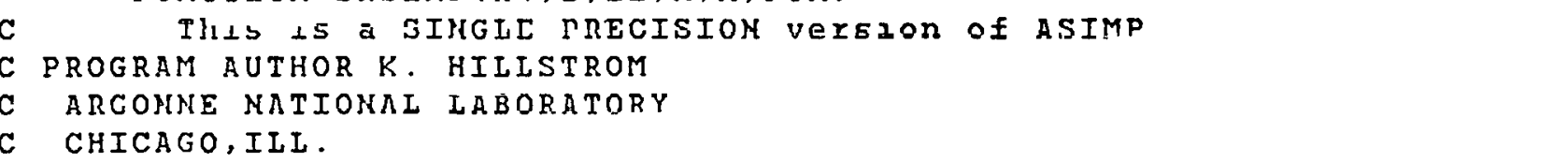

THIS VERSION HAS BEEN MODIFIED TO ELIMINATE ASIMP'S CHANGING

FIDO 3

FLDO 3

FLDO3

FLDO 3

FLDO 3

FLDO3

FLDO3

FLDO 3

FLDO 3

OF ANY OF ITS ARGUMENTS EXCEPT M. IF A $1=B$ ON CALL, THEN

FLDO 3

A VALUE OF ZERO IS RETURNED IMMEDIATELY, AND $M=0$.

FLDO 3

FLDO3

REAL

FLDO 3

$\varepsilon$

SASIMP, A 1, B, EP, FUN, A, EPS, ABSAR, EST, FA, FM, FB, DX, SX, FLDO3 
$>\quad F 1, F 2, F B P, E S T 2, N R T R, E S T 1$, SUM, DAFT, ESUM, TSUM, DA, DIFF

$F L D O 3$

REAL AEST2,FTST, FMAX, AF 1, AF2, AEST 1, DELTA, AEST

DIMENSION F2(30), FBP $(30)$, EST $2(30)$, NRTR $(30)$

DIMENSION AEST2(30), FTST ( 3 )

C

THE PARAMETER SETUP FOR THE INITIAL CALL

$\operatorname{IF}((B-A)$. EQ.O.EO)GO TO 200

$E P=E E$

IF (N.LE.O) GO TO 40

IF (N.GT.3) GO TO 50

$A=A 1$

$E P S=E P * 15.0 E 0$

$E S U M=0.0 \mathrm{E} O$

TSUM $=0.0 E 0$

IVI $=1$

$D A=B-A$

$F A=F \cup N(A)$

$F M=F \cup N((A+B) * 0.5 E 0)$

$F B=F \cup N(B)$

$M=3$

$F M A X=A B S(F A)$

FTST $(1)=F M A X$

$\operatorname{FTST}(2)=A B S(F M)$

$\operatorname{FTST}(3)=A B S(F B)$

DO $10 \quad I=2,3$

IF (FMAX.GE.FTST(I)) GO TO 10

FMAX $=F T S T(I)$

10 CONTINUE

$E S T=(F A+4.0 E O * F M+F B) * D A / 6.0 E O$

ABSAR $=($ FTST $(1)+4.0$ EO *FTST $(2)+F T S T(3)) * D A / 6.0 E 0$

AEST = ABSAR

C $\quad 1=R E C U R$

$20 D X=D A /(2.0 E 0 *$ LVL $)$

$S:=D X / 6.0 E O$

$F 1=F \cup N(A+0.5 E O * D X)$

$F 2(L V L)=F U N(A+1.5 E 0 * D X)$

EST $1=3 X *(F A \mid 4.0 E O * F 1+F M)$

$F B P(L V I)=F B$

ESIZ(LVL) $S X *(F H+4.0 E O * F Z(L V L)+F B)$

SUM $=E S T 1+E S T 2($ IVI)

$\operatorname{FTST}(1)=\operatorname{ABS}(F 1)$

$\operatorname{FTST}(2)=\operatorname{ABS}(F 2(L V L))$

$F \operatorname{TST}(3)=A B S(F M)$

AEST $1=S X *(A B S(F A)+4.0 E 0 * F T S T(1)+F T S T(3))$

$A \operatorname{EST}(L V L)=S X *(\operatorname{FTST}(3)+4.0 \mathrm{EO} * F T S T(2)+A B S(F B))$

$A B 3 A R=A B S A R$ ALST+AEST $1+$ AEST2 (LVI)

$M=M+2$

GO TO $(60,30,70), \mathrm{N}$

30 DELTA $=$ ABSAR

GO TO 90

40 PRINT 10000

RETURN

50 PRINT 10100

RETURN

60 DELT $=1.0 E O$

GO TO 90

$F L D O 3$

FLDO 3

FLDO 3

FLDO3

FLDO 3

FLDO 3

FLDO 3

FLDO 3

FLDO 3

FLDO 3

FLDO 3

FLDO 3

FLDO 3

FIDO 4

FLD 04

FLDO 4

FLDO 4

FLDO 4

FLDO 4

FLD 04

FLDO 4

FLDO4

FLDO 4

FLDO 4

FIDO 4

FLD 04

FIDO 4

FLDO 4

FLD 4

FLD 04

FLDO 4

FID 04

FID 04

FIDO 4

FLDO 4

FLDO 4

FI.Dก 4

FLDO 4

FLDO 4

FLDO 4

FLDO4

FID 04

FIDO 4

FIDO 4

FIDO 4

FLDO 4

FLDO 4

FLDO4

FLDO 4

FLD 04

FLDO 4

FLD 04

FID 04

FLDO 4 


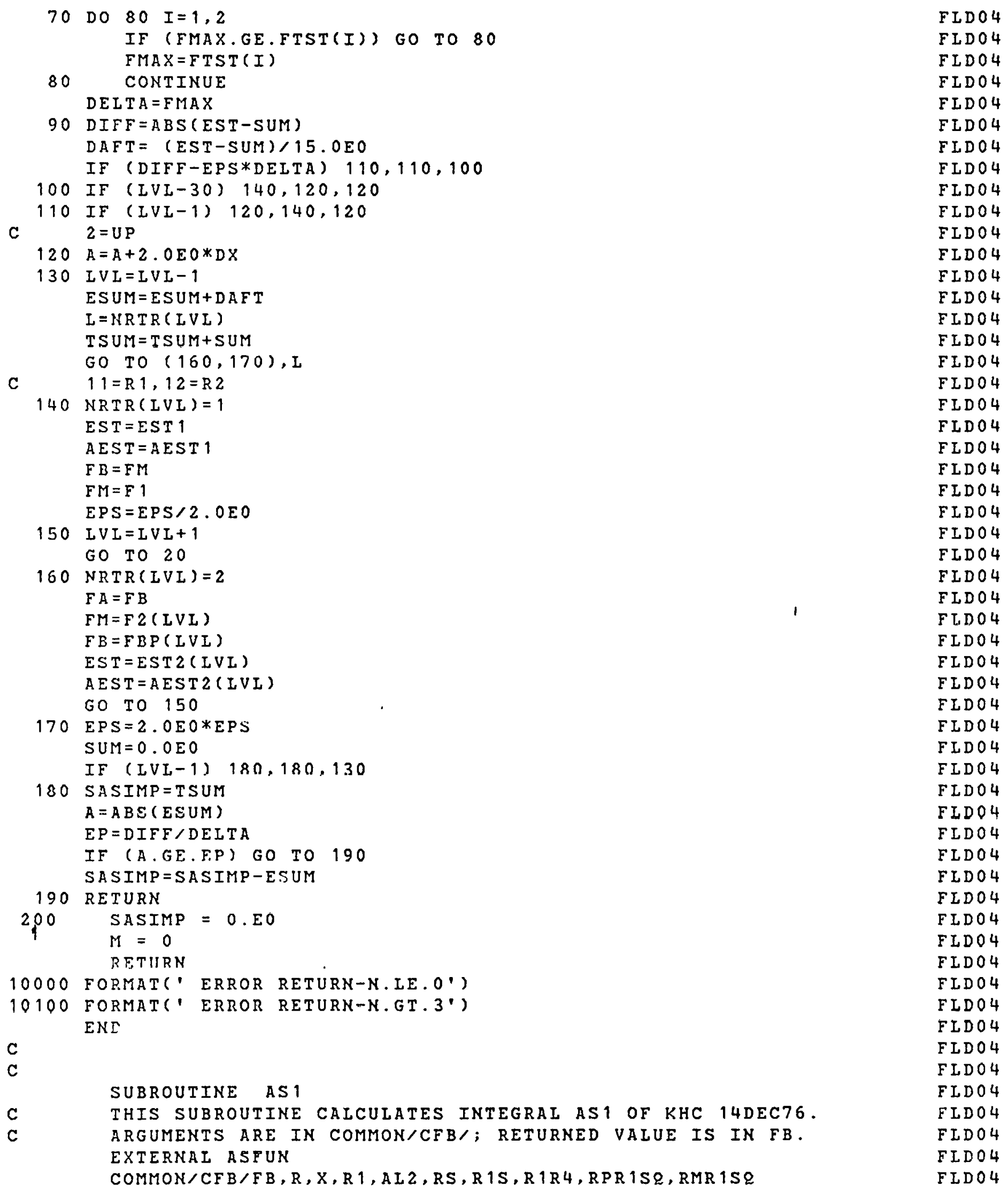

FLDO 4

FLDO 4

FLDO 4

FLDO 4

FLD 04

FLDO 4

FLDO 4

FLDO 4

FLD 4

FLDO 4

FLDO 4

FLDO 4

FLDO 4

FL DO 4

FLDO 4

FLD 4

FLDO 4

FLDO 4

FLDO 4

FLD 4

FLDO 4

FLDO 4

FLDO 4

FLDO 4

FLDO 4

FLDO 4

FLDO 4

FLDO 4

FLDO 4

FLDO 4

FLDO 4

FIDO 4

FIDO 4

FLDO 4

FLD 04

FIDO 4

FLDO 4

FLDO 4

FLDO 4

FLDO 4

FLD 4

FIDO 4

FLDO 4

FIDO 4

FIDO 4

FLD 04

FIDO 4

FID 04

FLDO 4

FLD 4

FLD 4

FLDO 4

FLDO 4

FLDO 4

FIDO 4 


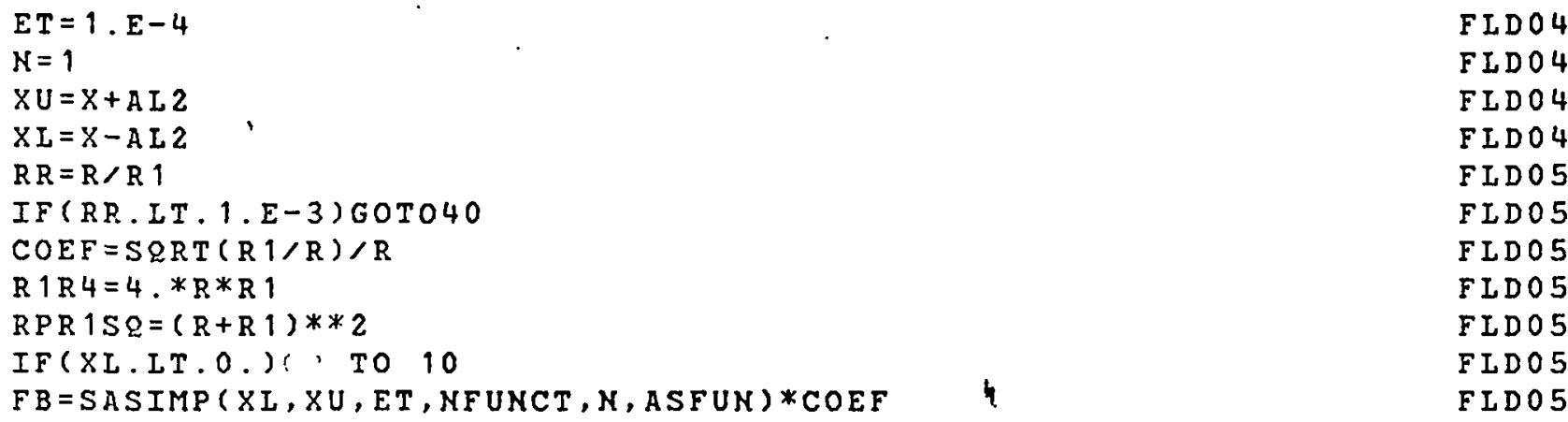

C $10 \quad F B=(\operatorname{SASIMP}(X I, 0 \ldots, E T, M, N, A S F U N)+\operatorname{SASIMP}(0 ., X U, E T, M, N, A S F U N)) * C O E F$ FIDO5 RETURM

$10 \quad I F(A B S(1 .-R R) . I T \cdot 1 . E-3)$ GOTO30

$F B=2, * C O E F * S A S I M P(X L, 0, E T, N F U N C T, N, A S F U N)$

FID 05

$F B=F B+C O E F * S A S I M P(-X I, X U, E T, N F U N C T, N, A S F U N)$

FLDO5

20 RETURN

$30 \quad \mathrm{R} 1 \mathrm{R} 4=\mathrm{R} 1 * \mathrm{R} 1 * 1.001 * 4$.

SPR 1SQ $=(\mathrm{R} 1 *(2.001)) * * 2$

$F B=C O E F * S A S I M P(X I, 0 ., E T, N F U N C T, N, A S F U N)$

$\mathrm{R} 1 \mathrm{R} 4=\mathrm{R} 1 * \mathrm{R} 1 * 0.999 * 4$.

$F L D O 5$

FLDO5

FLDO5

FLDO5

FLDO5

FLD 05

$\mathrm{RPR} 1 \mathrm{SQ}=(\mathrm{R} 1 *(1.999)) * * 2$

FLDO5

$F B=F B+C O E F * S A S I M P(X I, 0$, ET, NFUNCT, N, ASFUN $)$

FLDO5 GOTO2O

$40 \quad \mathrm{R} 1 \mathrm{~S}=\mathrm{R} 1 * \mathrm{R} 1$

$F \mathrm{~B}=(3.141592653589793 \mathrm{D} 0 / 4) *.(X \mathrm{X} / \mathrm{S} 2 \mathrm{RT}(\mathrm{R} 1 \mathrm{~S}+\mathrm{XU} * X \mathrm{U})$

$1-X I / S 2 R T(R 1 S+X L * X L))$

END

FLDO5

FID 05

FLDO5

FLDO 5

FLDO 5

$F \perp D O 5$

FUNCTION ASFUN(Z)

C MODIFIED $30 M A Y 77$ TO CALC. K \& E IN-LINE.IN-LINE CODE

C FROM ROUTINE CEIB. (REPLACES CALLS TO CELZ)

COMMON/CFB/FB, R, X, R 1, AL2, RS, R 1S, R 1R4, RPR 1S\&, RMR 1SQ

FLDO5

$F \perp D O 5$

$F \perp D O 5$

FLDO5

DATA $P / 1 . E-5 /, P I 2 / 1.570796326794897 /$

FLDO5

$A K 2=R 1 R 4 /(R P R 1 S Q+Z * Z)$

$A K=S \& R T(A K 2)$

C CALCULATE RH=K(AK2) AND RE=E(AK2)

T.F ( (AK2.IT.O.).OR. (AK2.GT..9999999)) GOTO55

$A=1$.

$\mathrm{B}=\mathrm{S} 2 \mathrm{RT}(1 .-\mathrm{AKR})$

$\mathrm{C}=.5 * \mathrm{AK} 2$

$C M=.25$

$10 \quad T=A-B$

IF (T.LE.P)GOTO2,0

FLDO5

FLDO5

FLDO5

$F \perp D 05$

FLDO5

$F L D O 5$

FLDO 5

FLD 05

$F I D 05$

$A 1=A$

$A=.5 *(A+B)$

$B=S \operatorname{SRT}(A 1 * B)$

$\mathrm{C}=\mathrm{C}+\mathrm{CM} * \mathrm{~T} * \mathrm{~T}$

$\mathrm{CM}=\mathrm{CM} * 2$

GOTO 10

$20 \quad \mathrm{RK}=\mathrm{PI2} / \mathrm{A}$

$R E=R K-R K * C$

C USE RK \& RE TO GET ASFUN:

$A S F U N-((1-A Y .2 / 2) * R Y-.R E) / \Lambda Y$.

RETURN

FLD 05

FLDO5

FID 05

$F L D 05$

FIDO5

FLDOS

FLDO5

FLD 05

FID 05

FID 05

FIDO5

FLD 05

FLDO5 
FILE: FLDEQ FORTRAN A UNIVERSTTY OF MISSOURI COMPUTER NETWORK

55 WRITE $(6,60)$

60 FORMAT(' BAD ARG. TO K IN AS1')

STOP

FLDO5

FLD 5

FLDO 5

END

FLDO5 


\section{EQUIL program}

The EQUIL FORTRAN code produces the MHD equilibrium for a two-dimensional bumpy cylinder. The code of Hedrick ${ }^{11}$ has been modified. The majority of changes are in the main program and subroutine BATS, hence only these are listed here. Following this listing we have included the outputs from the code for the four cases summarized above in Table 2 .

The meaning of output values (which include echoing of input) are not always clear, so a description of them is tabulated here. Table 4 has the input variables while Table 5 has the output variables. The listings of sample output (following the tables) may be consulted for more details. 


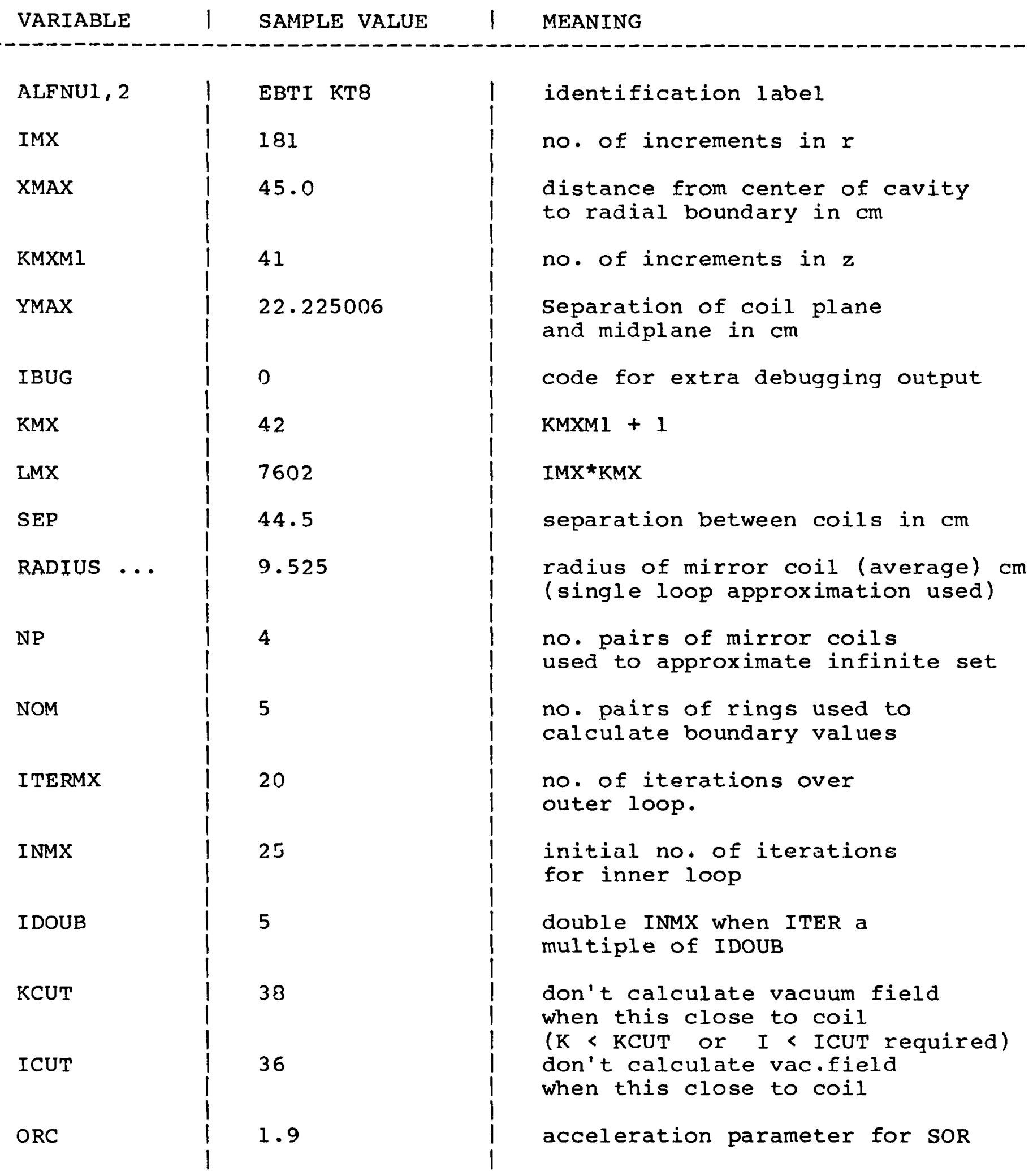

Table 4. Explanation of values that must be input to EQUIL code. 


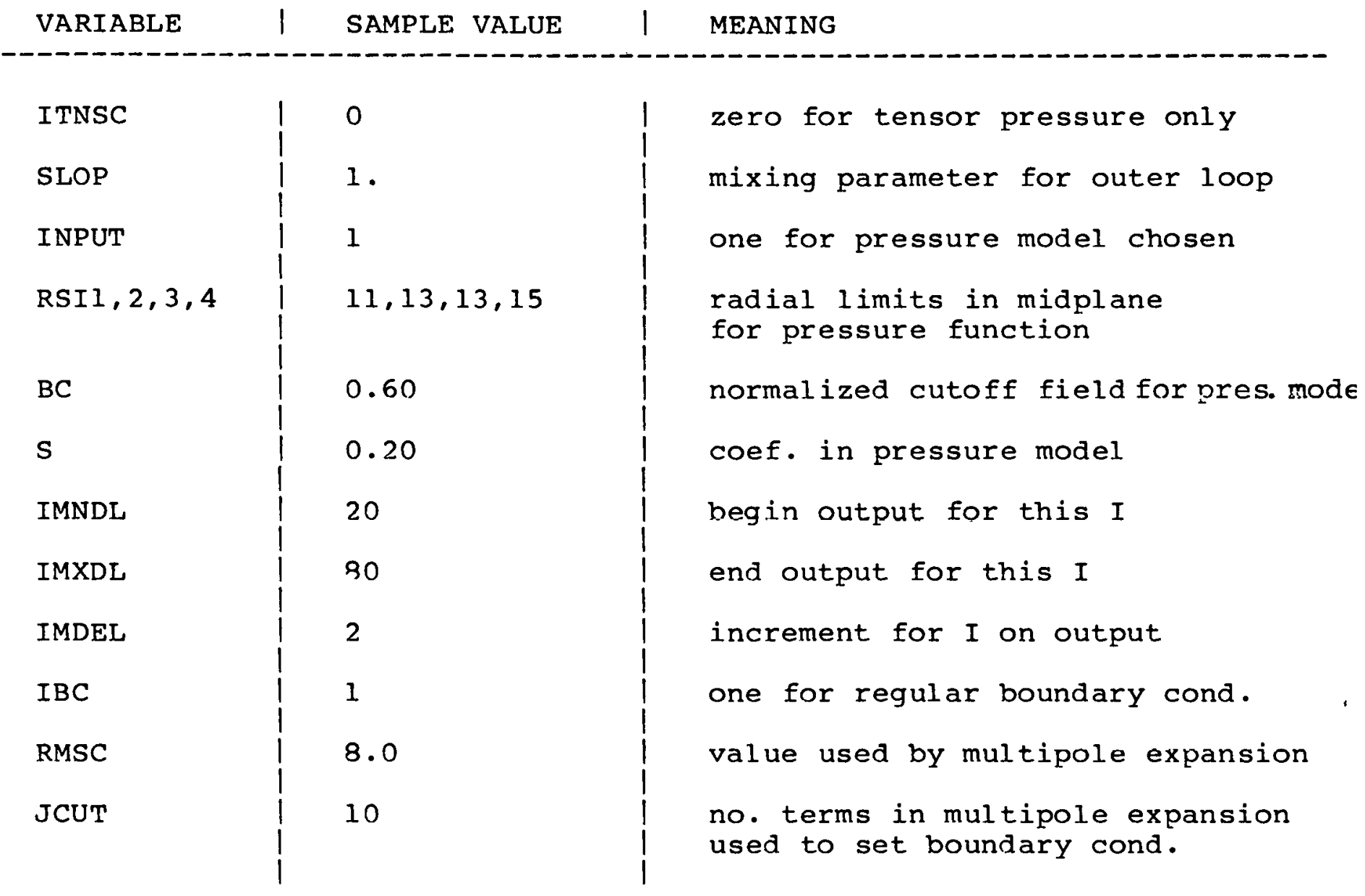

Table 4. (continued) 


\begin{tabular}{|c|c|c|}
\hline ITER & 10 & outer loop iteration no. \\
\hline $\mathrm{N}$ & 25 & inner loop iteration no. \\
\hline RES & $0.17 \mathrm{E}-2$ & residual for SOR at ITER, $N$ \\
\hline RMID & $0.475 \mathrm{E}+01$ & radius in midplane in $\mathrm{cm}$ \\
\hline CURD & $-0.599 E-04$ & current density at RMID \\
\hline MODB & $0.916 E+00$ & normalized $B$ field at RMID \\
\hline P-PERP & 0.0 & perpendicular pressure (normalized) \\
\hline P-PARA & 0.0 & parallel pressure (normalized) \\
\hline DLOB & 0.0 & not calculated by this version \\
\hline SI & $-0.142 \mathrm{E}-02$ & diamagnetic flux value (normalized) \\
\hline SIV & $0.108 \mathrm{E}+02$ & vacuum flux coordinate \\
\hline WPER & $0.80354 \mathrm{E}+00$ & perpendicular energy (normalized) \\
\hline WPAR & $0.48644 \mathrm{E}-01$ & parallel energy (normalized) \\
\hline RAD & 4.75 & radius for pressure map $(\mathrm{cm})$ \\
\hline $\mathrm{z}$ & .56 & axial coord. for pres. map $(\mathrm{cm})$ \\
\hline \multicolumn{3}{|c|}{ pressure map follows } \\
\hline RS & $2.8000 E+01$ & pickup coil radius $(\mathrm{cm})$ \\
\hline $\mathrm{zS}$ & 9.5 & $\begin{array}{l}\text { pickup coil axial position } \\
\text { (cm from midplane) }\end{array}$ \\
\hline SI & $-9.5891 E+02$ & $\begin{array}{l}\text { diamagnetic flux linked by } \\
\text { pickup coil (normalized) }\end{array}$ \\
\hline SIV & $1.4291 \mathrm{E}+02$ & vacuum $\mathrm{flux}$ linked \\
\hline STP & $1.4282 \mathrm{E}+02$ & $S I+S I V$ \\
\hline
\end{tabular}

Table 5. Explanation of calculated values output by EQUIL code. 
CKHC $\mathrm{CKHC}$ CKHC CKHC CK.HC CKHC CRHC CYHC $\mathrm{CKHC}$ $\mathrm{CKHC}$ CKHC CKHC

C

$\mathrm{C}$

C

C

C

VERSION WITH MAXIMUM ARRAY DIMENSIONS. REQUIRES IM TO LOAD. VERSION WITHOUT PHI, PHIR, VR, VZ, RMID USE; HENCE NO DLOB CALC. ZOJAN8 1 CORRECT INCORRECT OUTPUT OF SOME ZEROS IN P MAP. 13 JAN8 1 ADD DOUBLING OF ITERATIONS OF DESI AT ITER = MULTIPIES OF IDOUB. ADD STOP IN DESI WHEN RES.GT. 100 AND IBUG $=0$.

1OJAN8 1 ADD INPUT OF IMDEL; CHANGE OUTPUT OF WPER MAP.

O5JAN8 1 CORRECT PLACEMENT OF LL \& II IMSIDE LOOP IN CALB.

O3JAN8 1 INSERT SECTION IN BATS TO CALCULATE WPER, OUTPUT P MAP AND PSI VALUES; OTHER CHANGES AT CK COMMENT LINES.

22 DEC 80 CHANGE READS TO 5 WRITES TO 6 TO ALLOW OVER 80 CHAR LINES 18 DEC 80 THIS VERSION RESTORES LINES KRIS HAD COMMENTED OUT

$18 D E C 80$ CHANGE READ UNIT FROM 50 TO 7, WRITE UNIT FROM 51 TO 8. PROGRAM EQUIL(DATA, TAPE50=DATA, OUTPUT, TAPE5 $1=$ OUTPUT, *

EULER, TAPE $52=E U L E R$ )

MAIN PROG AXIALLY SYMMETRIC ERUILIBRIA

COMMON/DEX/ IMX,KMX, IMXM1, KMXM1, IMX, KFIG, KCUT, ICUT, ITERMX, INMX COMMON/GEO/ XMAX, XMIN, DELX, YIAAX, YMIN, DELY, SEP, RADL

COMIOH/SCALE/ SC1(250), SC2,SC3,SC4, SC5, SC6(250), SC7, SC8, SC9(250),

* SC10(250), SC12(250), SC13

COMMON/BCAL/ IMIN1(250), IMAX1(250)

COMMON/PCAL/ SIO,BA,BA2,BC,SIMK, SIMX, BETA

COMMON/NPCA/ ICALP,ISICR

COIMON/ADE/ ORC

COIMON/MODGR/ KMXGR, IMNGR, IMXGR

COMMON/BCDEX/IBC, JCUT

COMMON/RETI/ ITER

COMMON/NUALF/ ALFNU1, ALFNU2

COMMON/PRSTP/ ITHSC

COMMON/PAIRS/ NP, NPM

COMMON/ADAUX/ IMXTP, IMNTP, IMDEL

COMMON/BUG/ IBUG

DINENSION SI (12000), SIV (12000), STP(12000),SIGMA (12000), CO1(12000), EQU00

* C02(12000),DTRM (12000), CTRM (12000),B(12000),

* PHI (1), PHIR (1)

DIMENSION VR $(1), \mathrm{VZ}(1)$,

* RMID ( 1$)$

1000 FORMAT $(1 \mathrm{H}, 2(\mathrm{I} 4,2 \mathrm{X}, \mathrm{F} 14,6,2 \mathrm{X}), \mathrm{I} 4)$

1001 FORIAT (1H, $6 \mathrm{HIMX}=, \mathrm{I} 4,2 \mathrm{X}, 7 \mathrm{HXMAX}=, \mathrm{F} 14.6 /$

* $1 \mathrm{H}, 8 \mathrm{HKMXM1}=, \mathrm{I} 4,2 \mathrm{X}, 7 \mathrm{HYMNX}=, \mathrm{F} 14.6$,

* $1 \mathrm{H}, 7$ HIBUG $=, I 4,5 \mathrm{X}, 33$ HIBUG OF ZERO GIVES MIN DIAG PRINT)

1002 FORMAT $(1 \mathrm{H}, 4(\mathrm{~F} 14.6,2 \mathrm{X}))$

1003 FORMAT( $1 \mathrm{H}, 13$ HINPUT BETA $=, F 14.6,2 \mathrm{X}, 11 \mathrm{HCUTOFF} \mathrm{B}=, F 14.6 /$

* $1 \mathrm{H}$, , YHMIN $S I=, F 14.6,2 \%, 9 \mathrm{HMAX} S I=, F 11.6)$

1004 FORMAT $(1 \mathrm{H}, 2(\mathrm{~F} 14,6,2 \mathrm{X}), 2(\mathrm{I} 4,2 \mathrm{X}))$

1005 FORIAT $(1 \mathrm{H}$, GHSEF $=, F 11.6,2 \%, 17$ HRADIUS OF T.OOP $=, F 14.6 /$

* IH , 2OHNO COIL PAIRS MP $=, I 4 /$

* $1 \mathrm{H}, 37 \mathrm{HNO}$ PJASMA PAIRS FOR MULTIPOLE NPM =, I4)

1006 FORMAT ( $1 \mathrm{H}, 5(\mathrm{I} 4,2 \mathrm{X}), \mathrm{F} 14.6)$

1007 FORMAT 1 H , 39 HMAX NO OF OVERALL ITERATIONS ITERMX =, I $4 /$

* $1 \mathrm{H}, 37 \mathrm{HMAX}$ NO OF ITERATIONS FOR DE INMX $=$, I 4 /

* 1H, 40HDOUBLE INMX HHEN ITER A MUIT. OF IDOUB $=$, I4

* $1 \mathrm{H}$, 5OHTO AVOID THE SINGULARITY FOR THE VAC FLUX FUNCTION,

* $1 \mathrm{H}, 45 \mathrm{HIT}$ IS SET TO ZERO FOR K GE KCUT AND I GE ICUT/

EQU0O

EQU00

$E \& \cup 00$

EQU00

EQU00

$E \& \cup 00$

EQU0O

EQU0O

EQU0O

EQU0O

EQU0O

EQUOO

EQUOO

EQUOO

EQUOO

EQUOO

EQUOO

EQU 00

EQUOO

EQU 00

EQUOO

EQUOO

EQU0O

EQUOO

EQUOO

EQU0O

EQUOO

EQUOO

EQUOO

EQUOO

EQUOO

EQUOO

EQUOO

EQUOO

E. 91100

EQUOO

E\&UOO

EQUOO

EQUOO

EQUOO

EQU0O

EQUOO

EQU 00

EPUOO

EQUOO

EQU 00

EQUOO

EQUOO

EQU 00

EQUOO

EQUOO

EQU0O

EQU0O

EQUOO 


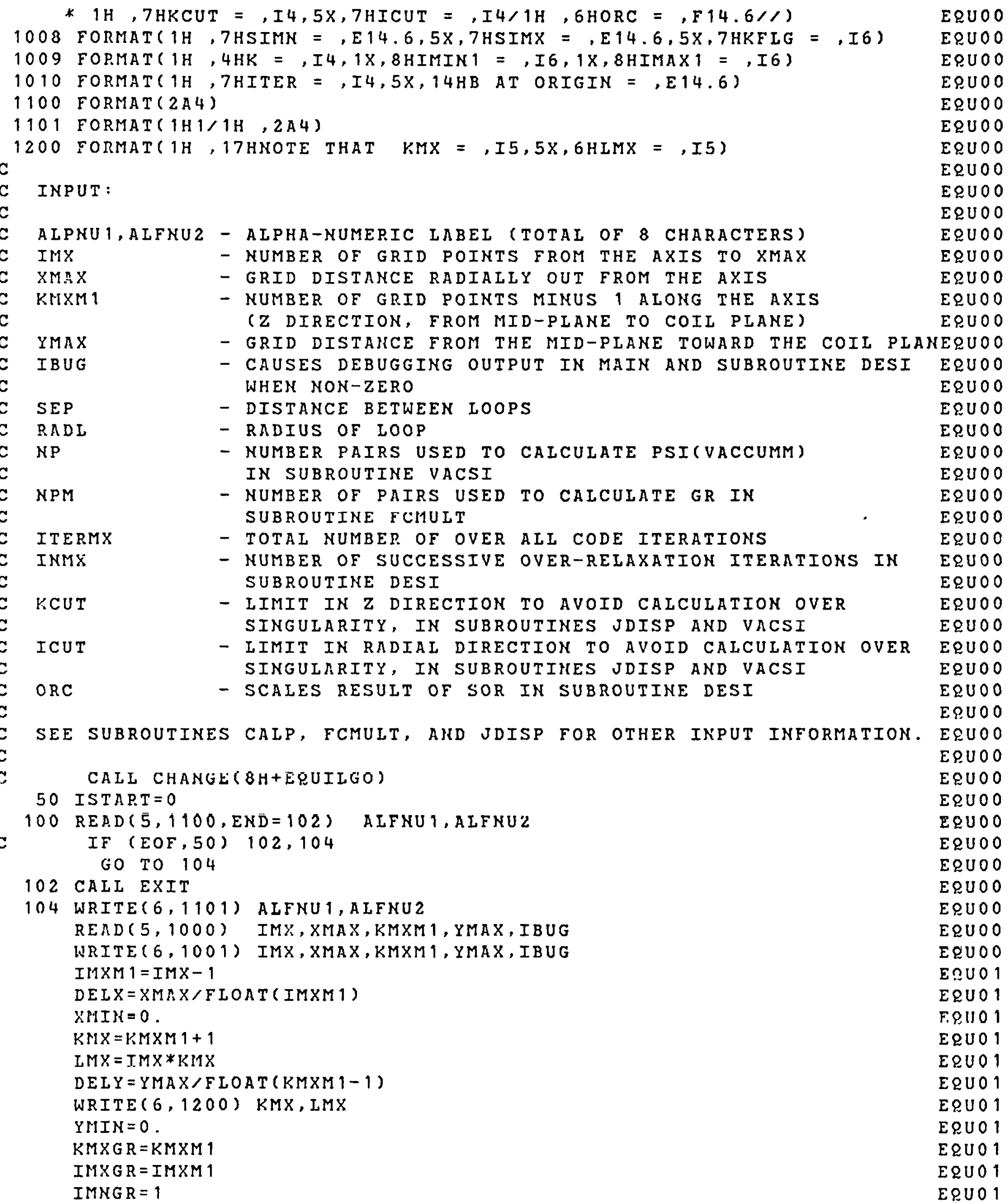


FILE: EQUIL FORTRAN A UNIVERSITY OF MISSOURI COMPUTER NETWORK

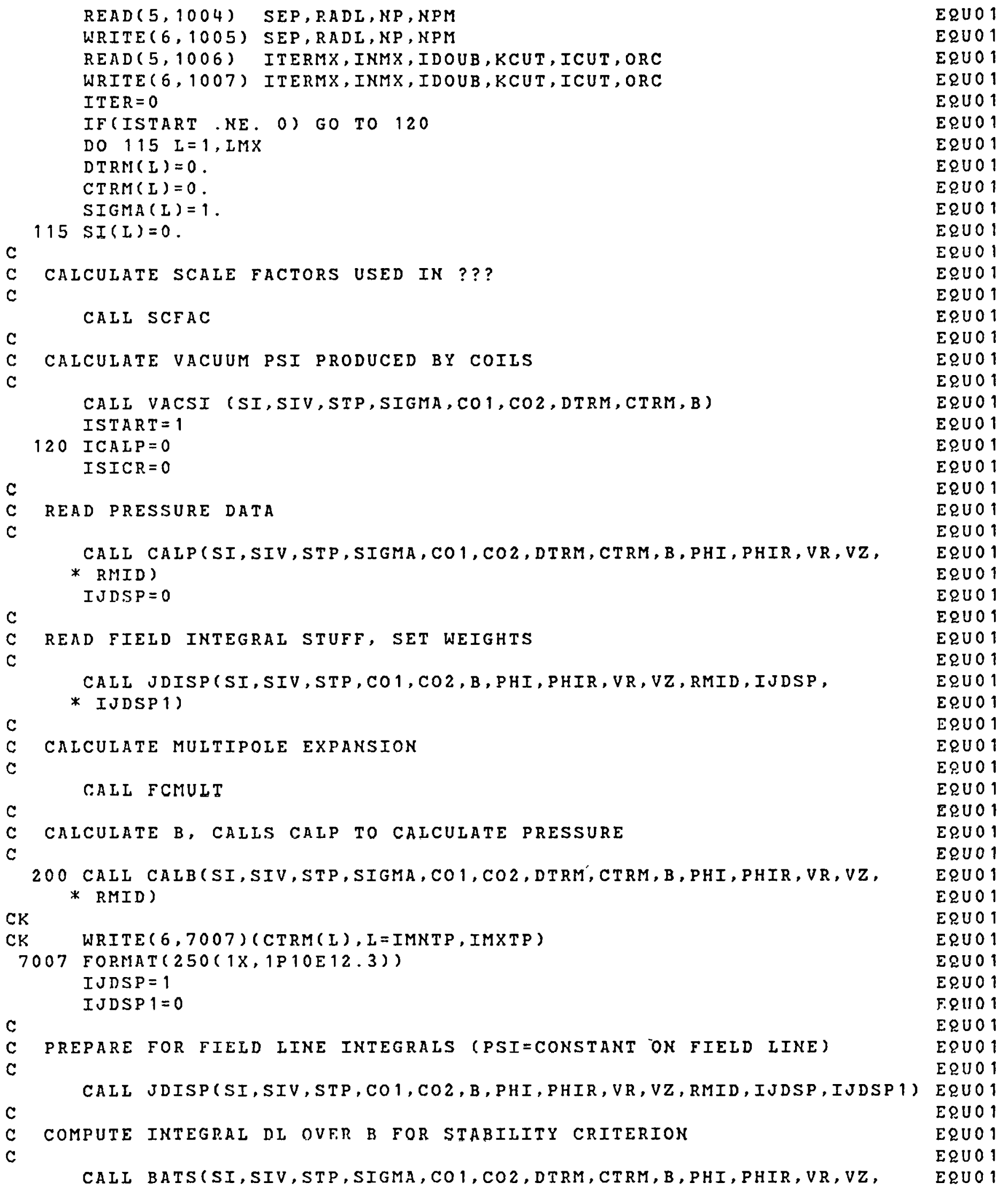


FILE: EQUIL FORTRAN A UNIVERSITY OF MISSOURI COMPUTER NETWORK

* RMID )

EQU0 1

$\mathrm{C}$

DAVE NELSON'S PERSONAL STUFF, DONE ON FINAI ITERATION

EQU01

c

CK CALL DAVE(SI, SIV,STP, SIGMA, CO1, CO2, DTRM, CTRM, B, PHI, PHIR,VR,VZ,

CK * RMID )

C

$\mathrm{C}$ C

DETERMINE DRIVING TERMS AND COEFFECIENTS FOR DEL*PSI, MULTIPOL

CALL DTCOF (SI,SIV,STP,SIGMA, CO1, CO2,DTRM, CTRM, B)

EQU 01

E\&U 01

EQU0 1

EQU 01

EQU01

IF(IBC.ER. O) GO TO 201

EQ $Q 01$

E\&U0 1

EQU0 1

EQU01

SET UP LATERAL BOUNDARY CONDITIONS BASED ON MULTIPOLE MOMENTS

CALI SETBC (SI, SIV, STP, SIGMA, CO1, COZ, DTRM, CTRM, B)

201 WRITE $(6,1010)$ ITER,B(1)

CK

CK WRITE $(6,7007)(D T R M(L), L=I M N T P, I M X T P)$

C 201 CONTINUE

IF (IBUG .EQ. 0) GO TO 211

WRITE $(6,1008)$ SIMN, SIMX,KFIG

DO $210 \quad K=1, K M X M 1$

WRITE $(6,1009) K, \operatorname{IMIN} 1(K), \operatorname{IMAX} 1(K)$

210 CONTINUE

211 IF(ITER . GE. ITERMX) GO TO 500

ITER = ITER+1

$\mathrm{CK}$

IF (MOD (ITER, IDOUB ). EQ.O) INMX $=$ INMX *2

EQU 01

EQU01

EQU 01

EQU01

EQU01

EQUO 1

EQU 01

EQUO 1

EQU 01

EQUO 1

EQU 01

EQU 01

EQU 01

EQU 01

EQU 01

EQU 01

EQU 01

EQU 01

SOLVE DEL*PSI+GRAD(SIGMA)/SIGMA.GRAD(PSI (P)) $=-(R * * 2 / S I G M A) \ldots$

EQUO 1

FOR FIXED SIGMA AKD P-PARALLEL

EQU 01

215 CALL DESI (SI,SIV,STP,SIGMA, CO 1, CO2, DTRM, CTRM, B)

EQU 01 GO TO 200

ERU 1

500 CONTINUE

EQU02

I J D S P $=1$

EP.U०2

I JDSP $1=1$

EQU 02

C

PREPARE FOR FINAL FIELD LINE INTEGRALS

EQUD2

EQU 02

EQU02

CALI JDISPCSI,SIV,STP,CO1, CO2, B, PHI, PHIR, VR,VZ, RMID, IJDSP,

EQU02

* IJDSP 1)

GO TO 100

EQU02

END

$\mathrm{C}$ 
SUBROUTINE BATS(SI, SIV, STP, SIGMA, CO 1, CO2, DTRM, CTRM, B, PHI, PHIR, * VR,VZ,RMID)

C
C
C
C
C

C

COMPUTES DL OVER B AND ITS PSI DERIVATIVE AND INTEGRAL $B$ DL AND INTEGRAL DL OVER B-CUBED ALSO FORMS STABILITY CRITERIA BASED ON FIELD LINE INTEGRALS

COMMON/DEX/ IMX, KMX, IMXM1,KMXM1, LMX, KFLG, KCUT, ICUT, ITERMX, INMX COMMON/SCALE/ SC1 $(250), \mathrm{SC} 2, \mathrm{SC} 3, \mathrm{SC} 4, \mathrm{SC} 5, \mathrm{SC} 6(250), \mathrm{SC} 7, \mathrm{SC} 8, \operatorname{SC} 9(250)$,

* SC10(250),SC12(250), SC 13

COMMON/GEO/ XMAX, XMIN, DELX, YMAX, YMIN, DELY, SEP, RADL

COMMON/PCAL, SIO,BA,BA2,BC,SIMM,SIMX,BETA

COMMON/PAVE/ AVEP, PSCL, PSCLP,PERP, PERPP, PARA, PARAP, CHAT, GO,GPO,

* IOUT

COIMON/STAB/ DLOB(250), BDL (250), DLOB3(250), DLOBP(250), PSAVE(250),

* PPSAVE(250)

COMMON/ADAUX/ IMXTP, IMNTP, IMDEL

COMMON/RETI/ITER

DIMENSION SI(1), SIV(1), STP(1), SIGMA(1), CO1(1), CO2(1),DTRM(1),

* $\operatorname{CTRM}(1), B(1), \operatorname{PHI}(1), \operatorname{PHIR}(1), \operatorname{VR}(1), \mathrm{VZ}(1), \operatorname{RMID}(1)$

DIMENSION WTS(7)

DATA WTS $(1) / .3042245 /$,WTS( 2$) / 1.460384 /$,WTS(3)/.45344640/

DATA WTS $(4) / 1.471429 /, W T S(5) / .7393932 /, W T S(6) / 1.082474 /$

DATA WTS $(7) / .9886326 /$

1002 FORMAT $(1 \mathrm{H}, 7(\mathrm{E} 10.3,1 \mathrm{X}))$

1022 FORMAT $(1 \mathrm{H}, 8(\mathrm{E} 10.3,1 \mathrm{X}))$

1003 FORMAT $(1 H, 2(5 X, E 14.6))$

1006 FORMAT $(1 \mathrm{H}, 6(\mathrm{E} 14.6,1 \mathrm{X}))$

1000 FORIIAT ( $/ 7 X, 4$ HRID $, 7 X, 4$ HPSCL , 6X, 5HPSCLP , 5X, 6HP-PERP, 5X, * $6 H P-P A R A, 7 X, 4 H D L O B)$

1020 FORMAT ( 7 X , 4HRMID , 7X, 4HCURD, 6X, 5HMODB , 5X, 6HP-PERP, 5X,

* 6HP-PARA, 7X, 4HDLOB, 7X, 4HSI, 7X, 4HSIV)

1004 FORMAT (1H 1/1H , 4X, 6HRADIUS, 5X, 14HPPRIME+GAMMA*P, $2 X$,

* 13 HUPRIME-PPRIME

* , $1 \mathrm{X}, 14$ HUPRIML-FPRIME*, 4X, 11 HGENERALIZED, $3 \mathrm{X}, 10$ HBALLOONING

* $1 \mathrm{H}, 15 \mathrm{X}, 9 \mathrm{H} * \mathrm{UPRIME} / \mathrm{U}, 8 \mathrm{X}, 6 \mathrm{HU} * * 2 / \mathrm{I}, 7 \mathrm{X}, 15 \mathrm{HDL}$ OVER B-CUBED, $4 \mathrm{X}$,

* 11 HINTERCHANGE/)

C

CK SKIP DLOB CAL TO ELIMINATE USE OF PHI,PHIR,VR,VZ,RMID

GO TO 150

C CATC DLOB BDL DLOB 3

$\mathrm{C}$

$\mathrm{Cr}$

10 IF (ITER.IT.ITERMX) RETURN

CK

CW100DO $110 \quad I=1$, IMXT $\Gamma$

DO $110 \quad I=I M N T P$, IHXTP

$D I O B(I)=0$.

$B D L(I)=0$.

$D I O B 3(I)=0$.

$\mathrm{L}=\mathrm{I}-\mathrm{IMX}$

DO $110 \mathrm{~K}=1, \mathrm{KMXM1}$

$\mathrm{L}=\mathrm{L}+\mathrm{I} I \mathrm{IX}$

DUM $=\mathrm{CO} 2(\mathrm{~L})$
BATOO

BATOO

$B A 100$

BATOO

BATOO

BATOO

BATOO

BATOO

BATOO

BATOO

BATOO

BATOO

BATOO

BATOO

BATOO

BATOO

BATOO

BATO 0

BATOO

BATOO

BATO 0

BATOO

B $\triangle T 00$

В А ТО 0

BATOO

BATOO

BATOO

BATOO

BATOO

BATOO

BATOO

BATOO

BATOO

BATOO

B ATOO

B $\triangle T 00$

B ATO 0

B $\triangle$ TO

BATOO

BATOO

BATOO

BATOO

BATOO

BATOO

BAT 00

BATOO

B $\triangle \mathrm{T} 00$

BATOO

BATOO

BATOO

BATOO

BATOO

BATOO

BATOO

BATOO 
$\mathrm{C}$

CK.

$$
B A=\operatorname{COT}(\pi)
$$

$B A=B(I)$

CALI CALP(SI,SIV,STP, SIGMA, CO1,CO2, DTRM, CTRM, B, PHI, PHIR, VR, VZ,

* RMID)

PSAVE $(I)=P S C L$

PPSAVE $(I)=P S C L P$

$P E R=P E R P-P S C L$

$P A R=P A R A-P S C L$

$\operatorname{CJT}=-0.5 * \operatorname{SC} 13 * \operatorname{SC} 12(I) *(\operatorname{SI}(I+1)+\operatorname{SI}(I-1)-2 . * S I(I))+$

$1 \operatorname{SCg}(I) * \operatorname{SC} 12(1) *(S I(I+1)-S I(I-1))$

CK WRITE $(6,1002) \operatorname{SC6}(I), P S A V E(I), P P S A V E(I), P E R, P A R, D I O B(I)$ WRITE(, 1022$)$ SCG(I), CJT,BA, PER, PAR, DLOB(I), SI(I), SIV(I)

210 CONTINUE

CK SKIP SECOHD TABIE GO TO 220

C

C

C.

C

CK DO $220 \quad I=1$, IMXTP
BATOO

BATOO

BATOO

BATOO

BATOO

BATOO

BATOO

BATOO

BATOO

BAT 00

BATOO

BATOO

BATOO

BATOO

BATOO

BATOO

BATOO

BATOO

BATOO

BATOO

BATOO

BATOO

BATOO

BATOO

BATOO

BATOO

BATOO

BATOO

BATOO

BATOO

BATOO

BATOO

BATOO

BATOO

BATOO

BATก

BATOO

BATOO

BATOO

BATOO

B A T 00

BATOO

BATOO

BATOO

BATO 1

BATO 1

BATO 1

BATO 1

BATO 1

BATO 1

BATO 1

BATO 1

BATO 1

BATO 1

BATO 1 


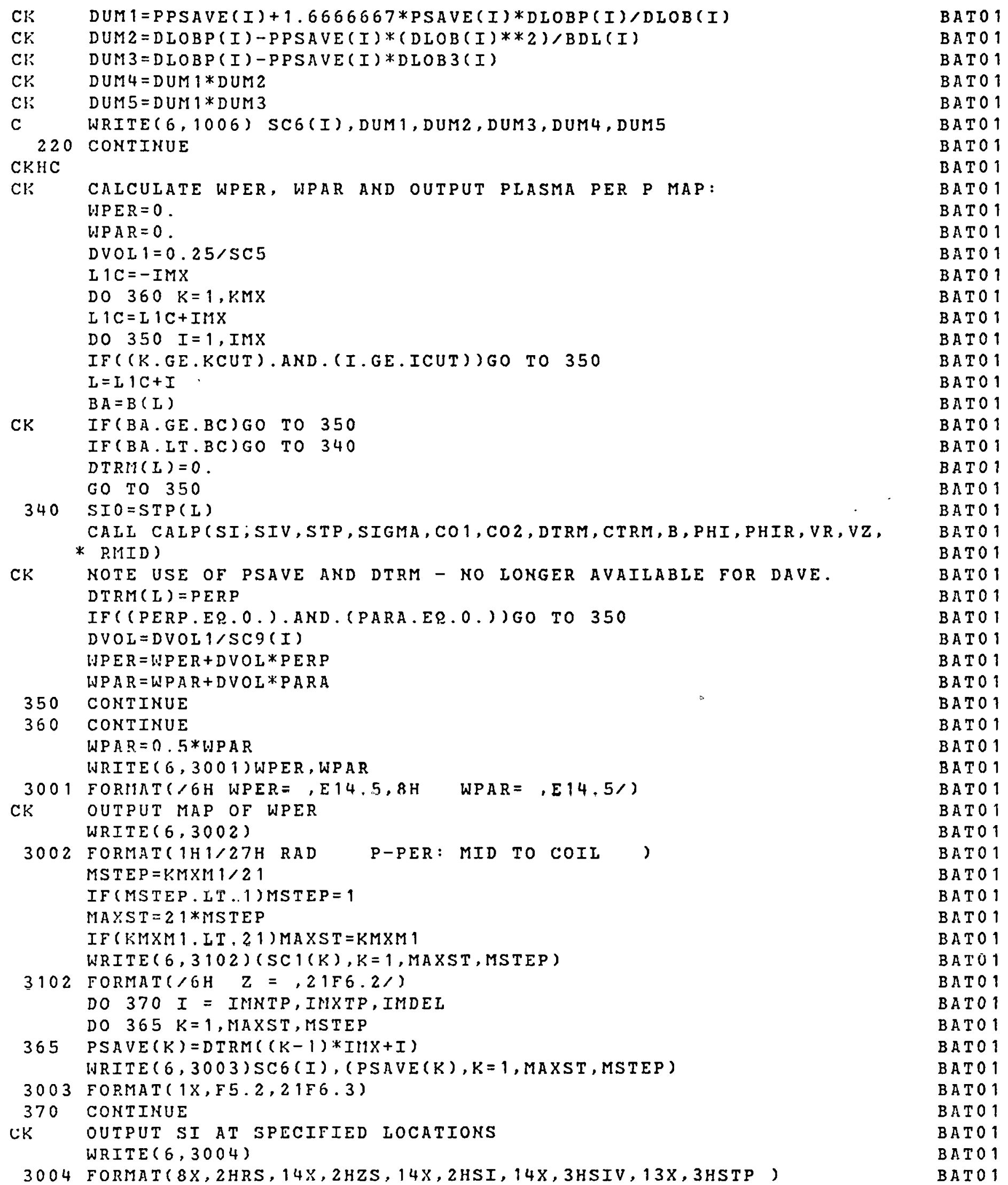




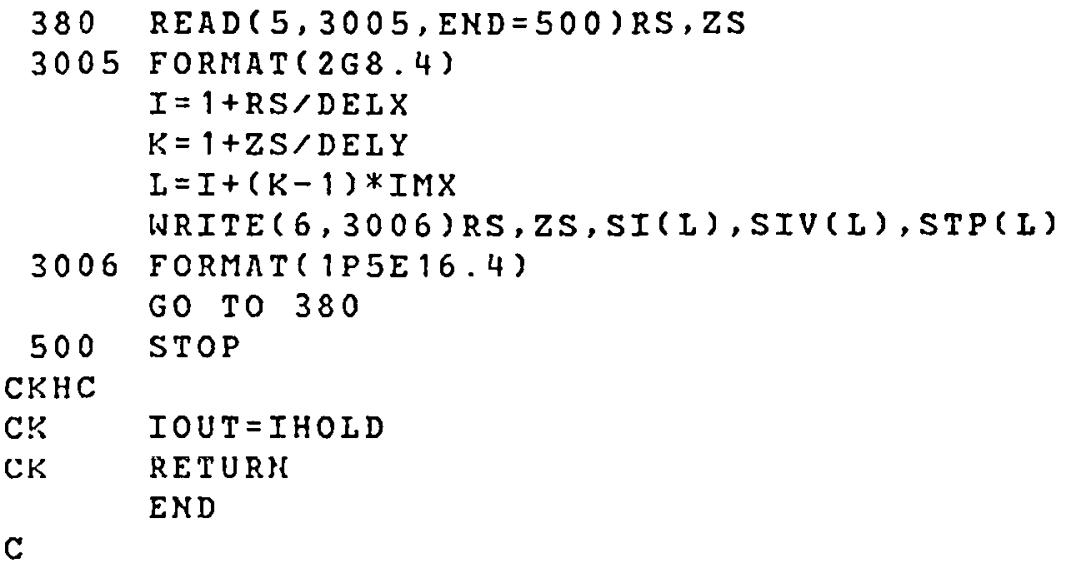

BATO 01

BATO 1

BATUT

BATO 01

ВАТ 01

BATOI

BATO 1

BATO 1

BATO ?

BATO

BATOI

BATO 1

BATO 1

BATO 1 


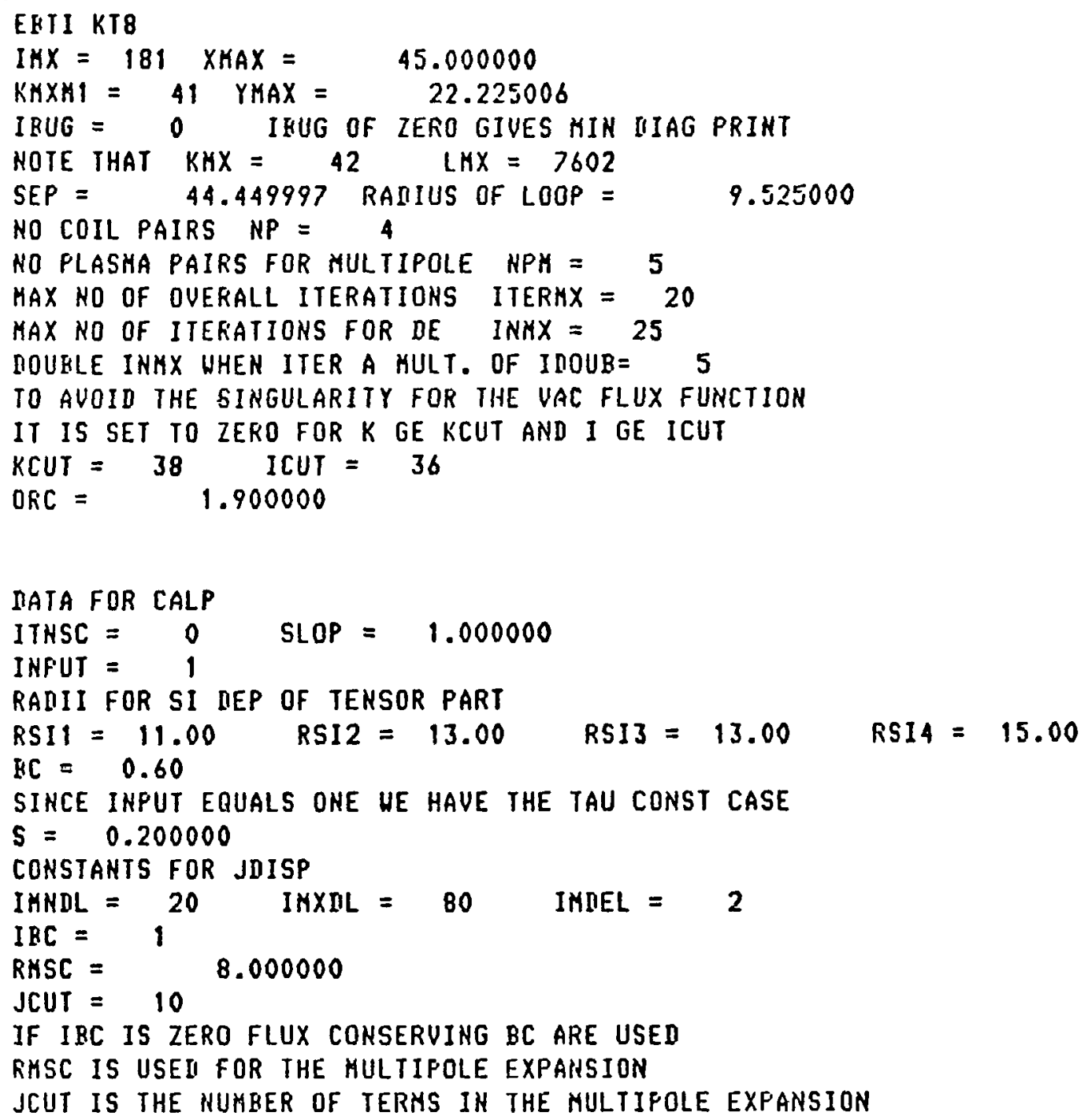

(Output from EQUIL for $2 \%$ "beta" case)

(on this and next 3 pages) 


\begin{tabular}{|c|c|c|c|c|c|}
\hline IER & $=$ & 0 & 8 & AT ORIGIN = & 0.10 \\
\hline$=$ & 1 & RES & $=$ & $0.167818 E-01$ & \\
\hline$=$ & 25 & RES & $=$ & $0.512126 E-02$ & \\
\hline ITER & $=$ & 1 & $B$ & AT ORIGIN = & $0.100012 E+0$ \\
\hline$M=$ & 1 & RES & $=$ & $0.948173 E-02$ & \\
\hline$=$ & 25 & RES & $=$ & $0.321801 E-02$ & \\
\hline ITER & $=$ & 2 & B & AT ORIGIN = & $0.100012 E+0$ \\
\hline$N=$ & 1 & RES & $=$ & 0.631 & \\
\hline$H=$ & 25 & RES & $=$ & $E-02$ & \\
\hline IJER & $=$ & 3 & B & AT OI & $0.100009 E+01$ \\
\hline$N=$ & 1 & RES & $=$ & 0.36 & \\
\hline $8=$ & 25 & RES & $=$ & $E-02$ & \\
\hline ITER & $=$ & 4 & B & $N=$ & $0.100008 E+0$ \\
\hline " & 1 & RES & $=$ & $E-02$ & \\
\hline- & 50 & RES & $=$ & $E-03$ & \\
\hline ITER & $=$ & 5 & B & AT OR & $0.100006 E+0$ \\
\hline$=$ & 1 & RES & $=$ & $E-02$ & \\
\hline$N=$ & 50 & RES & $=$ & $\varepsilon-03$ & \\
\hline ITER & $=$ & 6 & $B$ & AT of & $0.100008 E+01$ \\
\hline$M=$ & 1 & RES & $=$ & $E-03$ & \\
\hline$N=$ & 50 & RES & $=$ & $E-03$ & \\
\hline ITER & $=$ & 7 & B & AT of & $0.100009 E+0$ \\
\hline$N=$ & 1 & RES & $=$ & $E-03$ & \\
\hline$N=$ & 50 & RES & $=$ & $=-03$ & \\
\hline ITER & $=$ & 8 & B & AT 0 & $0.100010 E+0$ \\
\hline & 1 & RES & $=$ & $E-03$ & \\
\hline$N=$ & 50 & RES & $=$ & $E-03$ & \\
\hline ITER & $=$ & 9 & B & AT OR & $0.100011 E+0$ \\
\hline$y=$ & 1 & RES & $=$ & $E-03$ & \\
\hline$N=$ & 100 & RES & $=$ & $E-03$ & \\
\hline ITER & $=$ & 10 & B & AT ORIGIN = & $0.100012 E+0$ \\
\hline 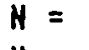 & 1 & RES & $=$ & $E-03$ & \\
\hline$N=$ & 100 & RES & - & $E-04$ & \\
\hline ITER & $=$ & 11 & B & AT OF & $13 E+0$ \\
\hline$=$ & 1 & RES & $=$ & $E-04$ & \\
\hline$N=$ & 100 & RES & $=$ & $E-04$ & \\
\hline $\begin{array}{l}\text { ITER } \\
N=\end{array}$ & $=1$ & $\begin{array}{l}12 \\
\text { RES }\end{array}$ & B & $\begin{array}{l}N= \\
E-04\end{array}$ & $0.100014 E+0$ \\
\hline $1=$ & 100 & RES & $=$ & $=-04$ & \\
\hline TER & $=$ & 13 & B & AT 0 & $0.100014 E+01$ \\
\hline & 1 & RE $\dot{S}$ & $=$ & $E-04$ & \\
\hline & 100 & RES & $=$ & $E-04$ & \\
\hline I TER & $=$ & 14 & B & AT & $0.100014 E+0$ \\
\hline & 1 & $\mathbf{R I}$ & $=$ & $=-04$ & \\
\hline & 200 & RES & $=$ & $E-04$ & \\
\hline I IER & $=$ & 15 & B & $N=$ & $0.100015 E+0$ \\
\hline & 1 & RES & $=$ & -04 & \\
\hline $1=$ & 200 & RES & $=$ & $\mid E-05$ & \\
\hline IIEK & $=$ & 16 & B & AT 0 & $0.100015 E 10$ \\
\hline & 1 & RES & $=$ & $E-04$ & \\
\hline$N=$ & 200 & RES & $=$ & $4\left[\begin{array}{ll}05 \\
0\end{array}\right.$ & \\
\hline ITER & $=$ & 17 & B & AT Of & 0 \\
\hline & 1 & $R E$ & $=$ & $\begin{array}{l}E-05 \\
E-05\end{array}$ & \\
\hline $\begin{array}{l}= \\
T E R\end{array}$ & 2 & 18 & $\mathrm{~B}$ & $I E-05$ & $0.100015 E+01$ \\
\hline & 1 & $R$ & $=$ & $E-05$ & \\
\hline$=$ & 200 & RES & . & $6 E-06$ & \\
\hline TER & & 19 & B & AT 0 & $0.100015 E+01$ \\
\hline & 1 & & 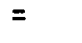 & $E-05$ & \\
\hline$=$ & 00 & RES & $=$ & $17566 E-06$ & \\
\hline
\end{tabular}


$0.475 E+01-0.599 E-04$

$0.500 E+01-0.660 E-04$

$0.525 E+01-0.730 E-04$

$0.550 E+01-0.804 E-04$

$0.575 E+01-0.890 E-04$

$0.600 E+01-0.983 E-04$

$0.625 E+01-0.109 E-03$

$0.650 E+01-0.121 E-03$

$0.675 E+01-0.134 E-03$

$0.700 E+01-0.149 E-03$

$0.725 E+01-0.166 E-03$

$0.750 E+01-0.185 E-03$

$0.775 E+01-0.207 E-03$

$0.800 E+01-0.231 E-03$

$0.825 E+01-0.260 E-03$

$0.850 E+01-0.292 E-03$

$0.875 E+01-0.329 E-03$

$0.900 E+01-0.371 E-03$

$0.925 E+01-0.420 E-03$

$0.950 E+01-0.476 E-03$

$0.975 E+01-0.540 E-03$

$0.100 E+02-0.614 E-03$

$0.103 E+02-0.700 E-03$

$0.105 E+02-0.798 E-03$

$0.108 E+02-0.910 E-03$

$0.110 E+02-0.104 E-02$

$0.113 E+02-0.118 E-02$

$0.115 E+02 \quad 0.335 E-03$

$0.118 E+02 \quad 0.453 E-02$

$0.120 E+02 \quad 0.951 E-02$

$0.123 E+02 \quad 0.137 E-01$

$0.125 E+02 \quad 0.169 E-01$

$0.128 E+02 \quad 0.163 E-01$

$0.130 E+02 \quad 0.115 E-01$

$0.133 E+02 \quad 0.520 E-02$

$0.135 E+02-0.228 E-02$

$0.138 E+02-0.108 E-01$

$0.140 E+02-0.175 E-01$

$0.143 E+02-0.205 E-01$

$0.145 E+02-0.189 E-01$

$0.148 E+02-0.115 E-01$

$0.150 E+02-0.100 E-02$

$0.153 E+02 \quad 0.177 E-02$

$0.155 E+02 \quad 0.140 E-02$

$0.158 E+02 \quad 0.116 E-02$

$0.160 E+02 \quad 0.987 E-03$

$0.163 E+02 \quad 0.851 E-03$

$0.165 E+02 \quad 0.742 E-03$

$0.168 E+02 \quad 0.650 E-03$

$0.170 E+02 \quad 0.573 E-03$

$0.173 E+02 \quad 0.507 E-03$

$0.175 E+02 \quad 0.451 E-03$

$0.178 E+02 \quad 0.402 E-03$

$0.160 E+02 \quad 0.360 E-03$

$0.183 E+02 \quad 0.322 E-03$

$0.185 E+02 \quad 0.290 E-03$

$0.188 E+02 \quad 0.261 E-03$

$0.190 E+02 \quad 0.236 E-03$

$0.193 E+02 \quad 0.214 E-03$

$0.195 E+02 \quad 0.195 E-03$

$0.198 E+02 \quad 0.177 E-03$
$0.916 E+00$

$0.907 E+00$

$0.898 E+00$

$0.888 E+00$

$0.878 E+00$

$0.869 E+00$

$0.848 E+00$

$0.837 E+00$

$0.826 E+00$

$0.815 E+00$

$0.803 E+00$

$0.791 E+00$

$0.779 E+00$

$0.767 E+00$

$0.755 E+00$

$0.742 E+00$

$0.730 E+00$

$0.718 E+00$

$0.705 E+00$

$0.692 E+00$

$0.679 E+00$

$0.667 E+00$

$0.654 E+00$

$0.641 E+00$

$0.629 E+00$

$0.616 E+00$

$0.603 E+00$

$0.589 E+00$

$0.574 E+00$

$0.559 E+00$

$0.543 E+00$

$0.524 E+00$

$0.509 E+00$

$0.495 E+00$

$0.482 E+00$

$0.471 E+00$

$0.462 E+00$

$0.455 E+00$

$0.449 E+00$

$0.441 E+00$

$0.430 E+00$

$0.419 E+00$

$0.407 E+00$

$0.396 E+00$

$0.385 E+00$

$0.374 E+00$

$0.364 E+00$

$0.353 E+00$

$0.343 E+00$

$0.332 E+00$

$0.322 E+00$

$0.313 E+00$

$0.303 E+00$

$0.294 E+00$

$0.285 E+00$

$0.277 E+00$

$0.2 \angle 8 E+00$

$0.259 E+00$

$0.251 E+00$

$0.243 E+00$
$0.858 E+00$
P-FEFIF P-FARA

0.0

0.0

0.0

0.0

0.0

0.0

0.0

0.0

0.0

0.0

0.0

0.0

0.0

0.0

0.0

0.0

0.0

0.0

0.0

0.0

0.0

0.0

0.0

0.0

0.0

0.0

0.0

0.0

$0.487 E-03$

$0.171 E-02$

$0.354 E-02$

$0.579 E-02$

$0.825 E-02$

$0.101 E-01$

$0.111 E-01$

$0.112 E-01$

$0.102 E-01$

$0.321 E-02$

$0.566 E-02$

$0.303 E-02$

$0.901 E-03$

0.0

0.0

0.0

0.0

0.0

0.0

0.0

0.0

0.0

0.0

0.0

0.0

0.0

0.0

0.0

0.0

0.0

0.0

0.0

0.0

0.0

0.0

0.0

0.0

0.0

0.0

0.0

0.0

0.0

0.0

0.0

0.0

0.0

0.0

0.0

0.0

0.0

0.0

0.0

0.0

0.0

0.0

0.0

0.0

0.0

0.0

$0.443 E-05$

$0.371 E-04$

$0.125 E-03$

$0.291 E-03$

$0.555 E-03$

$0.832 E-03$

$0.106 E-02$

$0.122 E-02$

$0.123 E-02$

$0.106 E-02$

$0.775 E-03$

$0.435 E-03$

$0.137 E-03$

0.0

0.0

0.0

0.0

0.0

0.0

0.0

0.0

0.0

0.0

0.0

0.0

0.0

0.0

0.0

0.0

0.0

0.0

0.0

0.0
$0.0 \quad 0.0 \quad-0.149 E-02$

0.0

0.0

0.0

0.0

0.0

0.0

0.0

0.0

0.0

0.0

0.0

0.0

0.0

0.0

0.0

0.0

0.0

0.0

0.0

0.0

0.0

0.0

0.0

0.0

0.0

0.0

0.0

0.0

0.0

0.0

0.0

0.0

0.0

0.0

0.0

0.0

0.0

0.0

0.0

0.0

0.0 
RAD P-DER: MID TO COIL

$Z=\begin{array}{llllllllllllllllllllll}0.0 & 0.56 & 1.11 & 1.67 & 2.22 & 2.78 & 3.33 & 3.89 & 4.45 & 5.00 & 5.56 & 6.11 & 6.67 & 7.22 & 7.78 & 8.33 & 8.89 & 9.45 & 10.00 & 10.56 & 11 .\end{array}$

$\begin{array}{llllllllllllllllllllll}4.75 & 0.0 & 0.0 & 0.0 & 0.0 & 0.0 & 0.0 & 0.0 & 0.0 & 0.0 & 0.0 & 0.0 & 0.0 & 0.0 & 0.0 & 0.0 & 0.0 & 0.0 & 0.0 & 0.0 & 0.0 & 0.0\end{array}$

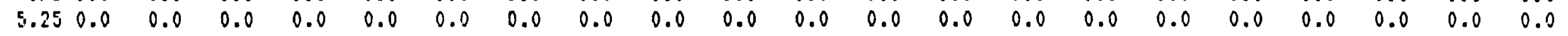

$\begin{array}{llllllllllllllllllllll}5.75 & 0.0 & 0.0 & 0.0 & 0.0 & 0.0 & 0.0 & 0.0 & 0.0 & 0.0 & 0.0 & 0.0 & 0.0 & 0.0 & 0.0 & 0.0 & 0.0 & 0.0 & 0.0 & 0.0 & 0.0 & 0.0\end{array}$

$\begin{array}{lllllllllllllllllllllll}0.25 & 0.0 & 0.0 & 0.0 & 0.0 & 0.0 & 0.0 & 0.0 & 0.0 & 0.0 & 0.0 & 0.0 & 0.0 & 0.0 & 0.0 & 0.0 & 0.0 & 0.0 & 0.0 & 0.0 & 0.0 & 0.0\end{array}$

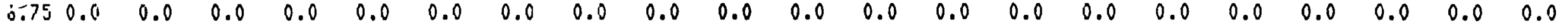

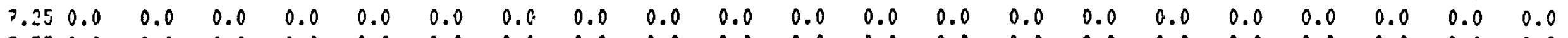

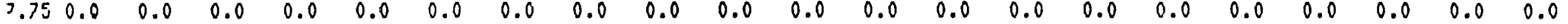

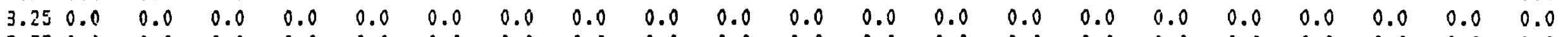

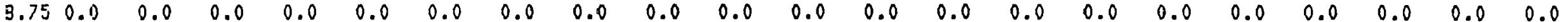

$\begin{array}{lllllllllllllllllllllll}9.25 & 0.1 & 0.0 & 0.0 & 0.0 & 0.0 & 0.0 & 0.0 & 0.0 & 0.0 & 0.0 & 0.0 & 0.0 & 0.0 & 0.0 & 0.0 & 0.0 & 0.0 & 0.0 & 0.0 & 0.0 & 0.0\end{array}$

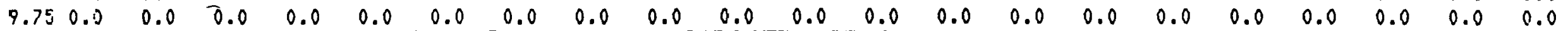

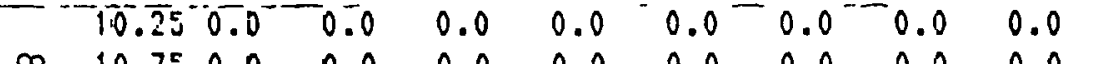

$\begin{array}{llllllllll}10.75 & 0.0 & 0.0 & 0.0 & 0.0 & 0.0 & 0.0 & 0.0 & 0.0 & 0.0 \\ 11.25 & 0.0 & 0.0 & 0.0 & 0.0 & 0.0 & 0.0 & 0.0 & 0.0 & 0.0\end{array}$

$\begin{array}{llllllllllll}0.0 & 0.0 & 0.0 & 0.0 & 0.0 & 0.0 & 0.0 & 0.0 & 0.0 & 0.0 & 0.0 & 0.0\end{array}$

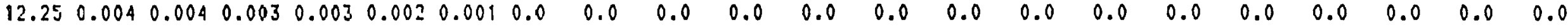

$\begin{array}{llllllllllllllllllllll}12.75 & 0.008 & 0.008 & 0.008 & 0.007 & 0.006 & 0.005 & 0.003 & 0.001 & 0.0 & 0.0 & 0.0 & 0.0 & 0.0 & 0.0 & 0.0 & 0.0 & 0.0 & 0.0 & 0.0 & 0.0 & 0.0\end{array}$

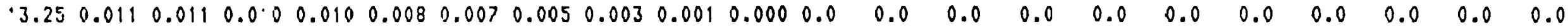

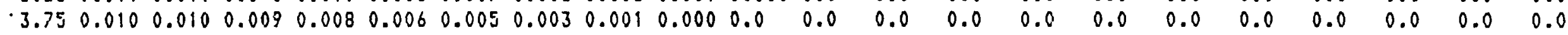

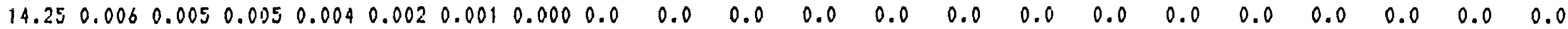

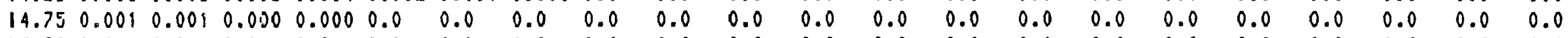

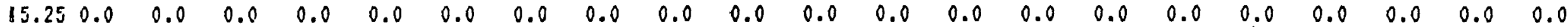

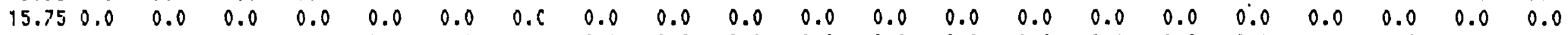

$\begin{array}{llllllllllllllllllllll}16.25 & 0.0 & 0.0 & 0.0 & 0.0 & 0.0 & 0.0 & 0.0 & 0.0 & 0.0 & 0.0 & 0.0 & 0.0 & 0.0 & 0.0 & 0.0 & 0.0 & 0.0 & 0.0 & 0.0 & 0.0 & 0.0\end{array}$

$\begin{array}{lllllllllllllllllllllll}16.75 & 0.0 & 0.0 & 0.0 & 0.0 & 0.0 & 0.0 & 0.0 & 0.0 & 0.0 & 0.0 & 0.0 & 0.0 & 0.0 & 0.0 & 0.0 & 0.0 & 0.0 & 0.0 & 0.0 & 0.0 & 0.0\end{array}$

$\begin{array}{llllllllllllllllllllll}17.25 & 0.0 & 0.0 & 0.0 & 0.0 & 0.0 & 0.0 & 0.0 & 0.0 & 0.0 & 0.0 & 0.0 & 0.0 & 0.0 & 0.0 & 0.0 & 0.0 & 0.0 & 0.0 & 0.0 & 0.0 & 0.0\end{array}$

$\begin{array}{llllllllllllllllllllll}17.75 & 0.0 & 0.0 & 0.0 & 0.0 & 0.0 & 0.0 & 0.0 & 0.0 & 0.0 & 0.0 & 0.0 & 0.0 & 0.0 & 0.0 & 0.0 & 0.0 & 0.0 & 0.0 & 0.0 & 0.0 & 0.0\end{array}$

$\begin{array}{lllllllllllllllllllllll}18.25 & 0.0 & 0.0 & 0.0 & 0.0 & 0.0 & 0.0 & 0.0 & 0.0 & 0.0 & 0.0 & 0.0 & 0.0 & 0.0 & 0.0 & 0.0 & 0.0 & 0.0 & 0.0 & 0.0 & 0.0 & 0.0\end{array}$

$\begin{array}{lllllllllllllllllllllll}18.75 & 0.0 & 0.0 & 0.0 & 0.0 & 0.0 & 0.0 & 0.0 & 0.0 & 0.0 & 0.0 & 0.0 & 0.0 & 0.0 & 0.0 & 0.0 & 0.0 & 0.0 & 0.0 & 0.0 & 0.0 & 0.0\end{array}$

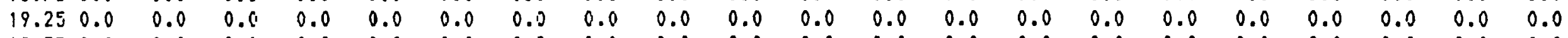

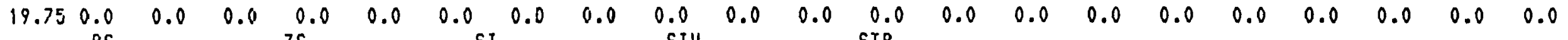

$\begin{array}{ccccc}R S & \text { ZS } & \text { SI } & \text { SIV } & \text { STP } \\ 2.8000 E+01 & 9.5000 E+00 & -9.5891 E-02 & 1.4291 E+02 & 1.4282 E+02\end{array}$

R; $T=802.58 / 812.35 \quad 11: 50: 37$ 
EBTI KT8

IHX $=181$ XHAX $=\quad 45.000000$

KHXHI $=41$ YHAX $=22.225006$

IRUG $=0$ IBUG OF ZERO GIVES MIN IIIAG FRINT

NOTE THAT KHX $=42 \quad$ LHX $=7602$

SEP $=\quad 44.449997$ RAIIUS OF LOOP $=9.525000$

NO COIL PAIRS NP $=4$

NO PLASHA FAIRS FOR YULTIFOLE KPH $=5$

MAX NO OF OVERALL ITERATIONS ITERHX $=20$

HAX NO OF ITERATIONS FOR IIE INHX $=25$

IOUBLE INHX WHEN ITER A MULT. OF IIOUE= 5

TO AVOID THE SINGULARITY FOR THE UAC FLUX FUNCTION

IT IS SET TO ZERO FOR $K$ GE KCUT AND I GE ICUT

KCUT $=38 \quad$ ICUT $=36$

ORC $=1.900000$

DATA FOR CALP

ITNSC $=0 \quad$ SLOP $=1.000000$

INPUT $=1$

RADII FOR SI DEP OF TENSOR PART

RSII $=11.00 \quad$ RSI2 $=12.00 \quad$ RSI3 $=14.00 \quad$ RSI4 $=15.00$

$\mathrm{BC}=0.75$

SINCE INPUT EQUALS ONE HE HAVE THE TAU CONST CASE

$S=0.200000$

CONSTANTS FOR JDISP

IMNDL $=20$ IMXIL $=80 \quad$ IHIEL $=2$

$I B C=1$

RHSC $=8.000000$

JCUT $=10$

IF IBC IS ZERO FLUX CONSERUING BC ARE USED

RHSC IS USED FOR THE MULTIFOLE EXPANSION

ICUT IS THE NUMBER OF TERMS IN THE MULTIPOLE EXPANSION

(Output from EQUIL for $8 \%$ "beta" case) 


\begin{tabular}{|c|c|c|c|c|c|}
\hline TE & $=$ & & B & ORIGIN = & $0.100012 E+01$ \\
\hline$N=$ & 1 & RES & $=$ & $0.110719 E+00$ & \\
\hline$=$ & 25 & RES & $=$ & $0.337880 E-01$ & \\
\hline TER & $=$ & 1 & B & AT ORIGIN = & $0.100012 E+01$ \\
\hline$=$ & 1 & RES & $=$ & $0.646567 E-01$ & \\
\hline$=$ & 25 & RES & $=$ & $0.218734 E-01$ & \\
\hline ITER & $=$ & 2 & B & AT ORIGIN = & $0.999994 E+00$ \\
\hline$N=$ & 1 & RES & $=$ & $0.454155 E-01$ & \\
\hline N & 25 & RES & $=$ & $0.169182 E-01$ & \\
\hline ITER & $=$ & 3 & B & AT ORIGIN = & $0.999836 E+00$ \\
\hline$N=$ & 1 & RES & $=$ & $0.274437 E-01$ & \\
\hline 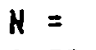 & 25 & RES & $=$ & 0.115 & \\
\hline ITER & $=$ & 4 & B & AT ORIGIN = & $0.999739 E+00$ \\
\hline$=$ & 1 & RES & $=$ & $0.171078 E-01$ & \\
\hline$=$ & 50 & RES & $=$ & $0.422405 E-02$ & \\
\hline I TER & $=$ & 5 & B & AT ORIGIN = & $0.999573 E+00$ \\
\hline & 1 & RES & $=$ & $0.102930 E-01$ & \\
\hline$=$ & 50 & RES & $=$ & 0.283 & \\
\hline ITER & $=$ & 6 & B & AT ORIGIN = & $0.999766 E+00$ \\
\hline & 1 & RES & 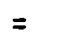 & 0.676 & \\
\hline & 50 & RES & $=$ & $=-02$ & \\
\hline ITER & $=$ & 7 & B & AT OR & $0.999984 E+00$ \\
\hline & 1 & RES & 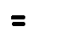 & $E-02$ & \\
\hline & 50 & RES & $=$ & -02 & \\
\hline ITER & $=$ & 8 & B & AT OF & $0.999966 E+00$ \\
\hline & 1 & RES & $=$ & -02 & \\
\hline$N=$ & 50 & RES & $=$ & $E-02$ & \\
\hline ITER & $=$ & 9 & B & AT ORIGIN = & $0.100002 E+0$ \\
\hline & 1 & RES & $=$ & $=-02$ & \\
\hline IER & 100 & RES & $=$ & 0.893 & \\
\hline TER & $=$ & 10 & B & AT OR & $0.100012 E+C$ \\
\hline & 1 & RES & $=$ & $:-02$ & \\
\hline & 100 & RES & $=$ & $E-03$ & \\
\hline TER & $=$ & 11 & B & AT of & $0.100018 E+01$ \\
\hline & 1 & RES & $=$ & -02 & \\
\hline & 100 & RES & $=$ & 0.43 & .1000 \\
\hline $\begin{array}{l}\text { ITER } \\
N=\end{array}$ & $=$ & 12 & $B$ & $\begin{array}{l}1 K= \\
8 E-03\end{array}$ & \\
\hline$N=$ & 100 & RES & $=$ & $E-03$ & \\
\hline ITER & $=$ & 13 & B & AT ORIC & $0.100025 E+0$ \\
\hline$N=$ & 1 & RES & $=$ & $=-03$ & \\
\hline$N=$ & 100 & RFS & & $E-03$ & \\
\hline ITER & $=$ & 14 & B & AT ORIGIN = & $0.100027 E+01$ \\
\hline & 1 & RES & $=$ & -03 & 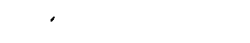 \\
\hline N & 200 & RES & & $E-03$ & \\
\hline ITER & $=$ & 15 & $B$ & AT $\underline{Q R}$ & $0.100030 E+01$ \\
\hline H & 1 & RES & $=$ & -03 & \\
\hline$N=$ & 200 & RES & $=$ & 0.550 & \\
\hline ITER & $=$ & 16 & B & AT OR & $0.100031 E+0$ \\
\hline 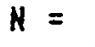 & 1 & RE & $=$ & -03 & \\
\hline N & 200 & RES & - & -04 & \\
\hline ITE & 1 & 17 & B & AT OR I & $0.100032 E+01$ \\
\hline$N=$ & $\begin{array}{r}1 \\
200\end{array}$ & $\begin{array}{l}\text { RES } \\
\text { RES }\end{array}$ & $=$ & $\begin{array}{l}52 E-03 \\
69 E-04\end{array}$ & \\
\hline ITER & $=$ & 18 & B & AT OF & $0.100032 E+01$ \\
\hline & 1 & RE & $=$ & & \\
\hline & 200 & RES & $=$ & 0.9672 & \\
\hline ITER & $=$ & 19 & B & AT OR & $0.100032 E+01$ \\
\hline & 1 & RE & $=$ & & \\
\hline$=$ & 0 & & $=$ & 05 & \\
\hline
\end{tabular}




\begin{tabular}{|c|c|c|c|c|c|c|c|}
\hline RHID & CURD & HODB & P-FEEFP & P-PARA & & IILOB & SIV \\
\hline $0.475 E+01$ & $-0.387 E-03$ & $0.915 E+00$ & 0.0 & 0.0 & 0.0 & $-0.106 E-01$ & $0.108 E+02$ \\
\hline $0.500 E+01$ & $-0.421 E-03$ & $0.906 E+00$ & 0.0 & 0.0 & 0.0 & $-0.112 E-01$ & $0.119 E+02$ \\
\hline $0.525 E+01$ & $-0.459 E-03$ & $0.897 E+00$ & 0.0 & 0.0 & 0.0 & $-0.117 E-01$ & $0.131 E+02$ \\
\hline $0.550 E+01$ & $-0.499 E-03$ & $0.887 E+00$ & 0.0 & 0.0 & 0.0 & $-0.121 E-01$ & $0.143 E+02$ \\
\hline $0.575 E+01$ & $-0.544 E-03$ & $0.878 E+00$ & 0.0 & 0.0 & 0.0 & $-0.123 E-01$ & $0.155 E+02$ \\
\hline $0.600 E+01$ & $-0.590 E-03$ & $0.869 E+00$ & 0.0 & 0.0 & 0.0 & $-0.123 E-01$ & $0.168 E+02$ \\
\hline $0.625 E+01$ & $-0.644 E-03$ & $0.858 E+00$ & 0.0 & 0.0 & 0.0 & $-0.121 E-01$ & $0.181 E+02$ \\
\hline $0.650 E+01$ & $-0.696 E-03$ & $0.848 E+00$ & 0.0 & 0.0 & 0.0 & $-0.116 E-01$ & $0.195 E+02$ \\
\hline $0.675 E+01$ & $-0.759 E-03$ & $0.837 E+00$ & 0.0 & 0.0 & 0.0 & $-0.108 E-01$ & $0.209 E+02$ \\
\hline $0.700 E+01$ & $-0.822 E-03$ & $0.826 E+00$ & 0.0 & 0.0 & 0.0 & $-0.964 E-02$ & $0.223 E+02$ \\
\hline $0.725 E+01$ & $-0.893 E-03$ & $0.815 E+00$ & 0.0 & 0.0 & 0.0 & $-0.808 E-02$ & $0.238 E+02$ \\
\hline $0.750 E+01$ & $-0.966 E-03$ & $0.804 E+00$ & 0.0 & 0.0 & 0.0 & $-0.606 \mathrm{E}-02$ & $0.252 E+02$ \\
\hline $0.775 E+01$ & $-0.105 E-02$ & $0.792 E+00$ & 0.0 & $0: 0$ & 0.0 & $-0.351 E-02$ & $0.268 E+02$ \\
\hline$E+01$ & $-0.114 E-02$ & $0.781 E+00$ & 0.0 & 0.0 & 0.0 & $-0.356 E-03$ & $83 E+02$ \\
\hline 01 & $-0.123 E-02$ & $0.769 E+00$ & 0.0 & 0.0 & 0.0 & $7 E-02$ & $99 E+02$ \\
\hline 01 & $3 E-02$ & $0.757 E+00$ & 0.0 & 0.0 & 0.0 & E-02 & $E+02$ \\
\hline+01 & -0 . & $E+00$ & 0.0 & 0.0 & 0.0 & $E-01$ & 02 \\
\hline$E+01$ & -0 . & $E+00$ & 0.0 & 0.0 & 0.0 & 01 & $E+02$ \\
\hline $925 E+01$ & $-0.168 E-02$ & $0.721 E+00$ & 0.0 & 0.0 & 0.0 & $0.274 E-01$ & $0.364 E+02$ \\
\hline+01 & $-0.181 E-02$ & $0.708 E+00$ & 0.0 & 0.0 & 0.0 & $0.361 E-01$ & $0.380 E+02$ \\
\hline$E+01$ & $-0.195 E-02$ & $0.696 E+00$. & 0.0 & 0.0 & 0.0 & $0.460 E-01$ & $0.397 E+02$ \\
\hline$E+02$ & $-0.209 E-02$ & $0.683 E+00$ & 0.0 & 0.0 & 0.0 & $0.575 E-01$ & $0.414 E+02$ \\
\hline $0.103 E+02$ & $-0.225 E-02$ & $0.671 E+00$ & 0.0 & 0.0 & 0.0 & $0.706 E-01$ & $0.431 E+02$ \\
\hline $0.105 E+02$ & $-0.239 E-02$ & $0.659 E+00$ & 0.0 & 0.0 & 0.0 & $0.854 E-01$ & $0.448 E+02$ \\
\hline+02 & $-0.255 E-02$ & $0.646 E+00$ & 0.0 & 0.0 & 0.0 & $2 E+00$ & $0.465 E+02$ \\
\hline+02 & $0.867 E-02$ & $0.632 E+00$ & 0.0 & 0.0 & 0.0 & $+\infty$ & $3 E+02$ \\
\hline+02 & $0.398 E-01$ & $0.613 E+00$ & $0.375 E-02$ & $0.376 E-03$. & 0.0 & $4 E+00$ & $0.500 E+02$ \\
\hline 0.11 & -01 & $=00$ & $0.126 E-01$ & $0.153 \mathrm{E}-02$ & 0.0 & $D E+00$ & $0.517 E+02$ \\
\hline+02 & -01 & 0.5 & $0.220 \mathrm{E}-01$ & -02 & 0.0 & 11 & 02 \\
\hline $\begin{array}{l}0.120 E+02 \\
0.123 E+02\end{array}$ & $\begin{array}{l}0.226 E-01 \\
0.128 E-01\end{array}$ & $\begin{array}{l}0.539 E+00 \\
0.522 E+00\end{array}$ & $\begin{array}{l}0.272 E-01 \\
0.290 E-01\end{array}$ & $\begin{array}{l}0.444 E-02 \\
0.518 E-02\end{array}$ & $\begin{array}{l}0.0 \\
0.0\end{array}$ & $\begin{array}{l}-0.354 E-01 \\
-0.151 E+00\end{array}$ & $\begin{array}{l}0.552 E+02 \\
0.569 E+02\end{array}$ \\
\hline $0.125 E+02$ & $0.139 E-01$ & $0.506 E+00$ & $0.306 \mathrm{E}-01$ & $0.594 E-02$ & 0.0 & $-0.279 E+00$ & $0.586 E+02$ \\
\hline+02 & $E-01$ & $0.489 E+00$ & $0.324 E-01$ & $0.683 E-02$ & 0.0 & $-0.421 E+00$ & $0.603 E+02$ \\
\hline $0.130 E+02$ & $0.138 E-01$ & $0.473 E+00$ & $0.339 E-01$ & $0.767 E-02$ & 0.0 & $-0.577 E+00$ & $0.620 E+02$ \\
\hline $0.133 E+02$ & $0.151 E-01$ & $0.458 E+00$ & $0.353 E-01$ & $0.852 E-02$ & 0.0 & $-0.747 E+00$ & $0.637 E+02$ \\
\hline$: 02$ & $0.169 E-01$ & $0.441 E+00$ & $0.368 E-01$ & $0.954 E-02$ & 0.0 & $3 E+00$ & $0.654 E+02$ \\
\hline $0.138 E+02$ & $0.150 \mathrm{E}-01$ & $0.424 E+00$ & $0.383 E-01$ & $0.106 E-01$ & 0.0 & $-0.114 E+01$ & $0.671 E+02$ \\
\hline+02 & $-0.640 E-02$ & $0.411 E+00$ & $0.394 E-01$ & $0.115 E-01$ & 0.0 & $E+01$ & $7 E+02$ \\
\hline 02 & $-0.726 E-01$ & 0.40 & $0.353 E-01$ & 0.104 & 0 . & 01 & 02 \\
\hline 02 & $-0.122 E+00$ & $0.42 i$ & $0.231 E-01$ & 0.64 & 0.0 & 01 & 02 \\
\hline 02 & -0 . & 0.4 & $0.801 \mathrm{E}-$ & 0.20 & 0. & & \\
\hline & & & 0.0 & 0. & 0. & 01 & $E+02$ \\
\hline 02 & & 0 & 0.0 & 0.0 & 0.0 & $-0.168 E+01$ & $0.769 E+02$ \\
\hline $0.155 E+02$ & $0.582 E-02$ & $0.418 E+00$ & 0.0 & 0.0 & 0.0 & $-0.162 E+01$ & $0.785 E+02$ \\
\hline $0.158 E+02$ & $0.474 E-02$ & $0.406 E+00$ & 0.0 & 0.0 & 0.0 & $-0.157 E+01$ & $0.800 E+02$ \\
\hline $0.160 E+02$ & $0.404 E-02$ & $0.394 E+00$ & 0.0 & 0.0 & 0.0 & $-0.153 E+01$ & $0.816 E+02$ \\
\hline 0.16 & $0.352 E-02$ & $0.382 \mathrm{E}+00$ & 0.0 & 0.0 & 0.0 & $-0.148 E+01$ & $0.831 E+02$ \\
\hline$: 02$ & $0.313 E-02$ & 0.371 & 0.0 & 0.0 & 0.0 & $-0.144 E+01$ & $0.846 E+02$ \\
\hline $0.168 E+02$ & $0.280 E-02$ & $0.359 E+00$ & 0.0 & 0.0 & 0.0 & $-0.141 E+01$ & $0.861 E+02$ \\
\hline+02 & $0.252 E-02$ & $0.349 E+00$ & 0.0 & 0.0 & 0. & $-0.137 E+01$ & $0.875 E+02$ \\
\hline $0.173 E+02$ & $.0 .227 E-02$ & $0.338 E+00$ & 0.0 & 0.0 & 0 . & $4 E+01$ & $0.890 E+02$ \\
\hline 0.17 & $0.206 E-02$ & $0.328 E+00$ & 0.0 & 0.0 & 0. & 01 & $4 E+02$ \\
\hline 02 & 0.18 & 0.3 & 0.0 & 0.0 & 0. & 11 & $=02$ \\
\hline 2 & 0 & 0.3 & 0.0 & 0.0 & 0 & 1 & \\
\hline 02 & 02 & 0.2 & 0.0 & 0.0 & 0.0 & +01 & $E+02$ \\
\hline 02 & $=-02$ & 0.28 & 0.0 & 0.0 & 0 & $20 E+01$ & $0.958 E+02$ \\
\hline 02 & 02 & $0.281 E+00$ & 0.0 & 0.0 & 0.0 & $-0.118 E+01$ & $0.971 E+02$ \\
\hline $0^{\circ} .190 E+02$ & $0.119 E-02$ & $0.272 E+00$ & 0.0 & 0.0 & 0.0 & $0.116 E+01$ & $0.984 E+02$ \\
\hline $0.193 E+02$ & $0.109 E-02$ & $0.263 E+00$ & 0.0 & 0.0 & 0.0 & $-0.114 E+01$ & $0.997 E+02$ \\
\hline 0.19 & $0.101 E-02$ & $0.254 E+00$ & 0.0 & 0.0 & 0.0 & $-0.112 E+01$ & $0.101 E+03$ \\
\hline $0.198 E+02$ & $0.925 E-03$ & $0.246 E+00$ & 0.0 & 0.0 & 0.0 & $-0.110 E+01$ & $0.102 E+03$ \\
\hline
\end{tabular}




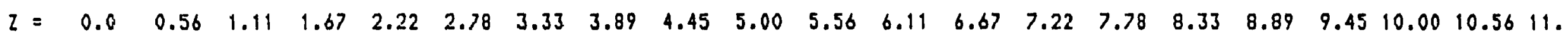

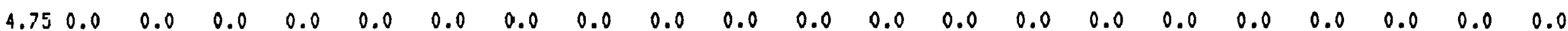

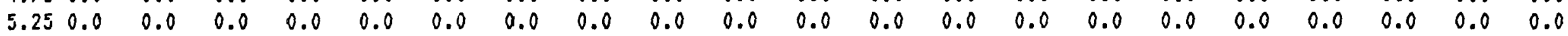

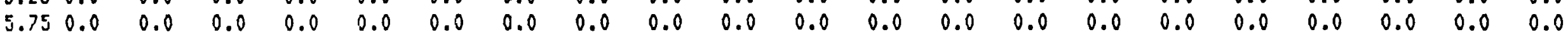

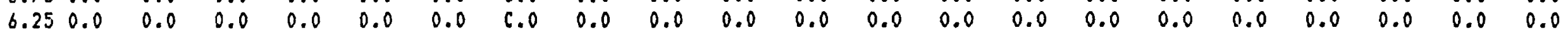
$\begin{array}{llllllllllllllllllllll}6.75 & 0.0 & 0.0 & 0.0 & 0.0 & 0.0 & 0.0 & 6.0 & 0.0 & 0.0 & 0.0 & 0.0 & 0.0 & 0.0 & 0.0 & 0.0 & 0.0 & 0.0 & 0.0 & 0.0 & 0.0 & 0.0\end{array}$

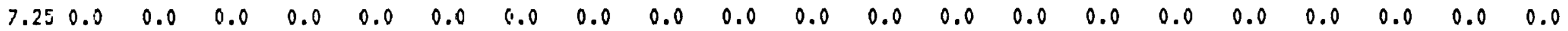

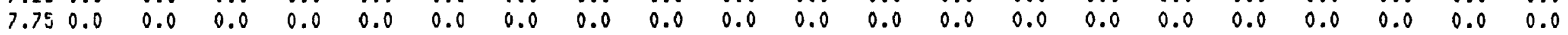
$\begin{array}{llllllllllllllllllllll}8.25 & 0.0 & 0.0 & 0.0 & 0.0 & 0.0 & 0.0 & 0.0 & 0.0 & 0.0 & 0.0 & 0.0 & 0.0 & 0.0 & 0.0 & 0.0 & 0.0 & 0.0 & 0.0 & 0.0 & 0.0 & 0.0\end{array}$

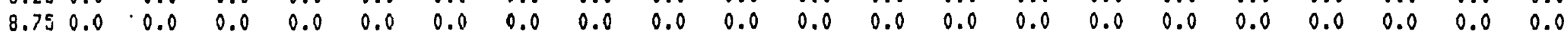

\section{$\begin{array}{lllll}2.8000 E+01 & 9.5000 E+00 & -6.8994 E-01 & 1.4291 E+02 & 1.4222 E+02\end{array}$}


EBTI $K T 8$

IHX $=181$ XHAX $=\quad 45.000000$

KHXHI $=41$ YMAX $=22.225006$

IBUG $=0$ IBUG OF ZERO GIVES MIN IIAG PRINT

NOTE THAT KHX $=42 \quad$ LMX $=7602$

SEP $=\quad 44.449997$ RAIIUS OF LOOP $=9.525000$

NO COIL PAIRS NP $=4$

NO PLASHA PAIRS FOR NULTIPOLE NPK $=\mathbf{5}$

HAX NO OF OUERALL ITERATIONS ITERMX $=20$

HAX NO OF ITEFATIONS FOR IIE INKX $=25$

IIOUHLE INHX WHEN ITER A KULT. OF IIIOUB $=5$

TO AVOIII THE SINGULARITY FOR THE VAC FLUX FUNCTION

IT IS SET TO ZERO FOR K GE KCUT AND I GE ICUT

KCUT $=38 \quad$ ICUT $=36$

ORC $=1.900000$

IATA FOR CALP

ITNSC $=0 \quad$ SLOP $=1.000000$

INPUT $=1$

RAIII FOR SI DEP OF TENSOR PART

RSI1 $=11.00 \quad$ RSI2 $=13.00 \quad$ RSI3 $=13.00 \quad$ RSI4 $=15.00$

$B C=0.60$

SINCE INPUT EQUALS ONE HE HAVE THE TAU CONST CASE

$S=0.800000$

CONSTANTS FOR IDISP

IHNBL $=20$ INXIL $=80 \quad$ INUEL $=2$

$I B C=1$

RHSC $=8.000000$

JCUT $=10$

IF IBC IS ZERO FLUX CONSERUING BC ARE USED

RHSC IS USEI FOR THE HULTIPOLE EXPANSION

JCUT IS THE NUMHER OF TERMS IN THE MULTIPOLE EXFANSION

(Output from EQUIL for 18\% "beta" case) 


\begin{tabular}{|c|c|c|c|c|c|}
\hline IIER & $=$ & 0 & B & AT ORIGIN = & $0.100012 E+01$ \\
\hline$N=$ & 1 & RES & $=$ & $0.657514 E-01$ & \\
\hline$H=$ & 25 & RES & $=$ & $0.200650 E-01$ & \\
\hline ITER & $=$ & 1 & B & AT ORIGIN = & $0.100012 E+01$ \\
\hline$N=$ & 1 & RES & $=$ & $0.493689 E-01$ & \\
\hline$N=$ & 25 & RES & $=$ & $0.163373 E-01$ & \\
\hline ITER & $=$ & 2 & B & AT ORIGIN $=$ & $0.100012 E+01$ \\
\hline$H=$ & 1 & RES & $=$ & $0.403318 E-01$ & \\
\hline$=$ & 25 & RES & $=$ & $0.143359 E-01$ & \\
\hline ITER & $=$ & 3 & B & AT ORIGIN = & $0.100000 E+01$ \\
\hline$N=$ & 1 & RES & $=$ & $0.312744 E-01$ & \\
\hline H & 25 & RES & $=$ & $0.125747 E-01$ & \\
\hline ITER & $=$ & 4 & $\mathrm{~g}$ & AT ORIGIN = & $0.999930 E+00$ \\
\hline $1=$ & 1 & RES & $=$ & $0.248373 E-01$ & \\
\hline$N=$ & 50 & RES & $=$ & $0.430526 \mathrm{E}-02$ & \\
\hline ITER & $=$ & 5 & B & AT ORIGIN = & $0.999789 E+00$ \\
\hline $\boldsymbol{N}$ & 1 & RES & $=$ & $9 E-01$ & \\
\hline$N=$ & 50 & RES & $=$ & $0.347072 E-02$ & \\
\hline IMER & $=$ & 6 & B & AI URIGIN = & $0.999903 E+00$ \\
\hline$N$ & 1 & RES & $=$ & $0.165749 E-01$ & \\
\hline$H=$ & 50 & RES & $=$ & $0.294961 E-02$ & \\
\hline ITER & $=$ & 7 & B & AT ORIGIN = & $0.999982 E+00$ \\
\hline$N$ & 1 & RES & $=$ & $0.137704 E-01$ & \\
\hline$N=$ & 50 & RES & $=$ & $0.253894 E-02$ & \\
\hline ITER & $=$ & 8 & B & AT ORIGIN = & $0.100004 E+01$ \\
\hline$=$ & 1 & RES & $=$ & $0.115135 \mathrm{E}-01$ & \\
\hline $\begin{array}{l}y=0 \\
N=0\end{array}$ & 50 & Res & $=$ & AT ORIGIN = & $0.100008 E+01$ \\
\hline$N=$ & 1 & RES & D & $0.970452 E-02$ & \\
\hline$K=$ & 100 & RES & $=$ & $0.107873 E-02$ & \\
\hline ITER & $=$ & 10 & B & AT ORIGIN = & $0.100016 E+01$ \\
\hline$N=$ & 1 & RES & $=$ & $0.794937 E-02$ & \\
\hline$N=$ & 100 & RES & $=$ & $0.798922 \mathrm{E}-03$ & \\
\hline ITER & $=$ & 11 & B & AT ORIGIN = & $0.100022 E+01$ \\
\hline$N=$ & 1 & RES & $=$ & 0.7450 & \\
\hline$N=$ & 100 & RES & $=$ & $0.615208 E-03$ & \\
\hline ITER & $=$ & 12 & B & AT ORIGIK = & $0.100027 E+01$ \\
\hline$=$ & 1 & RES & $=$ & $0.645208 E-02$ & \\
\hline$N=$ & 100 & RES & & $0.482136 E-03$ & \\
\hline ITER & $=$ & 13 & $B$ & AT ORIGIN = & $0.100030 E+01$ \\
\hline$N=$ & 1 & RES & $=$ & $0.557166 \mathrm{E}-02$ & \\
\hline$N=$ & 100 & RES & $=$ & $0.382962 \mathrm{E}-03$ & \\
\hline ITER & $=$ & 14 & B & AT ORIGIN = & $0.100033 E+01$ \\
\hline H & 1 & RES & $=$ & $0.481144 E-02$ & \\
\hline$=$ & 200 & RES & $=$ & 0.2026 & \\
\hline ITER & & 15 & B & AT ORIGIN = & $0.100037 E+01$ \\
\hline $\mathrm{N}$ & 1 & $R E$ & $=$ & -02 & \\
\hline$N=$ & 200 & RES & $=$ & $0.121323 E-03$ & \\
\hline ITER & $=$ & 16 & B & AT ORIGIN = & $0.100039 E+01$ \\
\hline$N=$ & 1 & RES & $=$ & $0.371663 E-02$ & \\
\hline$N=$ & 200 & RES & $=$ & $0.803160 E-04$ & \\
\hline I TER & $=$ & 17 & B & AT ORIGIN = & $0.100040 E+01$ \\
\hline$N=$ & 1 & RES & $=$ & $0.319615 E-02$ & \\
\hline$H=$ & 200 & RES & 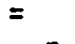 & $0.583668 E-04$ & \\
\hline ITER & & 18 & 8 & AT ORIGIN = & $0.100041 E+01$ \\
\hline$N$ & & RES & & 0.2736 & \\
\hline$N=$ & 200 & KES & $=$ & $0.4453 J 1 E-04$ & \\
\hline IIER & $=$ & 19 & B & AT URIGIN = & $0.100041 E+01$ \\
\hline$N=$ & 1 & RES & $=$ & $0.234167 \mathrm{E}-02$ & \\
\hline$N=$ & 400 & RES & $=$ & $0.175014 E-04$ & \\
\hline
\end{tabular}




\begin{tabular}{|c|c|c|c|c|c|c|c|}
\hline FiNID & CURD & MOHB & $P$ PEERP & POF'ARA & & IILOB & SIV \\
\hline $0.475 E+01$ & $-0.471 E-03$ & $0.915 E+00$ & 0.0 & 0.0 & 0.0 & $-0.167 E-01$ & $0.108 E+02$ \\
\hline $0.500 E+01$ & $-0.507 E-03$ & $0.906 E+00$ & 0.0 & 0.0 & 0.0 & $-0.179 E-01$ & $0.119 E+02$ \\
\hline $0.525 E+01$ & $-0.573 E-03$ & $0.897 E+00$ & 0.0 & 0.0 & 0.0 & $-0.190 E-01$ & $0.131 E+02$ \\
\hline $0.550 E+01$ & $-0.617 E-03$ & $0.887 E+00$ & 0.0 & 0.0 & 0.0 & $-0.199 E-01$ & $0.143 E+02$ \\
\hline $0.575 E+01$ & $-0.697 E-03$ & $0.878 E+00$ & 0.0 & 0.0 & 0.0 & $-0.206 E-01$ & $0.155 E+02$ \\
\hline $0.600 E+01$ & $-0.754 E-03$ & $0.869 E+00$ & 0.0 & 0.0 & 0.0 & $-0.211 E-01$ & $0.168 E+02$ \\
\hline $0.625 E+01$ & $-0.850 E-03$ & $0.858 E+00$ & 0.0 & 0.0 & 0.0 & $-0.214 E-01$ & $0.181 E+02$ \\
\hline $.650 E+01$ & $-0.922 E-03$ & $0.848 E+00$ & 0.0 & 0.0 & 0.0 & $-0.213 E-01$ & $0.195 E+02$ \\
\hline $675 E+01$ & $-0.104 E-02$ & $0.837 E+00$ & 0.0 & 0.0 & 0.0 & $-0.208 E-01$ & $0.209 E+02$ \\
\hline $00 E+01$ & $-0.113 E-02$ & $0.826 E+00$ & 0.0 & 0.0 & 0.0 & $-0.199 E-01$ & $0.223 E+02$ \\
\hline $5 E+01$ & $-0.128 E-02$ & $0.815 E+00$ & 0.0 & 0.0 & 0.0 & $-0.184 E-01$ & $0.238 E+02$ \\
\hline $0 E+01$ & $-0.140 E-02$ & $0.804 E+00$ & 0.0 & 0.0 & 0.0 & $-0.163 E-01$ & +02 \\
\hline$E+01$ & $8 E-02$ & $3 E+00$ & 0.0 & 0.0 & 0 & -0 & +02 \\
\hline 01 & $E-02$ & 0. & 0.0 & 0.0 & 0 & 2 & $E+02$ \\
\hline$E+01$ & $6 E-02$ & $0.769 E+00$ & 0.0 & 0.0 & 0.0 & $-0.500 E-02$ & $0.299 E+02$ \\
\hline$E+01$ & $-0.216 E-02$ & $0.758 E+00$ & 0.0 & 0.0 & 0.0 & $0.896 E-03$ & $0.315 E+02$ \\
\hline$E+01$ & $-0.244 E-02$ & $0.746 E+00$ & 0.0 & 0.0 & 0.0 & $0.813 E-02$ & $0.331 E+02$ \\
\hline $0.900 E+01$ & $-0.271 E-02$ & $0.734 E+00$ & 0.0 & 0.0 & 0.0 & $0.169 E-01$ & $0.347 E+02$ \\
\hline $0.925 E+01$ & $-0.306 E-02$ & $0.722 E+00$ & 0.0 & 0.0 & 0.0 & $0.275 E-01$ & $0.364 E+02$ \\
\hline $0.950 E+01$ & $-0.340 E-02$ & $0.710 E+00$ & 0.0 & 0.0 & 0.0 & $0.402 E-01$ & $0.380 E+02$ \\
\hline $0.975 E+01$ & $-0.384 E-02$ & $0.698 E+00$ & 0.0 & 0.0 & 0.0 & $0.553 E-01$ & $0.397 E+02$ \\
\hline $0.100 E+02$ & $-0.428 E-02$ & $0.686 E+00$ & 0.0 & 0.0 & 0.0 & $0.731 E-01$ & $0.414 E+02$ \\
\hline $0.103 E+02$ & $-0.482 E-02$ & $0.675 E+00$ & 0.0 & 0.0 & 0.0 & $0.941 E-01$ & $0.431 E+02$ \\
\hline $0.105 E+02$ & $-0.537 E-02$ & $0.663 E+00$ & 0.0 & 0.0 & 0.0 & $0.119 E+00$ & $0.448 E+02$ \\
\hline$E+02$ & $E-02$ & $0.651 E+00$ & 0.0 & 0.0 & 0.0 & $0.147 E+00$ & $0.465 E+02$ \\
\hline$E+02$ & $-0.670 E-02$ & $0.640 E+00$ & 0.0 & 0.0 & 0. & $1 E+00$ & $E+02$ \\
\hline 0.11 & $E-02$ & $E+00$ & 0.0 & 0.0 & 0. & 0 & $E+02$ \\
\hline+02 & $E-02$ & +00 & 0.0 & 0.0 & 0. & $=+\infty$ & $0.517 E+02$ \\
\hline+02 & $E-02$ & $0.604 E+00$ & 0.0 & 0.0 & 0.0 & $0.317 E+00$ & $0.534 E+02$ \\
\hline $0.120 E+02$ & $0.642 E-01$ & $0.582 E+00$ & $0.525 E-02$ & $0.797 \mathrm{E}-04$ & 0.0 & $0.364 E+00$ & $0.552 E+02$ \\
\hline $0.123 E+02$ & $0.138 E+00$ & $0.544 E+00$ & $0.202 E-01$ & $0.986 E-03$ & 0.0 & $0.362 E+00$ & $0.569 E+02$ \\
\hline $0.125 E+02$ & $0.188 E+00$ & $0.491 E+00$ & $0.436 E-01$ & $0.436 \mathrm{E}-02$ & 0.0 & $0.254 E+00$ & $0.586 E+02$ \\
\hline $0.128 E+02$ & $0.170 E+00$ & $0.432 E+00$ & $0.680 E-01$ & $0.111 E-01$ & 0.0 & $-0.402 E-02$ & $0.603 E+02$ \\
\hline $0.130 E+02$ & $0.961 E-01$ & $0.387 E+00$ & $0.842 E-01$ & $0.182 E-01$ & 0.0 & $-0.404 E+00$ & $0.620 E+02$ \\
\hline $0.133 E+02$ & $0.662 E-02$ & $0.363 E+00$ & $0.893 E-01$ & $0.220 E-01$ & 0.0 & $-0.891 E+00$ & $0.637 E+02$ \\
\hline $0.135 E+02$ & $-0.761 E-01$ & $0.359 E+00$ & $0.845 E-01$ & $0.213 E-01$ & 0.0 & $-0.139 E+01$ & $0.654 E+02$ \\
\hline $0.138 E+02$ & $-0.140 F_{.}+00$ & $0.373 E+00$ & $0.714 E-01$ & $0,167 \mathrm{E}-01$ & 0.0 & $-0.184 E+01$ & $0.671 E+02$ \\
\hline$E+02$ & -0.16 & $0.399 E+00$ & $0.526 E-01$ & $0.106 E-01$ & 0. & $-0.217 E+01$ & $0.687 E+02$ \\
\hline+02 & $=+00$ & $:+00$ & $0.329 E-01$ & 0.550 & 0 . & $B E+01$ & 0. \\
\hline+02 & -0.1 & $+\infty 0$ & $0.161 \mathrm{E}$ & 0.230 & 0 . & $E+01$ & 0. \\
\hline 0.1 & -0 . & $0.2 x-1$ & 0.4 & 0.61 & 0 . & $E+01$ & $0.737 E+02$ \\
\hline $0.150 E+02$ & $-0.827 E-03$ & $0.453 E+00$ & 0.0 & 0.0 & 0.0 & $-0.227 E+01$ & $0.753 E+02$ \\
\hline $0.153 E+02$ & $0.126 \mathrm{E}-01$ & $0.441 E+00$ & 0.0 & 0.0 & 0.0 & $-0.216 E+01$ & $0.769 E+02$ \\
\hline $0.155 E+02$ & $0.103 E-01$ & $0.426 E+00$ & 0.0 & 0.0 & 0.0 & $-0.209 E+01$ & $0.785 E+02$ \\
\hline $0.158 \mathrm{E}+02$ & $0.858 E-02$ & $0.413 E+00$ & 0.0 & 0.0 & 0.0 & $-0.201 E+01$ & $0.800 E+02$ \\
\hline $0.160 E+02$ & $0.738 E-02$ & $0.400 E+00$ & 0.0 & 0.0 & 0.0 & $-0.193 E+01$ & $0.816 E+02$ \\
\hline $0.163 E+02$ & $0.637 E-02$ & $0.388 E+00$ & 0.0 & 0.0 & 0.0 & $-0.187 E+01$ & $0.831 E+02$ \\
\hline $0.165 E+02$ & $0.560 E-02$ & $0.376 E+00$ & 0.0 & 0.0 & 0.0 & $-0.181 E+01$ & $0.846 E+02$ \\
\hline $0.168 E+02$ & $0.489 E-02$ & $0.364 E+00$ & 0.0 & 0.0 & 0.0 & $-0.175 E+01$ & $0.861 E+02$ \\
\hline $0.170 E+02$ & $0.436 \mathrm{E}-02$ & $0.353 E+00$ & 0.0 & 0.0 & 0.0 & $-0.170 E+01$ & $0.875 E+02$ \\
\hline 0.17 & $0.383 F-02$ & $0.342 E+00$ & 0.0 & 0.0 & 0.0 & $-0.165 E+01$ & $0.890 E+02$ \\
\hline 0.17 & $E-02$ & $E+00$ & 0.0 & 0.0 & 0. & $E+01$ & 0. \\
\hline 12 & 0.1 & 00 & 0.0 & 0.0 & $0.1-3$ & 1 & $E+02$ \\
\hline 0.1 & $=-02$ & $+\infty 0$ & 0.0 & 0.0 & 0. & $-0.152 E+01$ & $0.931 E+02$ \\
\hline $0.183 E+02$ & $0.244 E-02$ & $0.301 E+00$ & 0.0 & 0.0 & 0.0 & $-0.149 E+01$ & $0.945 E+02$ \\
\hline $0.185 E+02$ & $0.224 E-02$ & $0.291 E+00$ & 0.0 & 0.0 & 0.0 & $-0.145 E+01$ & $0.958 E+02$ \\
\hline $0.188 E+02$ & $0.199 E-02$ & $0.283 E+00$ & 0.0 & 0.0 & 0.0 & $-0.142 E+01$ & $0.971 E+02$ \\
\hline $0.190 E+02$ & $0.183 E-02$ & $0.273 E+00$ & 0.0 & 0.0 & 0.0 & $-0.139 E+01$ & $0.984 E+02$ \\
\hline $0.193 E+02$ & $0.163 E-02$ & $0.264 E+00$ & 0.0 & 0.0 & 0.0 & $-0.137 E+01$ & $0.997 E+02$ \\
\hline $0.195 E+02$ & $0.152 E-02$ & $0.256 E+00$ & 0.0 & 0.0 & 0.0 & $-0.134 E+01$ & $0.101 E+03$ \\
\hline $0.198 E+02$ & $0.135 E-02$ & $0.247 E+00$ & 0.0 & 0.0 & 0.0 & $-0.131 E+01$ & $0.102 E+03$ \\
\hline
\end{tabular}


RAD

P-PER: MID TO COIL

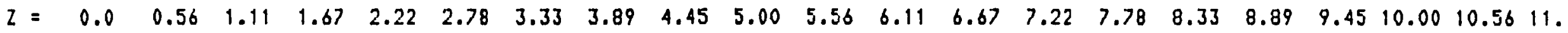

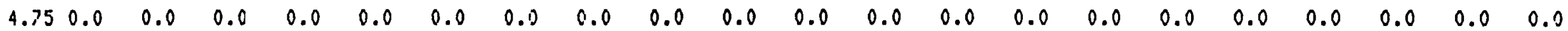

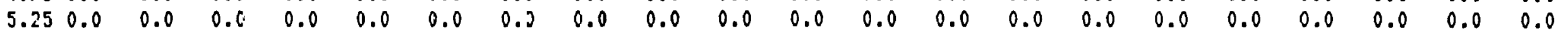

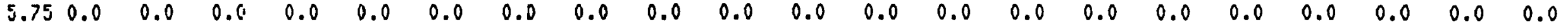

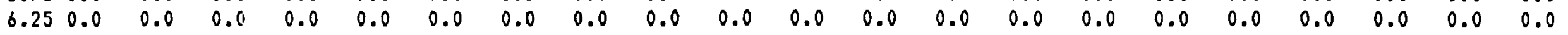

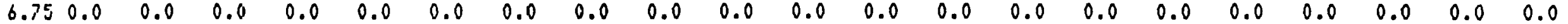

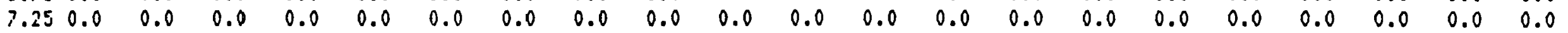

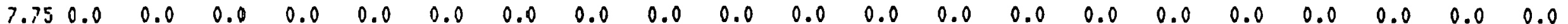

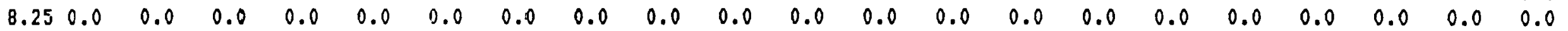

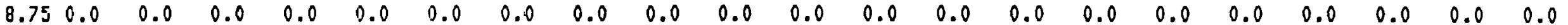

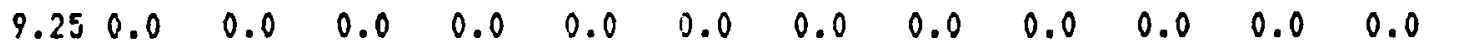

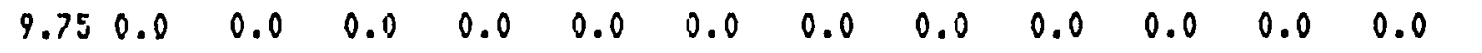

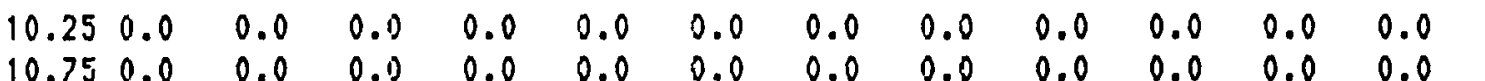

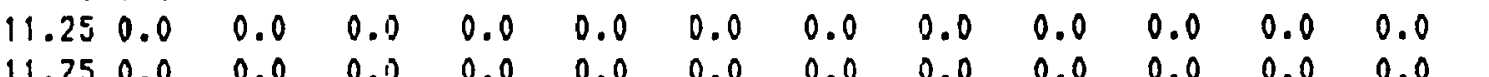

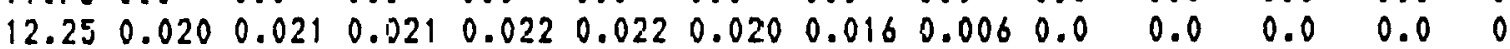

$\begin{array}{llllllllllllllllll}12.75 & 0.068 & 0.067 & 0.067 & 0.066 & 0.062 & 0.055 & 0.041 & 0.024 & 0.007 & 0.0 & 0.0 & 0.0 & 0.0\end{array}$

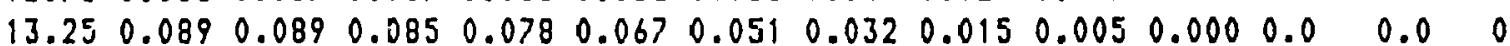

$\begin{array}{llllllllllllll}13.75 & 0.071 & 0.069 & 0.063 & 0.053 & 0.039 & 0.024 & 0.011 & 0.003 & 0.000 & 0.0 & 0.0 & 0.0\end{array}$

$\begin{array}{llllllllllllllll}14.25 & 0.033 & 0.031 & 0.026 & 0.018 & 0.010 & 0.004 & 0.000 & 0.0 & 0.0 & 0.0 & 0.0\end{array}$

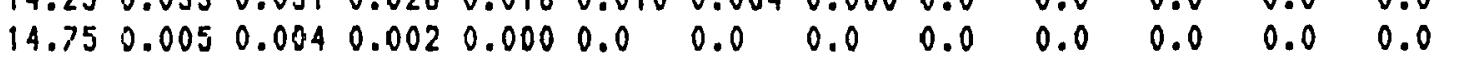

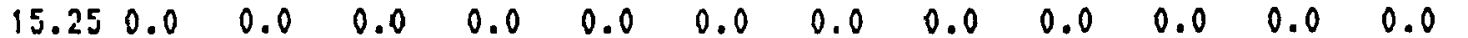

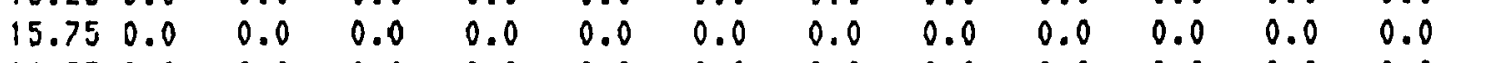

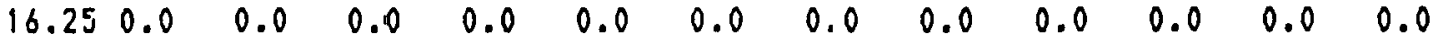

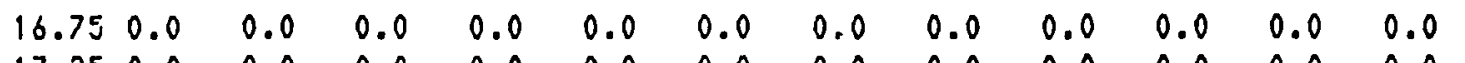

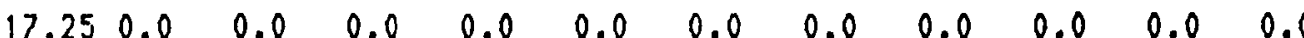

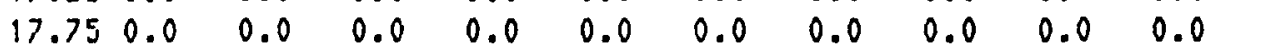

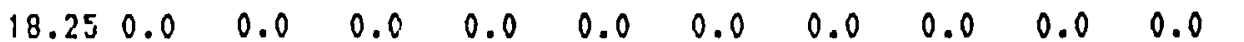

$\begin{array}{lllllllll}0.0 & 0.0 & 0.0 & 0.0 & 0.0 & 0.0 & 0.0 & 0.0 & 0.0\end{array}$

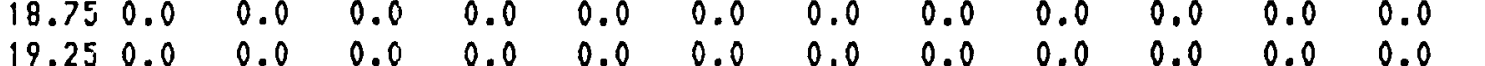

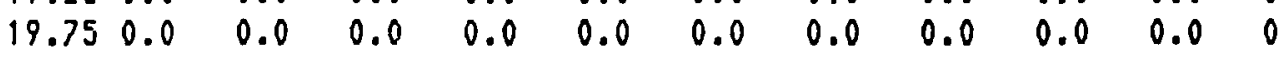

RS

$2.8000 E+0$ 25

$9.5000 E+00$ S I

$-7.8596 E-01$
SIV

1. $4291 E+02$ $\begin{array}{llll}0.0 & 0.0 & 0.0 & 0.0\end{array}$

0.0

0.0

0.0

0.0
0.0

0.0

0.0

0.0
0.0

0.0

0.0

0.0

0.0

0.0

0.0

0.0

0.0

0.0

0.0

0.0 STP

$1.4213 E+02$

$R ; T=798.82 / 811.35 \quad 17: 40: 40$ 


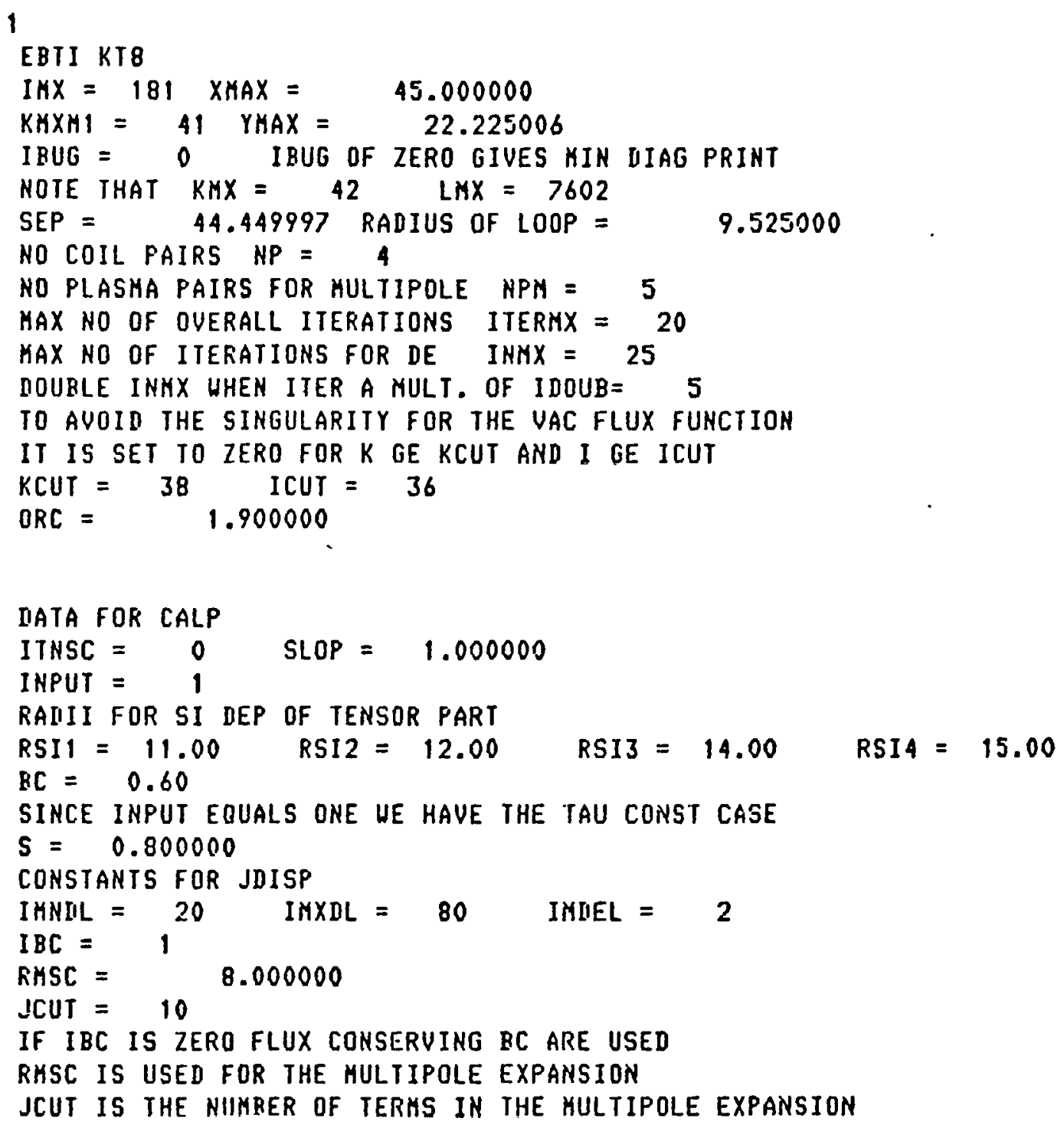

(Output from EQUIL for $23 \%$ "beta" case) 


\begin{tabular}{|c|c|c|c|c|c|}
\hline I TER & $=$ & 0 & B & AT ORIGIN & $2 E+C$ \\
\hline$N=$ & 1 & RES & $=$ & $0.874668 E-01$ & \\
\hline$=$ & 25 & RES & $=$ & $0.266914 E-01$ & \\
\hline TER & $=$ & 1 & B & AT ORIGIN = & $0.100012 E+01$ \\
\hline$=$ & 1 & RES & $=$ & $0.734369 E-01$ & \\
\hline$=$ & 25 & RES & $=$ & $16 E-01$ & \\
\hline ITER & $=$ & 2 & B & AT OR & $0.100011 E+01$ \\
\hline$=$ & 1 & RES & $=$ & 0.63 & \\
\hline & 25 & RES & & 0.222 & \\
\hline ITER & $=$ & 3 & B & AT OR & $0.999948 E+00$ \\
\hline & 1 & RES & $=$ & 0.527 & \\
\hline & 25 & RES & $=$ & 0.195 & \\
\hline ITER & $=$ & 4 & B & AT OR & $0.999831 E+00$ \\
\hline & 1 & RES & $=$ & 0.44 & \\
\hline & 50 & RES & $=$ & 0.64 & \\
\hline ITER & $=$ & 5 & B & AT 0 & $0.999589 E+00$ \\
\hline$=$ & 1 & RES & $=$ & 0. & \\
\hline$=$ & 50 & RES & $=$ & 0.5 & \\
\hline ITER & $=$ & 6 & B & AT 0 & $0.999746 E+00$ \\
\hline & 1 & RES & $=$ & 0.17 & \\
\hline & 50 & RES & $=$ & 0.450 & \\
\hline TER & $=$ & 7 & B & AT OR & $0.999857 E+00$ \\
\hline & 1 & RES & $=$ & 0.21 & \\
\hline & 50 & RES & & 0.39 & \\
\hline ITER & $=$ & 8 & $B$ & AT Of & $0.999908 E+00$ \\
\hline & 1 & RES & $=$ & 0.2 & \\
\hline & 50 & RES & $=$ & 0.3 & \\
\hline I TER & $=$ & 9 & $\mathrm{~B}$ & AT & $0.999948 E+00$ \\
\hline & 1 & KESS & $=$ & 0 & \\
\hline$=$ & 100 & RES & $=$ & 0.163 & \\
\hline TER & $=$ & 10 & $B$ & AT 0 & $0.100004 E+01$ \\
\hline & 1 & RES & $=$ & & \\
\hline & 100 & RES & $=$ & 0.1 & \\
\hline TER & $=$ & 11 & B & AT 0 & 0. \\
\hline & 100 & $\begin{array}{l}\text { RES } \\
\text { RES }\end{array}$ & $\begin{array}{l}= \\
=\end{array}$ & & \\
\hline TER & $=$ & 12 & B & AT ORIGIN = & $0.100018 E+01$ \\
\hline & 1 & RES & $=$ & 0.1 & \\
\hline$=$ & 100 & RES & $=$ & 0.8 & \\
\hline TER & $=$ & 13 & B & AT 0 & $0.100025 E+01$ \\
\hline & 1 & RES & $=$ & & \\
\hline$=$ & 100 & RES & $=$ & 0.69 & \\
\hline TER & $=$ & 14 & B & AT of & $0.100030 E+0$ \\
\hline & 1 & PES & $=$ & & \\
\hline$=$ & 200 & RES & $=$ & 3 & \\
\hline TER & $=$ & 15 & B & AT 0 & $0.100039 E+01$ \\
\hline & 1 & $\mathrm{RL}$ & . & & \\
\hline$=$ & 200 & RES & - & 0.2 & \\
\hline TER & $=$ & 16 & B & AT 0 & $0.100044 E+01$ \\
\hline$=$ & 1 & RE & - & & \\
\hline$=$ & 200 & $R E$ & 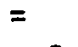 & 0 & \\
\hline JER & $=1$ & $\begin{array}{l}17 \\
\text { RES }\end{array}$ & B & AT 0 & 0. \\
\hline$y=$ & 200 & RES & $\overline{ }$ & -03 & \\
\hline TER & & 18 & $B$ & & $0.100049 E+01$ \\
\hline & 1 & $\mathrm{RE}$ & & & \\
\hline & 200 & RES & - & 0.1 & \\
\hline TE & & 19 & B & AT ORI & $0.100051 E$ \\
\hline & 100 & & & & \\
\hline & 400 & & & 4 & \\
\hline
\end{tabular}




\begin{tabular}{|c|c|c|c|c|c|}
\hline RHID & CURD & MODB & P-PERP & P-PARA & \\
\hline $0.475 E+01$ & $-0.717 E-03$ & $0.914 E+00$ & 0.0 & 0.0 & 0.0 \\
\hline $500 E+01$ & $-0.747 E-03$ & $0.906 E+00$ & 0.0 & 0.0 & 0.0 \\
\hline $525 E+01$ & $-0.864 E-03$ & $0.897 E+00$ & 0.0 & 0.0 & 0.0 \\
\hline $550 E+01$ & $-0.904 E-03$ & $0.887 E+00$ & 0.0 & 0.0 & 0.0 \\
\hline $.575 E+01$ & $-0.104 E-02$ & $0.878 E+00$ & 0.0 & 0.0 & 0.0 \\
\hline $600 E+01$ & $-0.110 E-02$ & $0.869 E+00$ & 0.0 & 0.0 & 0.0 \\
\hline $625 E+01$ & $-0.126 E-02$ & $0.858 E+00$ & 0.0 & 0.0 & 0.0 \\
\hline $650 E+01$ & $E-02$ & $0.848 E+00$ & 0.0 & 0.0 & 0.0 \\
\hline $675 E+01$ & $-0.152 E-02$ & 0.8378 & 0.0 & 0.0 & 0.0 \\
\hline $700 E+01$ & $-0.162 E-02$ & $0.827 E+00$ & 0.0 & 0.0 & 0.0 \\
\hline $0.725 E+01$ & $-0.184 E-02$ & $0.816 E+00$ & 0.0 & 0.0 & 0.0 \\
\hline $0.750 E+01$ & $-0.198 E-02$ & $0.805 E+00$ & 0.0 & 0.0 & 0.0 \\
\hline $775 E+01$ & $-0.225 E-02$ & $0.793 E+00$ & 0.0 & 0.0 & 0.0 \\
\hline $800 E+01$ & $-0.242 E-02$ & $0.782 E+00$ & 0.0 & 0.0 & 0.0 \\
\hline $825 E+01$ & $-0.275 E-02$ & $0.771 E+00$ & 0.0 & 0.0 & 0.0 \\
\hline $0.850 E+01$ & $-0.297 E-02$ & $0.759 E+00$ & 0.0 & 0.0 & 0.0 \\
\hline+01 & $E-02$ & $0.747 E+00$ & 0.0 & 0.0 & 0.0 \\
\hline+01 & $E-02$ & $B E+00$ & 0.0 & 0.0 & 0.0 \\
\hline 0.9 & -02 & 0. & 0 & 0 & 0.0 \\
\hline 0.9 & -02 & $13 E+00$ & 0 & 0 & 0.0 \\
\hline 0.97 & $1 E-02$ & $0.701 E+00$ & 0.0 & 0.0 & 0.0 \\
\hline 0.10 & $-0.560 E-02$ & $0.689 E+00$ & 0.0 & 0.0 & 0.0 \\
\hline $0.103 E+02$ & $-0.631 E-02$ & $0.678 E+00$ & 0.0 & 0.0 & 0.0 \\
\hline $0.105 E+02$ & $-0.692 E-02$ & $0.667 E+00$ & 0.0 & 0.0 & 0.0 \\
\hline $0.108 E+02$ & $-0.775 E-02$ & $0.655 E+00$ & 0.0 & 0.0 & 0.0 \\
\hline+02 & $-0.850 E-02$ & $0.644 E+00$ & 0.0 & 0.0 . & 0.0 \\
\hline$E+02$ & $3 E-02$ & $0.634 E+00$ & 0.0 & 0.0 & 0.0 \\
\hline$E+02$ & $E-01$ & $E+00$ & 0.0 & 0.0 & 0.0 \\
\hline+02 & $E-01$ & $E+00$ & 0.0 & 0.0 & 0.0 \\
\hline 0.12 & $=-01$ & 0.5 & $0.648 E-02$ & $0.747 E-04$ & 0.0 \\
\hline+02 & $E+00$ & $0.549 E+00$ & $0.233 \mathrm{E}-01$ & $0.102 E-02$ & 0.0 \\
\hline $0.125 E+02$ & $0.144 E+00$ & $0.503 E+00$ & $0.426 E-01$ & $0.373 E-02$ & 0.0 \\
\hline $0.128 E+02$ & $E+00$ & $0.453 E+00$ & $0.620 E-01$ & $0.867 \mathrm{E}-02$ & 0.0 \\
\hline +02 & $E+00$ & $=+00$ & $0.787 \mathrm{E}-01$ & $0.153 \mathrm{E}-01$ & 0.0 \\
\hline+02 & +00 & +00 & $0.929 E-01$ & $0.235 \mathrm{E}-01$ & 0.0 \\
\hline+02 & +00 & +00 & 0.10 & $0.333 \mathrm{E}-01$ & 0.0 \\
\hline 02 & -01 & & 0.1 & 0.424 & 0.0 \\
\hline+02 & $=-01$ & & 0.1 & & 0.0 \\
\hline 02 & -0.2 & 0 . & 00 & $0.379 \mathrm{E}$ & 0.0 \\
\hline 0.1 & -0.4 & 0. & 0.6 & $0.175 E-01$ & 0.0 \\
\hline 0.1 & -0.32 & $E+00$ & $0.211 E-01$ & $0.333 E-02$ & 0.0 \\
\hline 0.1 & -0.16 & $E+00$ & 0.0 & 0.0 & 0.0 \\
\hline $0.153 E+02$ & $0.272 E-01$ & $0.461 E+00$ & 0.0 & 0.0 & 0.0 \\
\hline 0.15 & $0.206 E-01$ & $+\infty 0$ & 0.0 & 0.0 & 0.0 \\
\hline+02 & -01 & +00 & 0.0 & 0.0 & 0.0 \\
\hline 0.1 & -01 & 0 & 0.0 & 0.0 & 0.0 \\
\hline +02 & -01 & 0. & 0.0 & 0. & 0.0 \\
\hline & & & 0.0 & 0.0 & 0.0 \\
\hline 0.1 & 0. & & 0.0 & 0.0 & 0.0 \\
\hline 0.1 & $E-02$ & 0.3 & 0.0 & 0.0 & 0.0 \\
\hline 0.17 & $0.681 E-02$ & 0.3 & 0.0 & 0.0 & 0.0 \\
\hline 0.1 & $E-02$ & 0.3 & 0. & 0.1 & 0.0 \\
\hline 0. & -02 & 0.3 & 0. & 0. & 0.0 \\
\hline 0. & $E-02$ & $E+00$ & 0.0 & 0.0 & 0.0 \\
\hline 0.1 & $0.429 E-02$ & $0.306 E+00$ & 0.0 & 0.0 & 0.0 \\
\hline $0.185 E+02$ & $0.396 E-02$ & $0.297 E+00$ & 0.0 & 0.0 & 0.0 \\
\hline $0.188 E+02$ & $=-02$ & 0.7 & 0.0 & 0.0 & 0.0 \\
\hline+02 & $0.324 E-02$ & $0.278 E+00$ & 0.0 & 0.0 & 0.0 \\
\hline $0.193 E+02$ & $0.283 E-02$ & $0.268 E+00$ & 0.0 & 0.0 & 0.0 \\
\hline $0.195 E+02$ & $0.268 E-02$ & $0.260 E+00$ & 0.0 & 0.0 & 0.0 \\
\hline $0.198 E+02$ & $0.233[02$ & $0.251 E+00$ & 0.0 & 0.0 & 0.0 \\
\hline
\end{tabular}

$-0.232 E-01$

$-0.247 E-01$

$-0.260 E-01$

$-0.272 E-01$

$-0.280 E-01$

$-0.285 E-01$

$-0.287 \mathrm{E}-01$

$-0.283 E-01$

$-0.273 E-01$

$-0.257 E-01$

$-0.233 E-01$

$-0.200 E-01$

$-0.156 E-01$

$-0.990 E-02$

$-0.284 E-02$

$0.587 E-02$

$0.165 E-01$

$0.292 E-01$

$0.444 E-01$

$0.625 E-01$

$0.837 E-01$

$0.109 E+00$

$0.138 E+00$

$0.172 E+00$

$0.211 E+00$

$0.257 E+00$

$0.309 E+00$

$0.370 E+00$

$0.439 E+00$

$0.501 E+00$

$0.510 E+00$

$0.424 E+00$

$0.222 E+00$

$-0.103 E+00$

$-0.552 E+00$

$-0.113 E+01$

$-0.182 E+01$

$-0.258 E+01$

$-0.332 E+01$

$-0.386 E+01$

$-0.403 E+01$

$-0.389 E+01$

$-0.371 E+01$

$-0.354 E+01$

$-0.340 E+01$

$-0.327 E+01$

$-0.315 E+01$

$-0.305 E+01$

$-0.295 E+01$

$-0.286 E+01$

$-0.277 E+01$.

$-0.269 E+01$

$-0.262 E+01$

$-0.255 E+01$

$-0.249 E+01$

$-0.243 E+01$

$-0.238 E+01$

$-0.233 E+01$

$-0.228 E+01$

$-0.223 E+01$

$-0.219 E+01$
$0.108 E+02$

$0.119 E+02$

$0.131 E+02$

$0.143 E+02$

$0.155 E+02$

$0.168 E+02$

$0.181 E+02$

$0.195 E+02$

$0.209 E+02$

$0.223 E+02$

$0.238 E+02$

$0.252 E+02$

$0.268 E+02$

$0.283 E+02$

$0.299 E+02$

$0.315 E+02$

$0.331 E+02$

$0.347 E+02$

$0.364 E+02$

$0.380 E+02$

$0.397 E+02$

$0.414 E+02$

$0.431 E+02$

$0.448 E+02$

$0.465 E+02$

$0.483 E+02$

$0.500 E+02$

$0.517 E+02$

$0.534 E+02$

$0.552 E+02$

$0.569 E+02$

$0.586 E+02$

$0.603 E+02$

$0.620 E+02$

$0.637 E+02$

$0.654 E+02$

$0.671 E+02$

$0.687 E+02$

$0.704 E+02$

$0.720 E+02$

$0.737 E+02$

$0.753 E+02$

$0.769 E+02$

$0.785 E+02$

$0.800 E+02$

$0.816 E+02$

$0.831 E+02$

$0.846 E+02$

$0.861 E+02$

$0.875 E+02$

$0.890 E+02$

$0.904 E+02$

$0.918 E+02$

$0.931 E+02$

$0.945 E+02$

$0.958 E+02$

$0.971 E+02$

$0.984 E+02$

$0.997 E+02$

$0.101 E+03$

$0.102 E+03$

HFER $=0.93756 E+01$ WFAR $=0.11633 E+01.96$ 
$z=\begin{array}{llllllllllllllllllllll}0.0 & 0.56 & 1.11 & 1.67 & 2.22 & 2.78 & 3.33 & 3.89 & 4.45 & 5.00 & 5.56 & 6.11 & 6.67 & 7.22 & 7.78 & 8.33 & 8.89 & 9.45 & 10.00 & 10.56 & 11 .\end{array}$

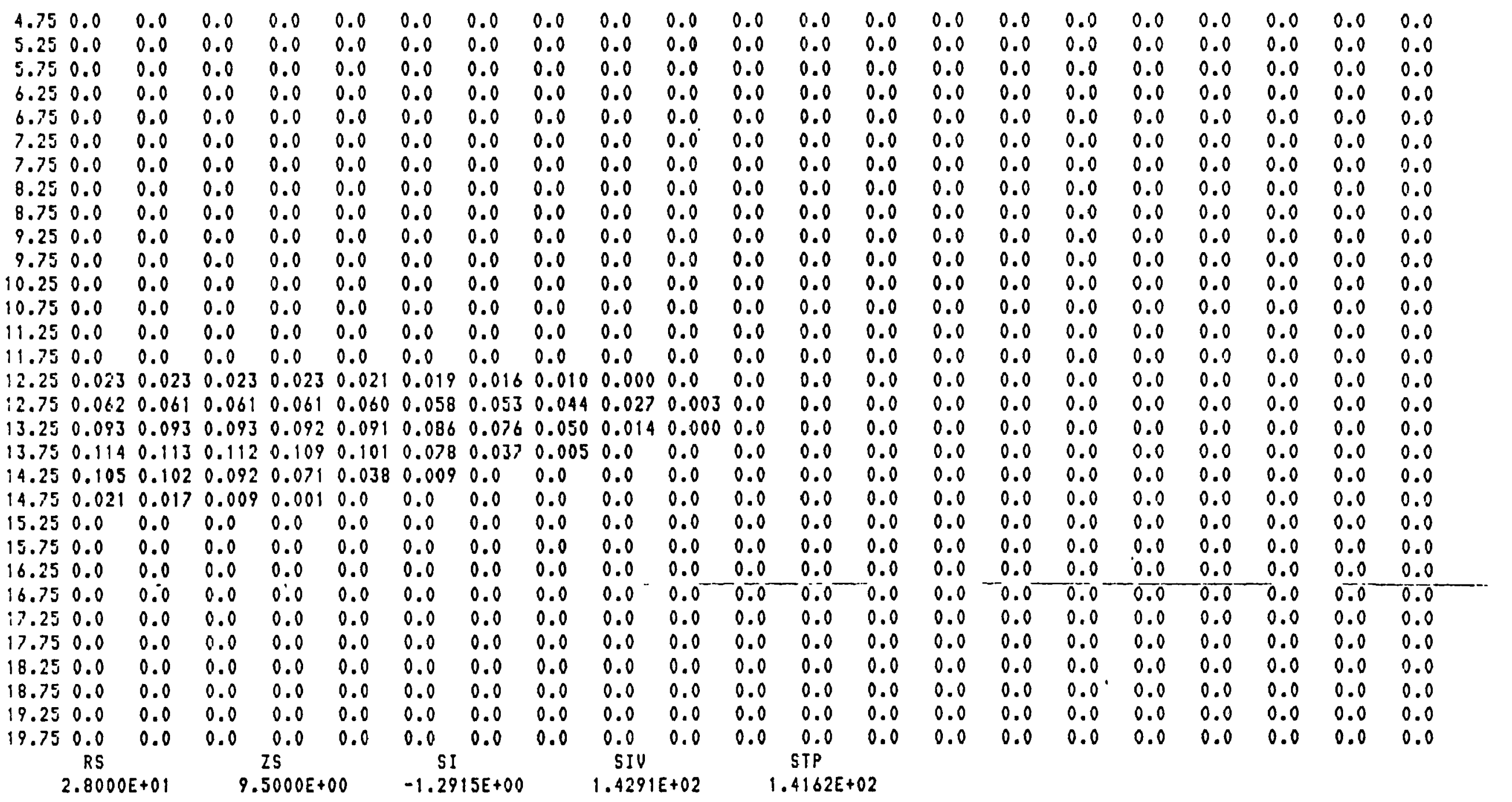


BUMCAL program

The BUMCAL program calculates the flux linkage for the diamagnetic pickup loop for a bumpy cylinder current sheet model. The next page gives a sample interactive terminal session using BUMCAL. The following pages provide a FORTRAN listing for BUMCAL and the ideal solenoid code, SOLBA, called by it. 
LOAN BUMCAL :NOMAP STARI

EXECUTION BEGINS...

ENTER NOC, RS , S!., SEP, :

$.511 \quad 10 \quad 44.45$

SBUMCAL

RF $=28.0000000006000000 \quad, Z F 1=9.50000000000000000 \quad, R S=11.0000000000000000$

NOC $=\quad 5$, SEF $=44.4499999999999993$

,APT $=.619572240251832690$

,$S L=10.0000000000000000$

SENII

.619572240251822690

ENTER NOC, KS, SL, SEP,:

$?$

.-11

R; 


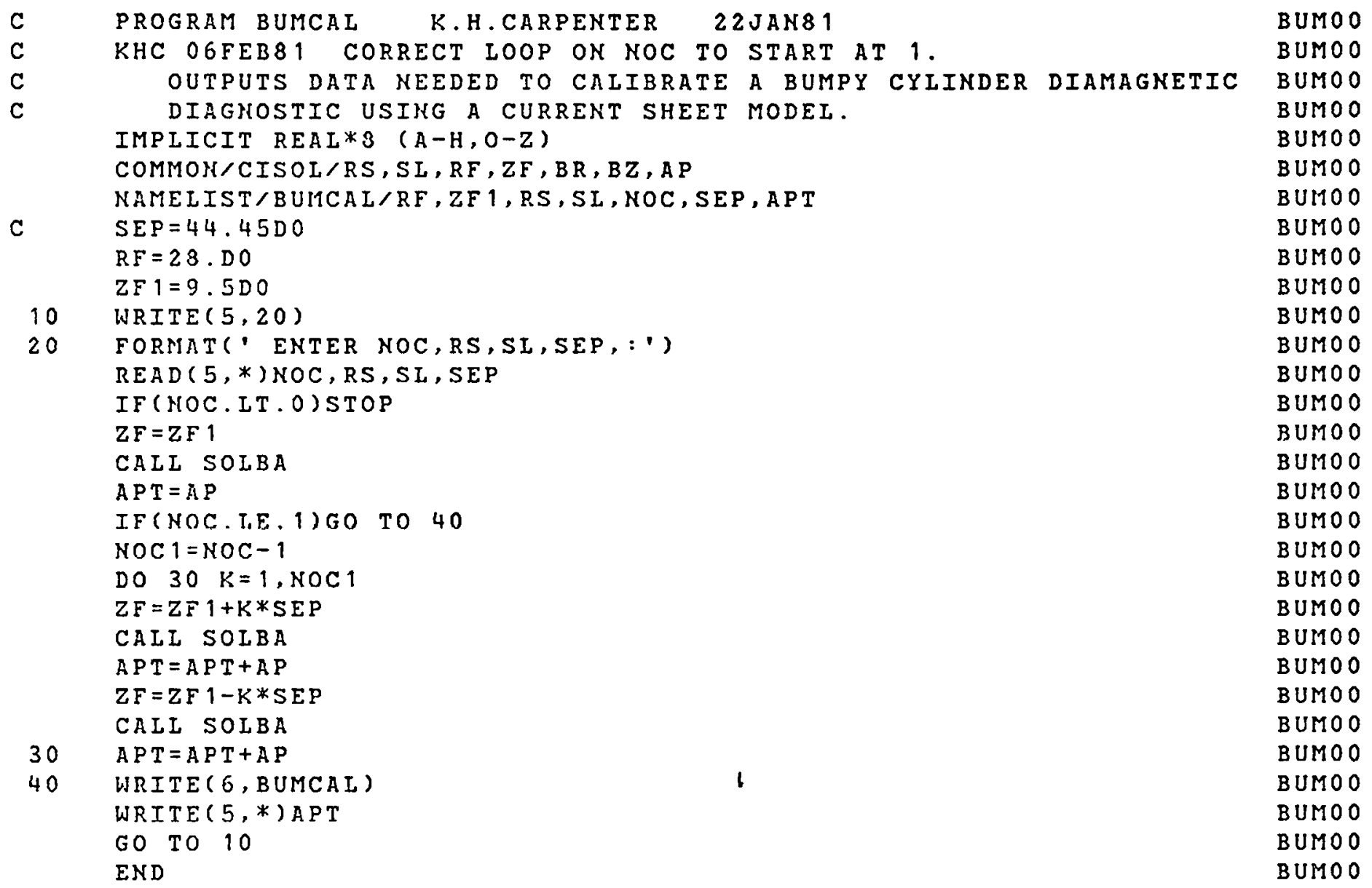


Calculates the B-field and A-field components for an ideal 


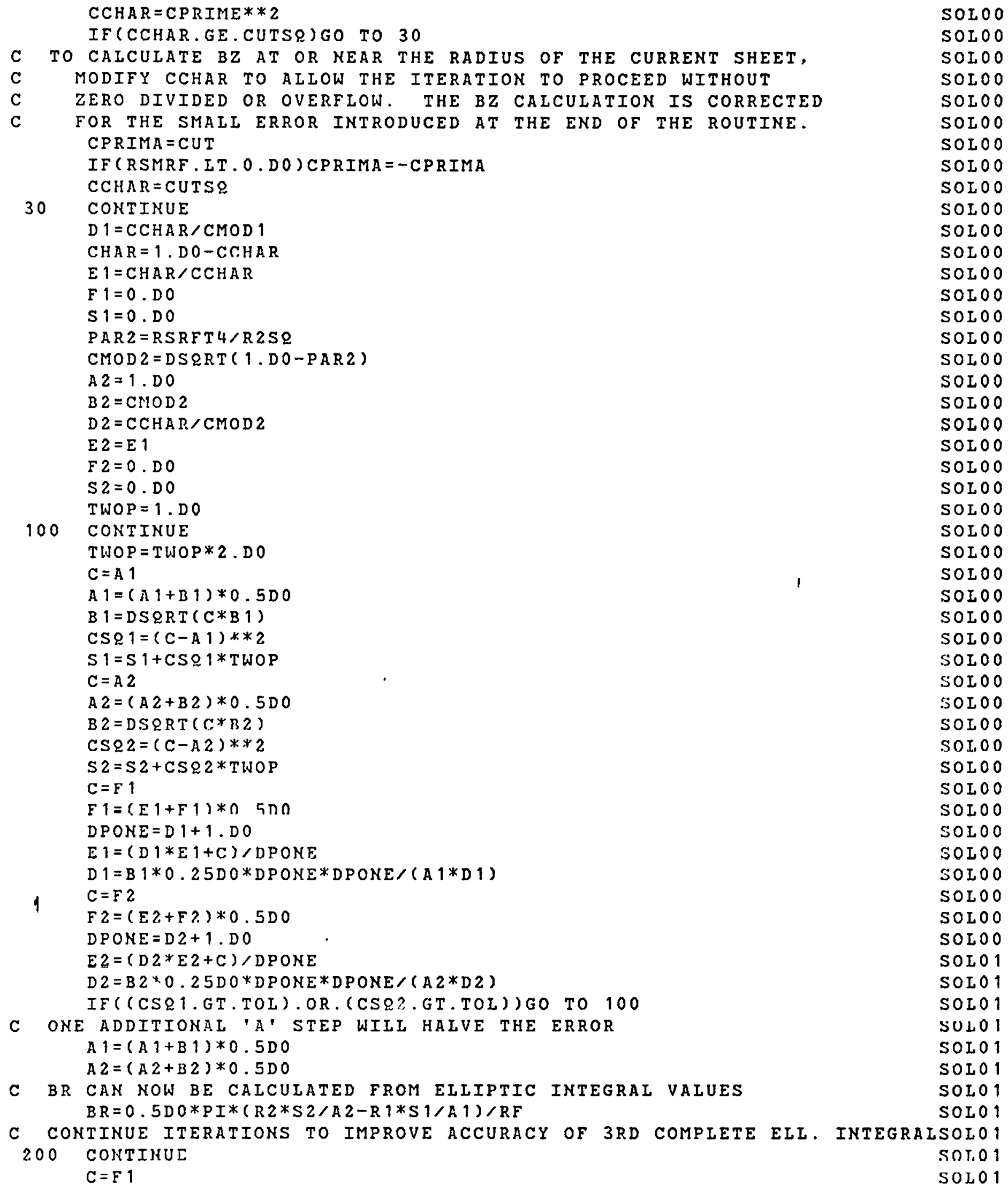

SOL 00

SOLOO

SOLOO

SOLOO

SOLOO

SOLOO

SOLOO

SOLOO

SOL 00

SOLOO

SOLOO

SOLOO

SOL 00

SOLOO

SOLOO

SOLOO

SOLOO

SOLOO

SOLOO

SOLOO

SOLOO

SOLOO

SOLOO

SOLOO

SOL 00

SOLOO

SOLOO

SOLOO

SOLOO

SOLOO

SOLOO

SOLOO

SOLOO

SOLOO

SOI.OO

SOL 00

SOLOO

SOLOO

SOLOO

SOLOO

SOLOO

SOLOO

SOLOO

SOLOO

SOL 01

SOL 01

SOLO 1

SULOI

SOL 01

SOLOI

SOLO 1

SOLO 1

SกT.0 1

SOLO 1 


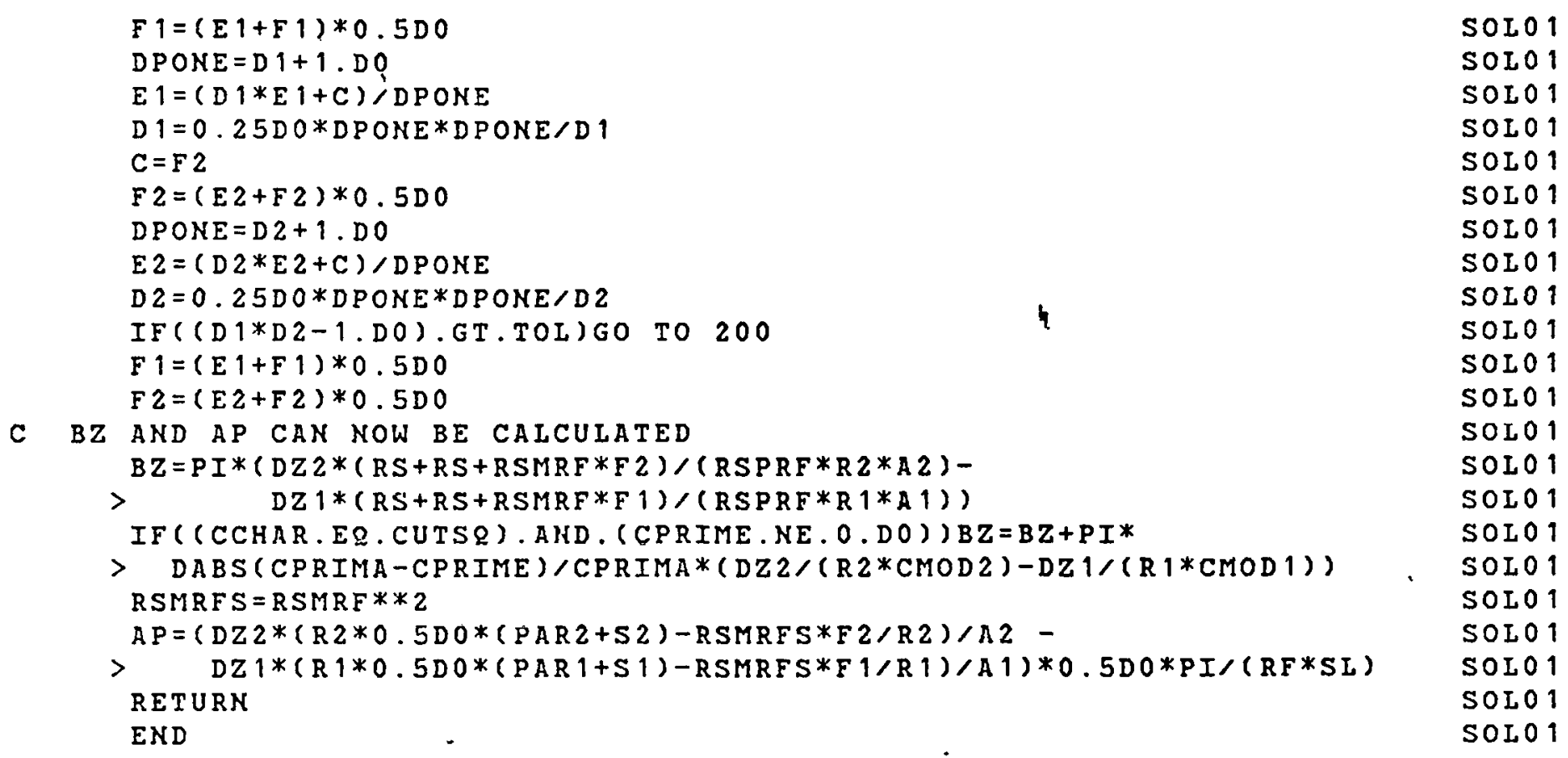

